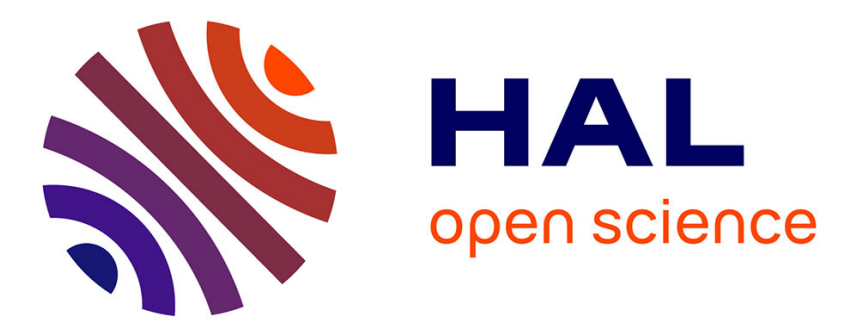

\title{
De loin, de près: Chronique des études pallava III
}

Emmanuel Francis, Valérie Gillet, Charlotte Schmid

\section{To cite this version:}

Emmanuel Francis, Valérie Gillet, Charlotte Schmid. De loin, de près: Chronique des études pallava III. Bulletin de l'Ecole française d'Extrême-Orient, 2007, 94, pp.253-317. 10.3406/befeo.2007.6072 . halshs-00861754

\section{HAL Id: halshs-00861754 https://shs.hal.science/halshs-00861754}

Submitted on 18 Mar 2020

HAL is a multi-disciplinary open access archive for the deposit and dissemination of scientific research documents, whether they are published or not. The documents may come from teaching and research institutions in France or abroad, or from public or private research centers.
L'archive ouverte pluridisciplinaire HAL, est destinée au dépôt et à la diffusion de documents scientifiques de niveau recherche, publiés ou non, émanant des établissements d'enseignement et de recherche français ou étrangers, des laboratoires publics ou privés. 
De loin, de près: Chronique des études pallava III

Emmanuel Francis, Valérie Gillet, Charlotte Schmid

\section{Citer ce document / Cite this document :}

Francis Emmanuel, Gillet Valérie, Schmid Charlotte. De loin, de près: Chronique des études pallava III. In: Bulletin de I'Ecole française d'Extrême-Orient. Tome 94, 2007. pp. 253-317;

doi : https://doi.org/10.3406/befeo.2007.6072

https://www.persee.fr/doc/befeo_0336-1519_2007_num_94_1_6072

Fichier pdf généré le 08/11/2019 


\title{
De loin, de près Chronique des études pallava III
}

\author{
Emmanuel Francis, Valérie Gillet, Charlotte SCHMid
}

\begin{abstract}
Dans cette troisième chronique des études pallava, nous nous intéresserons à trois ouvrages parus récemment qui se rapportent, de loin ou de près, à la dynastie des Pallava : Commanditaires \& artistes en Inde du Sud de Vincent Lefèvre (2006), Temples de l'Inde méridionale d'Édith Parlier-Renault (2006) et Early Saivism and the Skandapurāna. Sects and Centres de Peter C. Bisschop (2006). Il ne s'agit pas ici de faire des comptes rendus «classiques » de ces trois livres. Nous nous sommes restreints à certains de leurs aspects, qui apportent un éclairage nouveau sur les Pallava ou qui requièrent la prise en compte d'autres points de vue que ceux exposés par les auteurs.

Une remarque générale concernant les corpus de ces études s'impose car ils sont très différents. P. C. Bisschop publie deux recensions d'un même texte, dont l'une est une portion du Skandapurāna, en un ensemble qui occupe moins de quatre-vingts pages sur les trois cent soixante-huit que compte son livre. Index, concordance, annotations, introduction, le texte est étudié en profondeur. Le sujet que traite $V$. Lefèvre est en revanche immense puisqu'il s'agit de la création artistique en pays tamoul sur plus d'un millénaire, envisagée sous l'angle de l'interaction entre commanditaires et artistes. Embrassant l'ensemble de l'iconographie des dynasties des Gupta, des Kalacuri, des Cālukya, des Pallava et des Rāsțrakūṭa, le corpus que É. Parlier-Renault a choisi d'étudier est tout aussi vaste. Les projets de ces deux derniers auteurs nous paraissent d'autant plus ambitieux que, malgré l'ancienneté des études concernant les dynasties du pays tamoul et du Deccan, nous ne considérerions l'étude particulière d'aucune d'elles comme achevée aujourd'hui.

Les livres de V. Lefèvre et de É. Parlier-Renault, même s'ils ne sont pas exclusivement consacrés aux Pallava, traitent cependant abondamment de la production artistique de cette dynastie. Nous voudrions ici présenter en contrepoint nos propres vues concernant des sujets spécifiques. Le nom des Pallava n'apparaît pas dans l'index du livre de P. C. Bisschop, mais l'état de la mythologie çivaïte que contient la portion du Skandapurāna qu'il édite pourrait permettre de mieux comprendre certaines figures des temples pallava.

L'examen de ces trois livres sera guidé par des orientations qui nous sont propres : la nécessité du travail de terrain, l'intérêt de l'étude des textes ou encore le questionnement du rapport entre représentations sculptées et textuelles. Nous espérons montrer dès lors que tant l'accès direct aux sources primaires que l'usage qu'on en fait changent le point de vue sur le cas «Pallava »'.
\end{abstract}

1. Nous remercions toute l'équipe du centre EFEO de Pondichéry, en particulier N. Ramaswamy (alias Babu) et G. Vijayavenugopal, qui explorent avec enthousiasme et méthode les districts du nord du pays tamoul. Nous remercions aussi pour leurs sages critiques et conseils, portant sur l'ensemble ou les détails de cette chronique, Jean-Luc Chevillard. Bruno Dagens. Dominic Goodall. Arlo Griffiths. Karine Ladrech. Leslie Orr et Uthaya Veluppillai. 
Vincent Lefèvre, Commanditaires \& artistes en Inde du Sud. Des Pallava aux Nāyak $\left(v r^{e}-\right.$ xvII $^{e}$ siècle $)$, Paris, Presses de la Sorbonne Nouvelle, 2006, 416 pages et 38 figures. ISBN 2-87854-338-6; 28 euros. |Version remaniée et abrégée d'une thèse de doctorat soutenue à la Sorbonne nouvelle - Paris III].

Nous venons d'évoquer l'ampleur du sujet choisi par Vincent Lefèvre. Ce livre appelle par ailleurs une réflexion préalable concernant la constitution, la nature et l'utilisation d'un corpus épigraphique, base documentaire la plus importante de l'ouvrage considéré.

L'auteur a en effet constitué son large corpus d'inscriptions en dépouillant systématiquement la plupart des Annual Report on Epigraphy (ci-après ARE) entre 1887 et 1984. En ce qui concerne la commande portant sur l'architecture, il a " recherché avant tout les données enregistrant sans ambiguïté la construction d'un édifice " ou d'une partie de celui-ci (p. 62). Pour la sculpture, il a « relevé systématiquement les inscriptions où il est question de l'installation d'une image " (p. 63). Il recense ainsi six cent quatrevingt-huit inscriptions ayant trait à l'architecture et trois cent soixante et onze inscriptions touchant à la sculpture (p. 68; annexes, p. 327-379, pour leurs listes, topographique et chronologique). Rappelons que les $A R E$ fournissent en général des résumés - très rarement des extraits - d'inscriptions nouvellement découvertes et lues, parfois, par une seule personne. Ces publications s'assimilent donc en fait à de la littérature secondaire; elles se fondent parfois sur des interprétations et ne donnent que des renseignements partiels, voire erronés ${ }^{2}$.

Conscient de ces difficultés, V. Lefèvre s'est efforcé d'utiliser les éditions disponibles (p. 43 et 62), qui n'existent que pour une portion congrue des inscriptions répertoriées dans les $A R E^{3}$. La vérification des éditions, des transcrits et des inscriptions in situ entraîne, en effet, immanquablement des corrections, comme tout épigraphiste en fait l'expérience renouvelée, et comme nous le constaterons à la fin de cette chronique avec l'exemple du pilier de Vāyalūr.

2. Les $A R E$ (qui sont l'expression d'un travail de titan toujours en cours) comportent des erreurs dans le découpage ou le placement des inscriptions, ainsi que des crrcurs de compréhension.

3. Notons à cet égard que dans les annexes (p. 327-379), maintes épigraphes sont référencées seulement d'après les $A R E$ alors que des éditions (South Indian Inscriptions [ci-après SII ou Epigraphia Indica [ci-après $E I]$ ) en existent. Certaines de ces éditions sont connues de l'auteur, telle celle de l'inscription de Maṇtakappațtu, dont l'édition d'après $E I$ apparaît dans le corps du texte (p. 25, n. 25), mais que les annexes ignorent, ne mentionnant que l' $A R E$ (p. 344 et 349). En outre, comme nous le fait remarquer Leslie Orr, ce n'est qu'à partir de l'ARE 1894 (c'est-à-dire à partir de l'inscription $A R E 1893$, $n^{\circ} 181$ ) qu'on trouve de façon systématique des résumés des inscriptions répertoriées (dans la colonne "Remarks », qui fait alors son apparition dans les listes d'inscriptions publiées comme appendices aux $A R E$ ). Pour les inscriptions qui précèdent, soit presque mille épigraphes, on a occasionnellement des informations à propos de leur contenu dans les $A R E$ ou dans $S / I$ I-III, où certaines d'entre elles furent éditées. Cette particularité des $A R E$ explique peut-être pourquoi certaines inscriptions bien connues, telle l'inscription de fondation du Kailāsanātha $\left(I P \mathrm{n}^{\circ} 54=A R E 1888, \mathrm{n}^{\circ} 1\right.$; voir infica, note 7$)$, sont absentes du corpus de V. Lefêvre. Celui-ci en effet n'est établi qu'à partir des $A R E$. En ce qui concerne les citations d'inscriptions, nous signalons ici quelques coquilles : vastuvidyām pour $v / \bar{a}^{*} /$ stuvidām, simat pour śrimat, taksanā pour takṣnā dans $I P \mathrm{n}^{\circ} 95$ (édition imparfaite, apparemment reprise par V. Lefèvre) $=S I I$ VI, n 333 [et fac-similé, pl. iii, f. p. 164] (p. 88, note 46); eruppitta pour etuppitta dans $S / I$ III, $\mathrm{n}^{\circ} 147$ (p. 131); ellumarulivitta dans $S / I$ III, $\mathrm{n}^{\circ} 151$ (p. 131), alors qu'on y trouve seule-

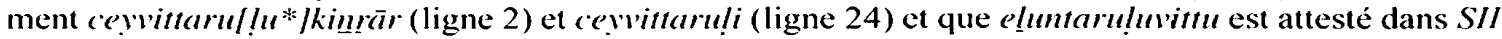

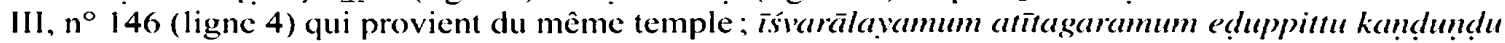

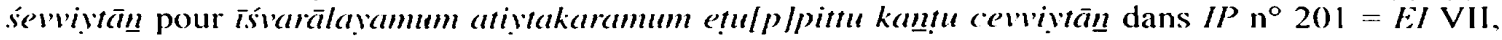
$\mathrm{n}^{\circ} 26$ (p. 292) où atiyta (comprendre atīta) est normalisé, mais pas cevviytān (comprendre cevvittānn), et où, pour kantu, il faut comprendre kan!u; voir aussi le compte rendu d'Oskar von Hinüber dans l'Indo-Iranian Journal 51 (2008, p. 71-77). 


\section{I) 'un corpus épigraphicute}

Constitution du corpus. V. Lefëvre ne doute pas que des "oublis involontaires" eurent lieu dans son travail de dépouillement des ARE (p. 64). Pour notre part, et en nous fondant uniquement sur les éditions, nous enrichirions son corpus (constitué de mille quarante-deux inscriptions), notamment en ce qui concerne les Pallava. On dispose en effet pour cette dynastie d'un corpus facile d'utilisation rassemblé par T. V. Mahalingam (Inscriptions of the Pallavas 1988 ; ci-après $I P$ ). On y trouve le texte - à vérifier systématiquement dans les éditions originales, car cet ouvrage est truffé de coquilles! - et le résumé de la plupart des inscriptions de la période des Pallava répertoriées jusqu'en 1976.

À Tiruttani, par exemple. si V. Lefèvre inclut dans son corpus des inscriptions de certains temples de ce site, il omet toutefois $I P \mathrm{n}^{\circ} 245$ au Vīratțāneśvara ${ }^{4}$. Cette inscription nomme pourtant sans équivoque le fondateur Nampi Appi, un particulier qui fait une donation au même temple dans une autre inscription, à savoir $I P \mathrm{n}^{\circ} 246(A R E 1905$, $n^{\circ} 435=S I I$ XII, ${ }^{\circ} 95$; dix-huitième année de règne du roi Pallava Aparājitavarman; IX ${ }^{c}$ siècle). Dans le corps de son texte, V. Lefèvre range le Vīratțāneśvara parmi les sept temples «fondés directement par un roi », au sein du corpus des cent cinquante temples de la période qui court de 870 à 1030 (p. 236). Ce serait, d'après lui, l'œuvre du roi Pallava Aparājita, et il précise que «toutes ces fondations [royales] sont attestées de façon sûre » (note 16). IP $\mathrm{n}^{\circ} 245$ atteste cependant qu'on a ici affaire à la fondation d'un particulier.

Nous n'avons pas non plus trouvé dans le corpus de V. Lefèvre l'inscription $I P \mathrm{n}^{\circ} 262$ ( $A R E 1888, \mathrm{n}^{\circ} 33=S I I \mathrm{IV}, \mathrm{n}^{\circ} 131 ; \mathrm{IX}^{\circ}$ siècle), qui enregistre au Vaikunțhaperumāl de Kãñoipuram la donation par le Pallava Abhimānasiddhi d'un plateau à offrandes et d'une image (palittālam patimamu) 5 .

Ces exemples ponctuels montrent que le corpus des commanditaires de la période pallava pourrait donc être modifié. Dans le même esprit, on notera que plusieurs inscriptions jaïnes enregistrant des donations de temples ou d'images, datées entre le vil" et le $I X^{*}$ siècle, sont absentes du corpus de l'ouvrage, qu'elles élargiraient. Celles qui concernent des sculptures infirment en outre le propos de V. Lefèvre, selon lequel aucune inscription antérieure au $x^{\circ}$ siècle ne témoigne d'une commande dans ce domaine (p. 68) ${ }^{6}$.

4. V. Lefèvre inclut dans son corpus $A R E 1905, n^{\circ} 442$ et 447 (p. 339 et 378 ; district de Tiruvallür au Tamil Nadu) et $A R E$ 1942-1943, n 130 (p. 346 et 365; district de Chittor en Andhra Pradesh). Il s'agit en fait du même site, Tiruttani se trouvant autrefois dans le district de Chittor de la Madras Presidency qui fut ensuite divisé entre le Tamil Nadu et l'Andhra Pradesh. $I P, \mathrm{n}^{\circ} 245\left(A R E 1905, \mathrm{n}^{\circ} 433=S I I\right.$ XII, $\left.n^{\circ} 94\right)$ n'a pas de date interne en année de règne.

5. Cette inscription mentionne aussi de l'or. Selon V. R. Mani (1968) il s'agirait de celui qui a servi à confectionner le plateau et l'image, mais nous n'excluons pas qu'il ait simplement permis d'en payer la confection. V. R. Mani s'appuie sur cette inscription pour arguer de l'existence d'images en métal sous les Pallava, mais V. Lefèvre n'y fait pas référence quand il traite des bronzes pallava (p. 221 et suiv.).

6. Ainsi $I P \mathrm{n}^{\circ} 65\left(A R E 1895, \mathrm{n}^{\circ} 10=E I \mathrm{IV}, \mathrm{n}^{\circ} 14 \mathrm{~A}\right.$; quinzième année de règne de Nandivarman II,

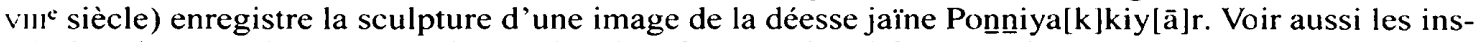
criptions jaïnes qui concernent la création d'un basti par le roi Ganga Rājamalla et la sculpture d'images à Vallimallai (EIIV, n $\left.{ }^{\circ} 15\right)$. P. Venkatesan (1984) date Rājamalla du ix $x^{\circ}$ siècle dans son édition de deux inscriptions de Cìyamankalam, dont l'une enregistre la fondation par ce roi de deux temples (niveśana) de Jinarāja. Leslie Orr nous signale en outre des inscriptions à Kalukumalai ; voir, par exemple, Inscriptions of the early Paindvas $\mathrm{n}^{\circ}$ 56, qui reprend en fait sous un même numéro plusieurs inscriptions dont certaines mentionnent explicitement des commanditaires de sculptures (SII V, n $310,316,319$. 322, 326, 328 et 384). Mais il y a, en réalité, à Kalukumalai des dizaines d'inscriptions du même genre, cf. $S I I \mathrm{~V}, \mathrm{n}^{\circ} 309$ à 400 ; voir, en outre, les inscriptions à Ānaimalai (SII XIV, n 99-106) et à Aivarmalai (SII XIV, $\left.\mathrm{n}^{\circ} 107-119\right)$. 
Enfin, pour notre part, nous inclurions également dans le corpus des « commanditaires et artistes » les inscriptions royales de fondation qui nomment les commanditaires. Ellescorrespondent en effet en tous points aux critères de sélection de V. Lefèvre ${ }^{7}$. Par ailleurs, il eût été intéressant d'examiner les inscriptions qui fournissent les noms de sanctuaires, car le premier membre de ces noms composés est, en général, le nom du commanditaire ${ }^{8}$. Mais il faut avouer que la collecte en serait ardue; de plus, le premier terme du composé est, parfois, le nom de la personne à qui le commanditaire désire transférer le mérite de sa fondation (et non celui du commanditaire lui-même).

L'inclusion dans le corpus de ces quelques inscriptions nommant les commanditaires modifierait très certainement les statistiques présentées. Elles changeraient alors la vision qu'on peut se faire de la commande royale, quel que soit le contexte dynastique envisagé. comme nous le verrons plus loin.

Nature du corpus. Soulignons par ailleurs que, comme tout corpus épigraphique, celui qui a été réuni par $V$. Lefèvre est partiel et partial. Il est partiel parce qu'une partie de la production épigraphique a disparu mais aussi parce qu'une autre partie n'a pas encore été répertoriée". Ensuite, comme nous l'a fait remarquer Leslie Orr, il apparaît que les épigraphistes de l'Archaeological Survey of India ont, à l'origine, marqué une préférence pour les inscriptions anciennes (pallava et cōla), négligeant de répertorier systématiquement celles qui dataient de l'époque de Vijayanagara ou des Marathes ${ }^{10}$. De nouvelles découvertes pourraient ainsi changer les rapports statistiques de tout corpus ". La nature particulière des documents épigraphiques, qui ne témoignent que d'une partie de la réalité et ne sont produits que pour certaines occasions ou par certaines personnes selon les périodes, rend par ailleurs partial un corpus de ce genre ${ }^{12}$.

7. Par exemple, à Kāñcipuram, IP n $\mathrm{n}^{\circ} 54\left(A R E 1888, \mathrm{n}^{\circ} \mathrm{I}=S I I\right.$ I, $\mathrm{n}^{\circ} 24$; inscription de fondation du Rājasiṃheśvara, c'est-à-dire le Kailāsanātha, par Narasiṃhavarman 11$)$ et $I P n^{\circ} 69(A R E 1888$, $\mathrm{n}^{\circ} 4=S / I 1, \mathrm{n}^{\circ} 27$; inscription de fondation du Mahendravarmeśvara, dans le même complexe, par Mahendravarman III, le fils de Narasiṃhavarman II).

8. Par exemple, à Kāñcipuram, IP n 80 au « Mukteśvara » enregistre la donation de Dharmatnahādevī au dieu Mānikkatēvar du Dha|rmama|hādevīśvaragṛa. Le nom du sanctuaire et le contenu de linscription semblent indiquer que cette reine est la fondatrice. La datation interne de l'inscription en l'année de règne d’un roi Nanti (Il ou III'?) suggère qu'elle était une de ses épouses.

9. V. Lefèvre cite l'exemple du corpus de Tiruvan!̣amalai enrichi de trois cent soixante inscriptions inédites lors de son étude par une équipe de l’EFFO (p. 64 et note 37). Sur la nature des inscriptions, voir L. Orr (2006).

10. Cette préfërence apparaît clairement si lon considère que des corpus plus récemment constitués tels les Pondichem Inscriptions ou les corpus par district publićs par le Tamil Nadu State I)epartment of Archaeology - incluent de nombreuses inscriptions qui n'ont jamais été reprises dans les $A R E$ et qui sont en général postérieures aux Cọla.

11. Contra. V. Lefèvre argue que son corpus est représentatif car « il n’est pas sûr que les proportions que l'on peut en dégager seraient fondamentalement différentes » si de nouvelles inscriptions venaient le compléter (p. 64).

12. V. Lefèvre dit avec justesse à propos des périodes pallara et cöla ancienne qu'on peut seulement conclure que les rois sont ceux qui ont particulièrement tenu à " laisser une trace écrite de leur action » (p. 67) ou, ajouterons-nous, ceux qui en avaient les ressources. 
Litilisation du corpus. V. Lefèvre n“ignore pas les caractéristiques particulières de son corpus épigraphique. L'utilisant dans une perspective principalement statistique, il reste prudent quant aux conclusions qu'il tire ains ${ }^{13}$. Des raisonnements d'un autre ordre pourraient cependant suppléer à certaines limites de l'analyse statistique, comme le suggère d'ailleurs V. Lefèvre. Nous prendrons deux exemples.

Observant la diminution progressive de la part de la commande royale dans son corpus, V. Lefèvre conclut son analyse statistique sur le constat d'une diversification sociale de la commande (p. 153-154). Pourtant, l'existence de modes épigraphiques (voir notre note 13) permet de supposer que le recours aux inscriptions est, à l'origine, une pratique royale, adoptée ensuite par une plus large portion de la société : la diversification sociale concernerait non la commande en tant que telle, mais son enregistrement dans une inscription; la commande pourrait être socialement diverse dès la période ancienne, mais son enregistrement épigraphique serait d'abord le seul fait des personnages royaux. La prise en compte d'un élément non statistique modifie, en l'occurrence, les conclusions qu'on pourrait tirer par la seule analyse quantitative du corpus.

Le second exemple concerne précisément la commande royale. Signalons d'abord que la définition d'un corpus royal fait débat. Ainsi, V. Lefèvre inclut parmi ses commanditaires royaux les Mūvēntavēlạn (des officiers royaux), parce qu'ils sont « liés à la famille royale » et semblent « agir essentiellement en qualité d'agents " (comprendre : exécuter une demande royale) (p. 137), ainsi que les reines. Contra, Padma Kaimal démontre, de façon convaincante à nos yeux, les singularités de l'activité fondatrice des reines, qu'elle lie à leur initiative personnelle (1996) ou à leur terroir d'origine $(2002-2003)^{14}$. Utilisant donc un corpus royal cọla très large et avec un raisonnement purement quantitatif, V. Lefèvre situe l'âge d'or de la commande royale entre 970 et 1030 sous les Cōla (p. 136). 11 compte en effet pour cette période le plus grand nombre d'inscriptions témoignant d'une telle commande (trente-trois inscriptions, représentant $25 \%$ de l'ensemble des inscriptions de cette période dans son corpus). Il ajoute cependant : « La période pallava pourrait prétendre aussi à ce titre, mais le faible nombre d'inscriptions de cette période

13. V. Lefëvre relativise en effet les conclusions qu'on peut tirer des pourcentages, en mettant en garde contre la conclusion qu'à la période pallava, la production artistique ne serait que royale eu égard au fait que les inscriptions de son corpus pour cette période sont presque toutes royales (p. 66-67). On peut en effet supposer la disparition de monuments en matériaux périssables et rappeler que le recours aux inscriptions est à période ancienne (jusqu'au vII siècle inclus) une pratique essentiellement royale, en tout cas en pays tamoul et en excluant le corpus des inscriptions tamil-brāhmi . V. Lefèvre cite également l'exemple des bronzes qui ne portent plus d'inscriptions en pays tamoul à l'époque nāyaka (à partir du $\mathrm{XIV}$ siècle), mais sont produits en plus grand nombre. Il suppose alors avec justesse un changement de pratique, sachant que l'absence d'inscription ne signifie pas nécessairement la disparition des usages, mais celle de leur enregistrement dans des inscriptions (p. 70). Notons aussi que V. Lefèvre évite les "doublons ", n'incluant dans son corpus pour une information dont témoignent plusieurs inscriptions qu'une seule de celles-ci « afin de ne pas surcharger la base de données » (p. 63). Mais cela permettrait surtout de ne pas biaiser les données statistiques.

14. Selon V. Lefèvre, les fondations des reines et des rois participent « du même esprit » et relèvent "d'une seule et même "stratégie familiale" " (p. 153, note 37). L'auteur conteste ainsi P. Kaimal (1996. p. 60-66). Il argue que, sur les vingt inscriptions de son corpus pour le $x^{c}$ siècle (incluant donc les fondations des reines), "plus de la moitié concerne des fondations d'un roi ou de son entourage. ce qui contredit les affirmations de P. Kaimal sur la faiblesse de la commande royale pendant cette période $"($ p. 235). 
incite à davantage de prudence. » Si l'on se réfère à la liste donnée à la p. 349 , le faible nombre auquel l'auteur fait ici allusion correspond à huit épigraphes, presque toutes dues à Mahendravarman I ${ }^{\mathrm{or}}$, sur les quinze inscriptions pallava de son corpus.

Il nous semble qu'il est en fait ici nécessaire, comme le conseille V. Lefèvre lui-même à propos des bronzes, de « combiner l'analyse des inscriptions à celle d'autres sources et des ceuvres produites » (p. 70 ; voir notre note 13, à propos de ces bronzes).

Tout d'abord, en ne considérant que les inscriptions du corpus de V. Lefèvre, il convient de distinguer les différents types de commande. Il paraît difficile de donner à une inscription mentionnant la commande d'un bronze la même valeur qu'à celle qui enregistre la fondation d'un temple. $V$. Lefèvre note que le cas de Tanjore, où quinze inscriptions concernent des bronzes, "tend à fausser la perspective " (p. 135). Mais il ne semble pas tenir compte de l'objection qu'il a lui-même soulevée lorsqu'il conclut à un âge d'or cōla de la commande royale. Si l'on envisage la commande royale en nombre de temples fondés, nous relevons, pour notre part, que les huit inscriptions de commande royale pallava du corpus - d'ailleurs incomplet - de V. Lefèvre proviennent de huit sites différents, tandis que, sur les trente-trois inscriptions cōla correspondantes, quinze au moins proviennent du seul site de Tanjore et concernent le type mineur de commande que sont les bronzes.

Ensuite, le corpus des inscriptions tel qu'il a été déterminé ne suffit pas. Il faut considérer celui des temples qui, bien que fondés par des rois, ne sont pas représentés dans le corpus épigraphique de $\mathrm{V}$. Lefèvre, parce qu'ils ne portent pas d'inscriptions de fondation. En ce qui concerne les Pallava, nous pensons, par exemple, aux grottes de Pallāvaram et de Māmanțūr : on y trouve des inscriptions royales de Mahendravarman I ${ }^{\mathrm{er}}$, leur probable fondateur. Nous pensons aussi au Kailāsanātha de Kāñcipuram, remarquable et fameuse fondation de Narasimhavarman II (IP $\left.\mathrm{n}^{\circ} 54\right)$, qui n'apparaît pas plus dans le corpus de l'ouvrage de V. Lefèvre. Lorsqu'il étudie la dynastie des Cōla, ce dernier prend pourtant en compte les temples de Tribhuvanam et de Darasuram, alors qu'ils n'apparaissent pas dans son corpus épigraphique puisqu'ils ne comportent pas d'inscription de fondation (p. 247 et note 40$)^{15}$. L'analyse statistique paraît ainsi biaisée. Nous inclurions d'ailleurs également pour la période pallava le temple dit du Kōtikal Mandapa de Mahābalipuram, contra V. Lefèvre (p. 246) qui, à la suite de K. R. Srinivasan (1964, p. 110), considère ce sanctuaire comme «le seul monument de Mahābalipuram à être clairement attribué à un personnage non royal ». Ces deux auteurs se basent ici sur l'unique inscription que

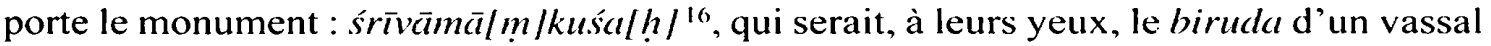
des Pallava. Certes ce biruda n'est connu pour aucun Pallava, mais cela n'empêche pas qu'il puisse être celui d'un roi de cette dynastie ${ }^{17}$. II pourrait s'agir simplement de son unique occurrence.

15. V. Lefèvre ne retient en effet que les inscriptions indiquant expressément une fondation (p. 247). Il est vrai que le temple de Darasuram n'est attribuable à Rãjarāja II que parce qu'il est nommé Rājarājeśvara dans l'épigraphie. Quant au temple de Tribhuvanam, son exclusion du corpus est plus discutable puisqu'il est mentionné, parmi d'autres fondations et rénovations de Kulottunga III, dans une inscription du site même ( $S / I$ XXIII, $\left.n^{\circ} 190\right)$.

16. Il s’agit là de notre lecture de $I P n^{\circ} 62-A R E 1907, n^{\circ} 530=E I X, n^{\circ} 1.19$. Cette inscription ne figure pas dans le corpus de V. Lefèvre, en accord avec ses principes : se resumant à un birtuda, elle n'est en effet pas très explicite.

17. Notons par exemple que le biruda Vāma est attesté deux fois au Dharmarājaratha du même site (IP $n^{\circ} 39$ ) et que Narasiṃhavarman Il porte le biruda Jñānāmkuśa ( $\left.I^{\circ} n^{\circ} 55.38\right)$. 
En revanche, nous n'attachons guère d'importance aux descriptions des rois colca comme grands fondateurs de temples dans des tablettes qui leur sont postérieures : il s'agit d'un topos panégyrique ${ }^{1 .}$. Il faut rappeler en outre, comme le souligne Leslie C. Orr (2007, p. 93), que la construction de temples dans le pays tamoul entre le $\mathrm{IX}^{\mathrm{C}}$ et le $\mathrm{XIII^{ \textrm {c } }}$ siècle, qu'on se trouve en territoire cōla ou pāndya, est, pour l'essentiel, le fait de patrons non royaux.

Ainsi, si l'on adopte nos méthodes, sur une durée à peu près équivalente (trois siècles), le nombre de fondations royales pallav'a peut parfaitement équivaloir, voire surpasser, celui des fondations royales cōlla - et cela même si l'on inclut parmi ces dernières les quatre grands temples de Tanjore, de Gangaikondacolapuram, de Darasuram et de Tribhuvanam, et si l'on prend en compte les fondations des reines ${ }^{19}$. Si l'on cherche à identifier un âge d'or de la commande royale, la période pallava peut donc prétendre à ce titre tout autant que la période colla.

\section{Dut traitement des données pallava}

Après ce bref aperçu des problèmes liés à la constitution et à l'exploitation de tout corpus épigraphique en Inde du Sud, nous considérerons certaines positions de V. Lefèvre sur des sujets qui concernent directement les Pallava, ou à propos desquels les données pallava peuvent changer les perspectives de son ouvrage.

Chronologie et analyse stylistique. En quatrième de couverture de l'ouvrage de V. Lefèvre, on peut lire que « la chronologie et l'analyse stylistique de[s] manifestations artistiques sont, dans l'ensemble, bien établies ». C'est là, nous semble-t-il, faire exagérément confiance à certains auteurs, du moins pour ce qui concerne les Pallava. Signalons, par exemple, que la question de l'histoire et du patronage du site de Mahābalipuram, un des deux sites majeurs de la dynastie, ne fait pas l'objet d'un consensus. Pour ne considérer que les positions extrêmes, rappelons que R. Nagaswamy (1960-62) attribue l'ensemble du site à Narasiṃhavarman II, dans le premier quart du vill' siècle, tandis que Marilyn Hirsh (1987) considère qu'un projet d'une telle ampleur correspond mieux à la personnalité de Mahendravarman I ${ }^{\mathrm{er}}$, dans le premier quart du $\mathrm{VII}^{\mathrm{E}}$ siècle ${ }^{20}$. Cette dernière auteure fait par ailleurs des observations importantes qui montrent la difficulté de la datation des différents monuments du site. Elle signale par exemple qu'une inscription peut être postérieure au monument qui la porte, ce qui est particulièrement pertinent à Mahābalipuram, où l'on constate des signes évidents d'appropriation çivaïte de monuments originellement vishnouites. D'autre part, si l'on considère que les monuments de Mahābalipuram sont les formes pétrifiées de types architecturaux antérieurs construits en matériaux périssables, l'évolution stylistique dont ils témoignent n'a pas forcément eu lieu sur le site même. Il nous paraît donc malaisé de préciser au quart de siècle près la

18. Contra. V. Lefèvre, à la suite d'Ogura (1998, p. 43-44 = 1999, p. 120-121), se fie aux tablettes d’Anpil (EIXV, n ${ }^{\circ}$ 5) qui décrivent Āditya I ${ }^{\mathrm{er}}$ et Parāntaka Iº comme fondateurs de nombreux temples (p. 237). Selon lui, plusieurs raisons peuvent expliquer que ce témoignage épigraphique ne corresponde pas à la réalité des découvertes archéologiques : soit ces temples auraient disparu, soit ces rois ne prirent pas soin de les « signer », soit ils furent en réalité fondés par leurs épouses, filles ou brus (p. 242 et note 31). Notons que les tablettes d'Anpil évoquent seulement les nombreuses fondations de Rãjakesarin $\left(=\bar{A}\right.$ ditya $I^{\mathrm{er}}:$ strophe 18$)$ et de son lointain ancêtre Koccemkanān (= Kōccenkaṇnān: strophe 13) en des termes elairement hyperboliques. Sur la valeur de ce témoignage, voir P. Kaimal (1996, p. 54).

19. Voir F. Francis (2009), \$2. 2 et appendice $n^{\prime 3} 7$ pour le détail des fondations royales pallava.

20. V. Lefèvre (p. 26) attribue à Narasimbavarman I*r (deuxième quart du vil゙ siècle) une grande partic des monuments de Mahābalipuram. 
datation des monuments de Mahābalipuram. Quant à la thèse de Michael Rabe (1996; 2001 ) qui considère que le grand bas-relief de l'ascèse à Mahābalipuram fut sculpté sous Narasiṃhavarman I ${ }^{\mathrm{er}}$ et qui l'interprète comme un sleṣa sculptural représentant à la fois la pénitence d'Arjuna et la descente du Gange, pour séduisante qu'elle soit, elle nous convainc peu. Cette analyse thématique et stylistique d'une grande créativité est loin de clore une fois pour toutes - comme l'espère pourtant son auteur $(2001, \mathrm{p}$. xxii) - la question de l'interprétation d'un des monuments les plus célèbres de l'Inde ${ }^{21}$.

Entre pallava et cōla. L'ouvrage de V. Lefèvre lui-même, dans d'utiles pages concernant les bronzes pallava (p. 221 et suiv.), atteste que chronologie et style sont, en l'occurrence, fort peu établis. Il fournit le corpus de ces sculptures en un tableau bienvenu (p. 224-227; vingt-sept bronzes au total), mais rejette en définitive l'appellation de «bronzes pallava». Elle induit en effet que ces images furent produites par la dynastie des Pallava, alors que ces bronzes proviennent en majorité du Delta de la Kāvēri qui a connu, avant l'émergence des Cōla de la lignée de Vijayālaya, « des développements artistiques dus à des petites dynasties locales » (p. 228).

L'expression «bronze pallava » associerait donc indûment à la dynastie pallava des œuvres d'art pré-cōlla. Pourtant, contra P. Kaimal (1996, p. 34), V. I efèvre préfère conserver plus loin l'appellation, purement chronologique et sans implication dynastique, d'architecture cōla pour des temples qui sont rarement des fondations des rois Cōla (p. 37-38). Nous notons par ailleurs que la grotte sculptée de Mahendravarman I $^{\mathrm{er}}$ avec son inscription à Trichy, au bord de la Kāvēri ( $I P \mathrm{n}^{\circ} 32-33$, premier quart du $\mathrm{VI}^{\mathrm{e}}$ siècle), justifie partiellement de ranger ces bronzes pré-cōla sous une étiquette pallava. Le territoire où ils furent produits relevait en effet d'une sphère pallava, dont cette grotte prouve qu'elle n'était pas que politique mais qu'elle fut, également, artistique.

Quelques points de détails concernant les Pallava n'ont guère d'impact sur le propos général de l'étude de $\mathrm{V}$. Lefèvre ${ }^{22}$. Il nous semble en revanche important de faire les quelques commentaires suivants inspirés aussi, entre Pallava et Cōla, par l'étude des manifestations artistiques de ces dynasties, avant d'en venir à l'importante question du portrait.

Notons tout d'abord que V. Lefèvre souligne avec justesse l'importance du Tripurāntaka, représentation de Śiva victorieux des trois cités des asura, comme figure royale sous les Cōla (p. 243, 297-298 et 311). Mais il fait à peine allusion à son importance sous les Pallava. Il signale que le Dīptāgama 38 indique clairement que Tripurāntaka se place face à la dynastie ennemie (p. 243 , note 35 ), confirmant là une hypothèse de Gerd J. R. Mevissen

21. V. Lefèvre traite de ce relief et tend à suivre M. Rabe (2001, p. 215-217). Contra, E. Francis et al. 2005 , p. $585-586$.

22. Par exemple, V. Lefèvre reprend la catégorie caduque des Ganga-Pallava (p. 3 et 369 ). Il présente, d'autre part, les tablettes de Kānukollu (EI XXXI, $\left.{ }^{\circ} 1 \mathrm{~A}\right)$ comme pallava, alors que son émetteur Nandivarman est un Śālañkāyana (p. 71). Par ailleurs, comme M. Rabe (2001, p. 142), V. Lefèvre fait, concernant les récits mythiques de la dynastie, un amalgame entre l'apsaras et la nāgĩ qu'il présente comme la mère de l'éponyme Pallava d'après les tablettes de Rāyakōta $\left(I P \mathrm{n}^{\circ} 257\right)(\mathrm{p} .23$ et 216$)$; mais dans cette charte le fils d'Aśvatthāman et de la nāgi est Skandaśisya et non Pallava. Enfin, il suggère que le nom de l'éponyme Pallava viendrait des pousses posées dans son berceau pour que son père puisse l'identificr, citant à l'appui $I P n^{\circ} 77$ (p. 23). Certes les pousses (pallara) y forment la couche du nourrisson, mais elles n'ont pas pour fonction d'aider le père à identifier son fils. Il s'agit simplement d'un jeu étymologique sur le nom de la dynastie. V. Lefèvre introduit en fait ici un mythème qui appartient à la légende d'lḷantiraiyan, roi de Kacci (Kāñcipuram), né loin de son père et identifiable grâce au tontai, un grimpereau qu'il portait autour du cou. 
(1994: 2006). Nous ajouterons qu'en contexte pallara. le dieu combattant les trois cités occupe certes une place particulière dans le programme iconographique, mais qu'elle procède, à notre sens, d'une thématique alors propre à la face orientée vers le nord, qui est celle des avatära ${ }^{23}$.

Remarquons ensuite que l'analyse des familles de graveurs et de poètes mentionnés dans les tablettes cōla, dont on peut suivre la lignée sous différents rois, est des plus intéressantes (p. 157-162). Ce type de travail peut se faire cependant dès l'époque des Pallava, dont les chartes contiennent déjà des mentions de poètes et de graveurs, similaires à celles que V. Lefèvre utilise pour les Cōla. Ces mentions permettent également de reconstituer des lignées d'artiste ${ }^{24}$. Dès lors, nous ne suivrons pas l'auteur quand il écrit que l'épigraphie est silencieuse sur les artistes avant le IX" siècle (p. 162 et 175).

Dans le domaine de l'évolution des cultes. V. Lefèvre fait remarquer « l'apparition des temples de la Déesse à côté de ceux de son époux » à partir du xl゙ siècle. Il associe cette nouvelle typologie de la commande à des commanditaires non royaux et conclut à un « développement de nouvelles formes de religiosité, s'éloignant du culte "officiel" centré uniquement sur Śiva et soutenu par le pouvoir royal » (p. 248). Nous ferons cependant obscrver que la Déesse, figure de la victoire et de la prospérité, occupe déjà une place fort importante dans les monuments royaux pallava : une grotte, un ratha et plusieurs rochers lui sont consacrés à Mahābalipuram ${ }^{25}$; ses images (dans des formes qui évoluent, de Korravai à celle que nous appelons la Déesse au lion) sont fréquentes dans les temples tant rupestres que construits; le maṇqapa du Kailāsanātha, enfin, est entièrement dévolu aux déesses. La nouveauté résiderait donc plus simplement, selon nous, dans la systématisation de l'allocation d'un sanctuaire distinct pour la Déesse, lors d'une deuxième phase de la période $c \bar{l} \underline{l} a$.

Le modèle roval. Nous nous interrogerons, pour finir cette brève revue de la vision des Pallava dans l'ouvrage de V. Lefèvre, sur la définition qu'il propose d'un modèle royal. Ce dernier est défini en effet sans envisager la question des moyens financiers. L'auteur suppose une forme de déférence envers les rois de la part de subordonnés qui s'abstiendraient de fonder certains types de sanctuaires. Sous les Pallava, le dispositif à trois cellas pour les grottes serait ainsi « réservé » au roi : Skandasena, vassal de Mahendravarman $I^{\mathrm{C}}$, marquerait délibérément « un certain recul par rapport au modèle royal », dans sa grotte à Vallam qui ne contient qu'une seule cella (p. 245). Sous les Cōla, les temples avec pavillons à trois niches seraient proprement royaux, les subordonnés ne prévoyant qu'une seule niche pour leurs pavillons, " afin de ne pas créer de "confusion" " (p. 240$241)^{26}$. La même conception est perceptible quand, voulant rejeter un argument selon

23. Sur l'importance de Tripurāntaka et sur la thématique associée à la direction du nord dans l'art royal pallava, voir E. Francis et al. (2005, p. 593-597). Pour des commentaires plus précis - et opposés - sur cette figure, voir E. Francis $(2009, \$ 5.6 .2$ et 5.7.5) et V. Gillet (2006, p. 241, et à paraitre).

24. Voir par exemple, pour les poètes auteurs de charte : $I P \mathrm{n}^{\circ} 17$ (strophe 9 , éloge de Medhāvin; vers 550 ) et $I P \mathrm{n}^{\circ} 78$ (strophe 8 , éloge de Parameśvara, qualifié de medhāvikulodbhava; deuxième moitié du vIII siècle). Quant aux graveurs, ils sont régulièrement mentionnés dans les chartes à partir de la deuxième moitié du viII" siècle.

25. La grotte en question est le Kōtikal Mạ̣dapa que V. Lefèvre considère, trop rapidement à notre avis, comme non royale (supra, p. 258) et. à tort en tout cas. comme le seul temple dédié à Durgā sous les Pallava (p. 248).

26. Dans ce cas précis. l’argument est encore plus faible. En effet si toute les grottes pallava à trois cellas sont royales. dans le cas des pavillons à trois niches, on ne peut dire qu il s'agit toujours de fondations 
lequel les temples en matériaux périssables de la période pallava, aujourd'hui disparus, seraient l'œuvre de commanditaires moins prestigieux que les rois, $V$. Lefèvre observe $q u$ '" à partir du $I x^{\circ}$ siècle, on voit des fondations importantes faites par des personnages non royaux et [que] rien n'indique qu'un changement économique majeur soit survenu ». Il ajoute que " cela étant, il est significatif que la majorité des temples "pallava" du $\mathrm{Ix}^{\mathrm{e}}$ siècle soient des fondations non royales mais dont seul le soubassement est en pierre : le reste de l'élévation est en briques, comme si on n'avait pas osé employer la pierre pour l'ensemble de l'édifice » (p. 246; nos italiques).

L'argument financier ne serait-il pas pourtant une explication plus, ou tout aussi plausible que celle d'un modèle réservé aux rois? Il n'est pas à la portée de toutes les bourses de faire excaver une grotte à trois cellas ou de commander trois statues pour chacune des façades du pavillon d'un temple. À période ancienne, pareilles ressources financières seraient disponibles seulement pour les rois. Cette hypothèse explique le caractère royal de la majorité des monuments pallava conservés qui sont antérieurs au $1 X^{\mathbb{C}}$ siècle. Le $1 x^{\circ}$ siècle témoigne plutôt, quant à lui, d'un changement économique par l'existence même de ces temples non royaux qui - contrairement à ce qu'écrit V. Lefèvre - sont majoritairement en pierre pour leur élévation (plus précisément, leur soubassement est en pierre et leurs murs sont en pierre parant de la brique; sur ces temples, voir M. W. Meister \& M. A. Dhaky 1983, chapitre 4).

Nous concevons donc un modèle royal d'un autre ordre : les rois, en particulier les Pallava, sont des précurseurs et sont les premiers à pouvoir, pour des raisons financières, utiliser la pierre, et corrélativement les inscriptions, dans l'art templier. À cet aspect financier s'ajoute peut-être un aspect culturcl, si l'on croit comme K. R. Srinivasan ( 1960, p. 1 et suiv.) à l'existence d'une charge mortuaire de la pierre dans la culture locale, qui aurait été rédhibitoire à son emploi comme matériau pour les temples et les images : non seulement il faut pouvoir «se payer» de la pierre, mais il faudrait le vouloir et assumer de briser un tabou. Les temples du $\mathrm{x}^{\mathrm{C}}$ siècle témoignent, selon nous, que des ressources financières suffisantes sont alors disponibles au-delà du cercle royal, et que le préjugé contre la pierre, s'il a vraiment existé, s'est estompé. Nous retrouvons ici la question de la diversification sociale de la commande défendue par l'auteur, à laquelle nous opposerons celle d'une diversification sociale de l'accès à la pierre et à l'épigraphie.

\section{La question du portrait}

Il nous reste à évoquer le dernier chapitre de l'ouvrage (" La question du portrait et du culte personnel », p. 251-301). Pour V. Lefèvre, «la question du portrait ne peut être dissociée de celle des cultes personnels » (p. 251). Ces cultes personnels ne sont pas définis, mais à la lecture du chapitre, il semble qu'il faut entendre par là, outre la dévotion personnelle, le culte des ancêtres et celui des rois divinisés. S’il en est bien ainsi, l'association entre le portrait et de tels cultes ne nous semble pas aussi évidente qu'à l'auteur, notamment en ce qui concerne sa conception de ce type d'images comme commémoratives, terme dont V. Lefèvre paraît parfois restreindre le sens à celui de commémoration

royales, mais seulement que. lorsque les commanditaires en sont connus, ils sont toujours d'origine royale. V. Lefèvre doit le reconnaître (p. 240), mais ne nous dit pas quelle proportion de ces temples a un commanditaire identifie. En outre. il faut tenir compte de la définition flottante du patronage royal : doit-on inclure les fondations des reines et des officiers royaux dans la commande royale? 
d'un mort ${ }^{27}$. Dès lors, nous voudrions mettre ici à l'épreuve ectte conception du portrait. au travers, plus spécifiquement. des exemples pallara.

Avant de passer en revue les portraits pallava, notons que la définition par V. Lefèvre du portrait comme « représentation d'une personne réelle (par opposition avec l'image divine) », que l'auteur avoue «minimale », nous paraît être, également, imprécise. Nous serons cependant d'accord avec lui qu'un portrait ne saurait être vraiment identifié comme tel sans une légende inscrite, même si son propos est alors illustré par une image que nous ne considérons pas être un portrait, à savoir le Gañgādhara de Trichy (p. 301 ).

Signalons d'abord que nous comptons moins de portraits pallava que $\mathrm{V}$. Lefèvre. A la suite de M. Lockwood (2001) et de M. Lockwood \& A. V. Bhat (2001), il inclut parmi les portraits pallava des images divines : la Somāskandamūrti qu’il qualifie de "portrait "déguisé" " (p. 295) et la Gangādharamūrti de Trichy, qu il considère comme une allégorie combinée avec un portrait (p. 31()-311), c’est-à-dire "le portrait idéalisé de Mahendravarman [ [ $\left.{ }^{\mathrm{rr}}\right]$ » (p. 294). Mais ces "God-King images » de M. Lockwood sont, à notre avis, seulement des images duelles, c'est-à-dire des représentations divines qui renvoient allégoriquement à la fonction royale. Concernant, d'autre part, l'Arjunaratha de Mahābalipuram, V. Lefèvre n'est pas sûr que les couples représentés sur ce monument soient des portraits à l'origine; il croit cependant qu'ils furent jugés comme tels un siècle plus tard, au Vaikunthaperumāl, où la composition en est reprise pour un des reliefs narratifs's royaux (p. 264). Cet argument ne nous éclaire pourtant guère sur la nature des sculptures de l'Arjunaratha, pour lesquelles l'identification comme mithuna nous paraît, quant à nous, la plus naturelle. Enfin, pour ce qui est de la Descente du Gange de Mahābalipuram, V. Lefèvre résume et accepte (p. 267) l'hypothèse de M. Rabe (1996; 2001 ) concernant deux portraits royaux, qui y figureraient devant le petit temple de Viṣnu. Nous n'y croyons pas beaucoup, mais V. Lefèvre fait une remarque interessante pour l'appuyer : la qualité unique de ronde-bosse de ces deux figures en ferait des spectateurs observant une scène. Cependant la spécificité de la sculpture à cet endroit est peut-être seulement l'indice d'une reprise destinée à inclure un temple et un ermitage vishnouite dans une scène originellement çivaïte.

Pour notre part, en définitive, si nous ne tenons pas compte des reliefs royaux du Temple du rivage de Mahābalipuram et du Vaikunțhaperumạ̄ de Kāñcipuram ${ }^{2 x}$, nous ne connaissons que deux monuments pallava comportant des portraits.

Deux portraits (portant respectivement les légendes « Siṃhaviṇna » et « Mahendra », $I P \mathrm{n}^{\circ} 40$ et 43) se trouvent dans la grotte d'Ādivarāha à Mahābalipuram. V. Lefèvre privilégie les hypothèses qui en font les portraits post mortem de deux rois successifs, installés par leur successeur, qui serait le patron de la grotte (p. 263). Il s'agirait donc soit de Narasiṃhavarman [ ${ }^{\mathrm{er}}$ et de Mahendravarman II, installés par Parameśvaravarman I ${ }^{\mathrm{or}}$ (hypothèse de K. R. Srinivasan 1964, p. 173), soit de Siṃhaviṣ̣u et de Mahendravarman I ${ }^{\mathrm{er}}$,

27. Cette conception " commémorative " est peut-être dérivée du Pratimànātaka (un drame dont l'attrihution à Bhāsa est discutéc et que l’auteur présente aux pages 287-288) : une galcrie où sont placés. post mortem. les portraits des rois Ikșiāku y joue un rôle important.

28. I.e caractère narratif de ces reliefs qui racontent l'histoire de la dynastie à la manière d"une généalogie épigraphique empêche à notre avis de les considérer comme des portraits stricte sensu. A l’instar de la distinction entre images cultuelles et narratives des dieux (Koṛavai iersus Mahiṣamardini par exemple). nous distinguons portraits royaux et representations royales. 
installés par Narasiṃhavarman Ir (hypothèse de M. Lockwood \& G. Siromoney 1992) ${ }^{29}$. V. Lefèvre conclut que « quelle que soit l'interprétation, on a affaire à des portraits commémoratifs » (p. 263), ce dernier terme devant être compris, semble-t-il, au sens restreint de commémorant un roi décédé.

Il nous semble qu'on peut, $\mathrm{cn}$ fait, ćcarter la première solution, pour laquelle penche néanmoins V. Lefèvre (voir les pages 295-296, qui sont plus explicites à ce sujet). Il nous paraît difficile, en effet, de considérer que la légende «Simhavinnạa » fasse référence à un roi nommé Narasiṃhavarman, et si les identifications que donne la deuxième hypothèse mentionnée nous paraissent les plus vraisemblables, nous n'excluons pas, pour notre part, que Mahendravarman I ${ }^{\text {er }}$ soit le patron de cette grotte. Nous rejoignons là l'hypothèse de T. G. Aravamuthan (1931, p. 12) et de Henry Heras (1935, p. 164), que V. Lefèvre écarte trop rapidement à notre sens ${ }^{30}$. Ni la paléographie des légendes, ni le style évolué de la grotte d'Ādivarāha par rapport aux sanctuaires excavés dont on est absolument certain qu'ils sont de Mahendravarman I ${ }^{\mathrm{er}}$, ne permettent de rejeter l'hypothèse en question ${ }^{31}$. De plus, le geste de la figure étiquetée « Mahendra», désignant du doigt le panneau adjacent ou la cella, tout en entraînant par le bras l'une des deux femmes qui l'accompagnent, évoque à nos yeux le patron faisant visiter sa fondation à ses deux épouses. Mahendravarman Ior aurait ainsi pu se faire représenter de son vivant et le portrait ne serait pas commémoration d'un mort mais figure d'un patron royal, évoluant avec ses épouses au milieu des dieux et des déesses.

Quant à l'unique portrait du niveau inférieur du Dharmarājaratha de Mahābalipuram, nous nous accordons dans les grandes lignes avec l'analyse de V. Lefèvre. Ce dernier note que les caractéristiques de la figure (deux bras, une tiare, aucun attribut divin) la différencient des autres images du même niveau qui, toutes, représentent des dieux. La figure en question est en outre placée « du côté des mortels » (p. 258; comprendre du côté des morts, vers le sud). Ces deux éléments plaident pour son identification comme un portrait. V. Lefèvre l'identifie comme celui du roi Narasimhavarman I ${ }^{\text {er }}$, sans toutefois pouvoir déterminer si ce dernier se serait fait représenter de son vivant ou si l'image fut installée par son successeur, Parameśvaravarman $I^{\text {er }}$, qui acheva le monument (p. 258-260). Nous noterons cependant que l'orientation de l'image vers le sud, la direction des morts, qui est aussi l'orientation du portrait de Simphavinna dans la grotte d'Ādivarāha, nous semble, en l'occurrence, favoriser l'hypothèse d'un portrait post mortem.

Après avoir achevé un " panorama rapide de l'art du portrait au Tamil Nāọu " (p. 283) commencé avec les portraits pallava, V. Lefèvre se penche sur « le problème de la ressemblance ". Il conclut qu'elle ne concerne qu'un seul type de portraits, qui est connu par la littérature, de type laïque et réalisé sur des matériaux fragiles (p. 284-287). Il s'intéresse ensuite à la question de la " commémoration, [du] "culte" des portraits

29. Nous ne croyons pas à Thypothèse de V. Lefëvre selon laquelle ces portraits seraient des « images doubles » (p. 295-296). Cette hypothèse consiste à superposer les deux hypothèses d'identifications privilégiées : Parameśvaravarman $I^{\mathrm{er}}$ rendrait hommage à son père et à son grand-père (Mahendravarman II et Narasimphavarman Ier) en même temps qu'au père et au grand-père de son grandpère Narasiṃhavarman I ${ }^{\text {er }}$ (les mêmes images représenteraient également Mahendravarman Ior et Simhaviṣnu $)$.

30. V. L.efèvre argue que plus aucun monument de Mahābalipuram n est attribué à Mahendravarman ler. Cette vue est contestable et fut contestée encore récemment par M. Itirsh (1987).

31. V. Lefèvre note que le monument montre des signes évidents de reprise. Le style évolué de la grotte pourrait dater de cette reprise, qu'on peut attribuer à Parameśvaravarman [er. 
et [du] "culte" des ancêtres $\gg$ (p. 287-293). s"occupant là des pallipatai, terme qui est utilisé dans l'épigraphie et qui désigne, d’après le Tamil lexicon, les temples érigés à la mémoire d'un roi. V. Lefèvre propose d'augmenter la liste des sanctuaires de ce type (en incluant des temples à portraits dont le corpus épigraphique n'atteste pas qu'ils sont des pallipatai), mais ne peut affirmer avec certitude qu'il s'agisse de temples funéraires au sens de sépultures.

V. Lefèvre achève son chapitre sur le portrait avec une synthèse intitulée «Portrait, apothéose et divinisation » (p. 294-301). Il distingue ici deux types de portraits : les uns, " civils », dont on aurait trace seulement dans la littérature, et les autres « stylisés, codifiés, voire transposés, qui prennent place dans un contexte religieux et pour lesquels l'application du mot "portraits" peut sembler discutable ». Parmi ces derniers, dont les exemples sont principalement des sculptures, il distingue, d"une part, des "portraits votifs ou commémoratifs », qui, placés à côté de la divinité d'élection, visent à immortaliser le don ou la dévotion, et, d'autre part, des " portraits porteurs d'un discours idéologique plus fort, allant jusqu'à identifier le donateur à la divinité » (p. 300).

Pour notre part, en nous cantonnant aux exemples sculptés de portraits, nous opposerions plutôt des portraits de dévots non royaux et des portraits de dévots royaux. Cette distinction ne reposerait pas sur la charge votive ou commémorative, commune aux deux types : royaux ou non, les dévots recherchent de la même manière le statut et le prestige durable qui dérivent de l'association avec la divinité. La spécificité du portrait royal serait de s'inscrire en outre dans une optique idéologique royale (le " discours idéologique plus fort » de V. Lefèvre). Celle-ci s'appuie sur la sacralité ancienne de la royauté en Inde et sur son assimilation à la divinité pour rapprocher, ontologiquement ou consubstantiellement, le roi de la divinité à des fins de légitimation et pour établir sa suprématie par rapport à la classe brahmanique. Les portraits pallava, tous royaux, sont à cet égard éloquents : ceux de Simhavinnna et de Mahendra prennent place entre, d'un côté, des images de Brahmā et de Śiva et, de l'autre, la cella; le portrait du Dharmarājaratha $s$ 'insère dans une série d'images divines. Par la métaphore ou par l'allégorie, les images duelles participent du même effort de divinisation, mais en opérant une identification avec la divinité plus prononcée que les portraits.

V. Lefèvre évoque aussi à plusieurs reprises les arts de l'Asie du Sud-Est, et notamment celui du Cambodge où des membres de la famille royale étaient représentés sous les traits de divinités (p. 296). Il considère ces portraits comme plus "lisible[s]" (p. 298). Il s'agirait là " d'une divinisation à travers le portrait 》 qui, " en germe dès les débuts de l'histoire du portrait en pays tamoul », se serait estompée en Inde tandis qu'elle s'implantait facilement dans une Asie du Sud-Est (p. 301 ) qui ira plus loin que ses modèles indiens (p. 309). V. Lefèvre conçoit aussi un retour, plus évident dans la littérature que dans les arts plastiques, de "la conception "divinisée" du pouvoir royal » sous les Nāyaka (p. 300).

Il nous semble qu'en fait une telle divinité, ou divinisation, de la royauté n'a jamais disparu ou ne s'est jamais estompée en Inde. Elle s'y exprimerait toutefois selon des modalités différentes suivant les époques. Sous les Cōla, l'on ne compte guère de portraits royaux comparables à ceux des Pallava, puisque les rois sont représentés en dévots du dieu. Il reste que les manifestations artistiques, à travers, notamment, la figure sculptée de Tripurāntaka, symbolisant la protection, fonction essentielle du souverain, et les comparaisons et métaphores divines appliquées aux rois dans les épigraphes témoignent de la persistance d'une conception "divine » de la royauté. Quant aux portraits royaux vijayanagara et nạyaka, ils s’inscrivent dans la continuité des précédents 
$c \bar{l} \underline{l} a$ : les rois sont représentés en tant que dévots, comme l'a d'ailleurs noté V. Lefèvre (p. 313). Ces portraits se situent d'ailleurs souvent sur des piliers de mandapa, parfois fort éloignés du sanctuaire, comme à Madurai ou à Śrīrangam. Mais, comme à la période $c \bar{l} \underline{l} a$, la « divinisation » du roi persiste, clairement, dans la littérature et dans l'épigraphie.

Remarquons ensuite qu'il faut s'entendre sur le sens de cette assimilation des rois à la divinité. V. Lefèvre s'appuie pour le Cambodge sur les travaux de George Codès (1947), qui fut le tenant d'une interprétation du fameux culte du devaräja comme celui du « roi-dieu », depuis remise en cause par Jean Filliozat (1966, pour qui devarāja, « roi des dieux », désigne Śiva) et par Hermann Kulke (1974). La divinisation du roi s'inscrit, à notre avis, dans le cadre d'un discours royal qui répond à une idéologie brahmanique tendant à séculariser la royauté. Il ne s'ensuit pas pour autant que le roi soit une divinité : l'analogie n'est pas l'identité, comme l'a souligné Jean-Claude Galey (1990, p. 150).

Un mot, enfin, sur le lien étroit que semble établir V. Lefèvre entre le portrait et la commémoration du mort. Deux des trois exemples pallava de portraits que nous croyons avérés ont pu être réalisés du vivant de leur modèle. Les images duelles, que V. Lefèvre considère comme des portraits, sont réalisées du vivant de leur commanditaire. Le cas du portrait post mortem de Gaṇuarāditya à Kōnēerirājapuram (étudié p. 275-276; SII III, n 146 en donne l'identification) nous semble hors norme car il est l'œuvre d'une veuve dévote. Et s'il est vrai que sur les reliefs narratifs du Vaikunthaperumā! ou dans les mandapa nāyaka, des morts sont représentés (et en plus grand nombre que les vivants), ils ne figurent là qu'en ancêtres d'un commanditaire, le dernier de la lignée, qui est bien vivant. Enfin, nous noterons - dans la même perspective, mais à l'inverse - que les portraits sont rares dans les pallipatai avérés. L'ensemble de ces données et de nos analyses nous font donc dissocier le portrait du culte des morts, sans pour autant qu'ils ne puissent, parfois, se rejoindre à travers des usages cultuels particuliers.

\section{Conclusions}

La grande ambition chronologique de Vincent Lefèvre l'empêche, nous semble-t-il, d'approcher de façon optimale ses sources primaires, et nous considérons, quant à nous, que l'avancement des études spécifiques rend prématurée une synthèse portant sur le phénomène de la commande en Inde du Sud. Il reste, en tout cas du côté des Pallava, tant à explorer, à comprendre et à éditer, que toute conclusion sur ce sujet paraît hâtive. Le projet de Vincent Lefèvre n'en est pas moins créatif et son approche nouvelle. On soulignera, pour conclure, l'originalité d'une synthèse s'appuyant à la fois sur les œuvres d'art, les documents épigraphiques et les textes normatifs pour établir certaines hypothèses vraisemblables sur des images concrètes, lorsqu'on a cherché « [...] qui les avaient fabriquées, pour qui, selon quels procédés et, le cas échéant, à quelles fins » (V. Lefèvre 2006, p. 9).

\section{Édith Parlier-Renault, Temples de l'Inde méridionale ( $\gamma^{\prime \prime-1} \prime^{\prime \prime}$ siècles). La mise en scène des mythes, Paris, Presses de l'université Paris-Sorbonne (coll. " Asie »), 2006, 413 pages, 282 figures et 54 plans |45 curos. ISBN : 9782840504641 ].}

Édith Parlier-Renault se propose d'étudier le « programme iconographique [des temples] en tant que système d'interprétation du mythe, [et] les transferts de thèmes entre le vI" et le vIII" siècle " (p. 7) dans le Decean et le nord du Tamil Nadu. Après un bref survol des 
thèmes abordés ${ }^{32}$, nous nous pencherons de manière plus détaillée sur les deux grands axes que É. Parlier-Renault définit dans le programme iconographique du Kailāsanātha de Kãñcipuram, fleuron de l'art pallava. Rappelons que, parmi les nombreux sujets traités par l'auteure, nous insisterons seulement sur les aspects de son travail qui nourrissent nos réflexions sur l'iconographie pallava.

L'ouvrage débute par une analyse approfondie des significations et des valeurs des directions, depuis la littérature védique jusqu'aux Purāna. Si les thèmes védiques constituent un ensemble relativement homogène, il semble presque impossible de dégager une évolution claire des valeurs des orients (p. 14 à 48 ; un tableau à la page 17 donne une idée précise de la situation et de l'évolution dans les textes de tradition védique) ${ }^{3.3}$. À la lecture de cette présentation (p. 33 à 48), on pourrait cependant définir certaines grandes lignes : le sud attaché aux ancêtres et aux démons, l'ouest lié à l'eau. l'est et lé nord. les deux directions véritablement fastes dès la littérature védique, associées au féu, aux dieux ou aux hommes.

Dans le reste de l'ouvrage, É. Parlier-Renault confronte les prescriptions des textes avec la réalité archéologique de son corpus. À plusieurs reprises, à propos des temples tant excavés que construits, elle fait remarquer que les images ne s'accordent pas avec la thématique des directions déterminée à partir des textes. Elle constate, par exemple, que l'orientation des aspects de Śiva dans la grotte de Dhumar Lena à Ellora « ne correspond pas du tout à l'orientation des trois visages de Śiva (féminin au nord et à gauche, terrible au sud et à droite, login au centre) » (p. 75); elle ajoute que " ce qui détermine surtout l'organisation du programme iconographique, c'est la direction dans laquelle les images sont tournées, non leur localisation ${ }^{34}$. Portant, en l'occurrence, sur un sanctuaire excavé, une telle observation nous semble pouvoir s'appliquer à l'ensemble des emplacements considérés comme "étranges " par É. Parlier-Renault : chaque monument nous apparaît plutôt comme une entité unique, ne répondant pas toujours aux exigences formulées dans les textes. Une fois incluses dans un programme iconographique, les images n'acquièrent-elles pas une organisation et une signification propres, qui n'ont pas toujours un écho dans les textes?

32. L'ouvrage se divise en deux parties. La première, nommée « L'appréhension de l'espace », regroupe les études sur les directions, sur les temples rupestres et monolithiques ainsi que sur les temples construits du VII" siècle. Dans la deuxième, bien qu'elle soit intitulée "Temples pallava Śivaïtes du vIII" siècle ", on trouve, outre une analyse de l’iconographie du Kailāsanātha et des autres monuments pallava du

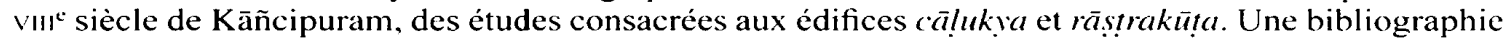
détaillée à la fin de l'étude est suivie d'un glossaire, qui ne remplace pas l'index qu'on aurait aimé trouver.

33. Les Purāna sont « peu éclairants », et «c'est souvent le rapprochement avec les éléments védiques qui permet de les comprendre » (p. 33, note 94). Pour des tableaux plus complets sur les divinités de l'espace, on consultera C. Wessels-Mevissen (2001).

34. Ainsi, les images de Varāha, à droite, et de Narasimha, à gauche, dans le temple du Kumrā Math à Nāchnā, sont «curieusement " inversées par rapport aux prescriptions pour la forme de Vaikuntha (p. 55). L'auteure évoque l'« Upper Śivālaya » à Bādāmi, dans lequel « la localisation de Narasimnha au nord contredit les prescriptions concernant la Vaikuṇthamūrti » (p. 119 ; la note 19 confirme qu'il s'agit là d'un fait courant), et le temple de Viṣnu à Mahākūṭa où, à nouveau, «bizarrement leur orientation est inversée par rapport à la règle fixée pour les deux visages de la Vaikunțhamūrti (Narasimnha au nord, Varāha au sud) » (p. 123). Dans son analyse de la grotte II de Bādāmi (p. 86), É. Parlier-Renault élabore des propositions intéressantes d’oppositions entre Eau/Fécondité, incarnées par Varāha, et Feu/ Souveraineté. représentés par Trivikrama, dans deux reliefśs qui se font face. Mais elle en conclut que leur position Trivikrama orienté vers l'ouest et Varāha vers l'est "semble en contradiction avec leur signification ". ćest-à-dire l'ouest relié à l'cau et l'est au feu. 
C'est en tout cas ce que laisse supposer l'analyse du temple construit de Deogarh (p. 58-61), où la cohérence du programme iconographique ne dépend pas du symbolisme des directions tel qu'il a été défini au début de l'ouvrage. É. Parlier-Renault détermine ici, de façon convaincante, une opposition entre, d'une part, au nord, la délivrance de l'éléphant, figure active qui renvoie au roi, à l'avatāra ainsi qu'au monde des hommes, et, d'autre part, au sud, le Viṣnu couché qui symbolise la contemplation et le monde des dieux. Deux figures ascétiques, Nara et Nārāyaṇa, l'une humaine, l'autre divine, occupent la façade est, marquant la transition entre le monde des hommes et celui des dieux.

La présentation de l'architecture rupestre hindoue du Deccan (Elephanta, Ellora, Bādāmi, p. 63-97), du pays tamoul (grottes pallava et ratha de Mahābalipuram, p. 99-116) et des temples construits călukya du vII siècle (p. 117-138) succède à celle des édifices gupta (p. 53-61). Elle offre d'utiles descriptions d'images et rassemble, pour la première fois, un grand nombre d'illustrations dans un même ouvrage.

É. Parlier-Renault conclut sa première partie avec le temple de Svarga Brahmā à Alampur (p. 128-134). Elle date cet édifice du règne du Cālukya Vinayāditya (681-696), d'après l'interprétation généralement acceptée d'une courte inscription de fondation (ARE 1959-1960, $\mathrm{n}^{\circ}$ 159, p. 60; Inscriptions of Andhra Pradesh I, p. 12). Considérant donc ce temple comme antérieur au Kailāsanātha de Kāñcipuram, elle en fait alors l'une de ses sources d'inspiration (p. 131-133;162), notamment pour les représentations de Trivikrama, de la Tripurāntakamūrti et de la Lingodbhavamūrti. L'affaire est d'importance puisqu'il s'agit de déterminer les sources de l'art pallava. Nous ne sommes pas aussi certains cependant que le temple d'Alampur soit antérieur au Kailāsanātha. À la lecture de l'inscription, on remarque en effet qu'elle est à la fois lacunaire et très obscure ${ }^{35}$. Le nom de Vinayāditya Prthivĩvallabha semble n'apparaître au début de l'épigraphe que pour signaler que ce personnage est l'époux d'une certaine mahādevit, mentionnée à la première ligne. Le rôle même de cette Mahādevī est difficile à cerner : on ne sait si elle fut commanditaire du temple ou s'il fut érigé en son honneur. Il est donc possible que ni le roi ni cette épouse n'aient été encore vivants au moment de l'érection du monument. Le Kailāsanātha datant, environ, du premier quart du vill siècle, il nous semble dès lors hasardeux de faire du Svarga Brahmā son précurseur ${ }^{36}$.

É. Parlier-Renault ouvre sa seconde partie avec l'étude du Kailāsanātha de Kāñncipuram, et la poursuit avec celles des temples construits callukya et des monuments rāstrakūta $\mathrm{du} \mathrm{V} \mathrm{I}^{\circ}$ siècle. L'analyse est ici très détaillée. Elle propose ainsi la première réflexion approfondie sur le temple cạlukya du Virūpākṣa à Paț̣ạakal (p. 280-305 et fig. 197 à 229). Après une longue description des images (p. 280 à 297), l'auteure détermine une organisation (p. 297-305), qui répartit des représentations de Viṣnu et de Śiva selon une opposition nord/sud (p. 297). On remarque cependant que celle-ci ne concerne en fait que les figures centrales du sanctuaire (voir plan 44a), les autres bas-reliefs n'apparaissant pas dans sa présentation. Quant à la succession des reliefs dans l'ordre de la pradaksināa (circumambulation dextrogyre), elle mettrait en scène la destruction du dharma (Vālin combat Sugrīva; Rāvaṇa enlève Sītā), puis sa restauration (Śiva met à mort Andhaka; Varāha secourt la Terre) (p. 301-303). C'est à peu près la même séduisante interprétation qui est présentée pour le Kailāsanātha à Ellora. On notera toutefois que, dans un cas comme dans

35. Le texte sur lequel nous nous appuyons est celui qui a été publié dans Inscriptions of Andhra Prokesh I. laute d avoir pu nous rendre in situ pour le vérifier.

36. Pour une brève discussion sur les différentes hypothèses que permet cette épigraphe, voir V. Gillet (à paraître). 
l'autre. l'auteure ne prend pas en compte l'ensemble des reliefs (sculptures de l'élévation du Virūpākṣa et du Kailāsanātha d Ellora: représentations de la galerie pourtournante du Kailāsanātha à Ellora). Cette interprétation devrait amener par ailleurs, nous semble-t-il. à donner au roi une place plus importante que celle que É. Parlier-Renault lui réserve, ne lui consacrant qu'une seule phrase, dans sa conclusion sur le Kailāsanātha d'Ellora (p. 357). Mettre en scène les exploits des avatăra divins et le thème de la restauration du dharma, n'est-ce pas, en effet, un moyen de représenter les exploits du roi et d'illustrer sa fonction, le souverain lui-même étant une incarnation divine?

\section{Le Kailāsanātha de Käñìipuram}

L'étude du Kailāsanātha de Kāñcipuram constitue l'une des parties les plus développées de louvrage. ("est aussi celle qui nous intéresse le plus directement dans le cadre de notre chronique. $\hat{E}$. Parlier-Renault consacre une trentaine de pages (p. 146-178) aux descriptions du corpus des images du sanctuaire el des textes qu elle va utiliser ${ }^{\lessgtr-}$. Elle dresse, dès la page 178, les contours d'un programme iconographique. Notre commentaire portera essentiellement sur l'axe central de celui-ci, à savoir la présence de deux divinités. Kāma et Kāmākṣī, intégrées chacunc dans un jeu d'alliance et d'opposition avec Śiva.

A la recherche de Käma. Pour É. Parlier-Renault, le mythe de la destruction de Kāma, et, par extension, le concept du kāma (amour. désir), structure le programme iconographique du Kailāsanātha ${ }^{3 *}$. Elle détermine une face sud, dont le thème majeur serait l'amour, opposée à une façade nord qui mettrait en scène le conflit (p. 218). Nous la rejoignons sur le principe de deux faces qui s'opposent, l'une apaisée, l'autre guerrière ${ }^{39}$. Cependant aucune référence, directe ou voilée, au mythe de Kāma ne nous paraît avoir été représentée dans le temple. La discussion portera ici sur l'interprétation des deux formes principales des façades sud et nord de la majorité des temples pallara construits : Dakṣināmūrti et Jalandharasaṃhāramūrti. É. Parlier-Renault propose en effet de considérer dans celles-ci, au-delà de l'expression de leur propre mythe, un lien avec Kāma, qui commanderait l'ensemble du programme du sanctuaire.

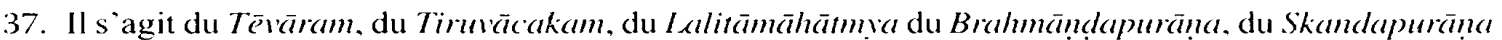

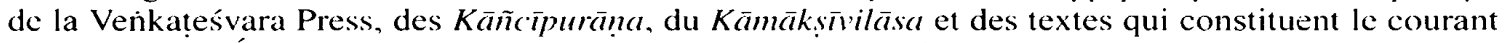
tantrique de la Srî̀idiā. La plupart de ces ouvrages sont postérieurs au Kailāsanātha, que l’on situe, au plus tard, à la fin du premier quart du viı̈ siècle. Seul le Tévēram pourrait, éventuellement, contenir des hymnes datant de cette époque.

38. L'auteure considère cet épisode comme omniprésent dans l'iconographie pallava après avoir octroyé un rôle central à la figure de la déesse de Kāñcipuram, Kāmākșī, qu elle envisage comme étroitement liée au cycle de Kāma. Si cette déduction, toujours suggérée, n’est pas exprimée clairement dans le présent ouvrage, elle est en revanche explicitée dans son article de $2000:$ « [..] le roi [...] aurait pris le biruda d'Atyantakāma en référence au principal mythe lié au culte de la déesse à Kāñcipuram, celui de la mort et de la résurrection de Kāma. À travers ce nom, le roi Pallava s`identifiait à Śiva sous les deux formes à la fois indissociables et antinomiques de Kāmāri, "l’adversaire de Kāma", et de Kāmeśvara (le Seigneur Kāma ou le scigneur de Kāma, Śiva revêtant l"apparence de Kāma), deux formes que mel au premier plan, comme on le verra, tout le cycle local des légendes liées à la déesse du Kāmakoștham. Kāmākșī, figure privilégiée de la divinité féminine dans le sud de l’Inde » (p. 122). C'ependant, comme nous le verrons plus loin, cette relation entre Kāmākși et Kāma n'apparaît pas. lors de l'élaboration du mythe, aussi prégnante que semble le penser l'auteure (infica. p. 275-277).

39. Voir E. Francis et al. 2005 . p. $592-596$. 
Daksinç̄mūrti. Dakṣināmūrti est une forme particulière de Śiva qui apparaît peut-être au Kailāsanātha pour la première fois (fig. 1) ${ }^{40}$. Certaines sources primaires l'associent indirectement à la légende de Kāma. En effet, la description de cette figure dans quelques Ägama (voir, par exemple, Rauravāgama Kp. 35. 287b-292; vol. II de l'édition et vol. I de la traduction) rappelle fortement celle du dieu en méditation dans son ermitagc gucttć par Kāma, tel qu'il apparaît dès le Kumārasambhava (III. 44-47). Par ailleurs, un texte tamoul, le Kantapuränam, datant du XII ${ }^{e}$ siècle environ, fait fusionner la figure de l'enseignant et celle du dieu menacé par les flèches de Kāma ${ }^{41}$. La tradition tamoule du XII" siècle intègre donc explicitement la figure du Śiva enseignant dans le cycle de Kāma.

La littérature secondaire reprend souvent ce lien suggéré dans les Āgama et exprimé dans le Kantapurānam. Cependant, il ne nous paraît pas avoir été établi avant la période cōlla, durant laquelle furent rédigés les $\bar{A} g a m a^{42}$ et sculptés des bas-reliefs où la suppression de certains éléments secondaires de l'image d'origine (sages et gazelles) rend possible une confusion avec un Śiva méditant que Kāma perce de ses flèches. En effet, si certains textes et certains bas-reliefs postérieurs au $x^{c}$ siècle semblent bien se répondre en renvoyant à la légende de Kāma, nous ne voyons rien de tel dans les représentations pallava. Śiva Dakṣināmūrti s'y présente comme un enseignant entouré de ses disciples, et l'on notera que le cycle de Kāma n'est pas associé à la transmission du savoir. Dans le Tèvāram, souvent cité par É. Parlier-Renault pour attester l'ancienneté du mythe de Kāmākṣī (infra, p. 276-277), le Śiva assis sous un arbre banian est celui qui enseigne, non le meurtrier de Kāma avec lequel il n'est jamais mis en relation ${ }^{43}$. Associer la légende de

40. Le terme de Dakșiṇāmūrti ( la forme au sud/du Sud») désignant la figure de Śiva assis sous le banian et entouré de disciples n'apparaît pas dans les textes antérieurs ou contemporains des images que nous étudions. Ce n'est qu’à partir des $\mathrm{XI}^{\circ}-\mathrm{XII}^{\circ}$ siècles que cette forme est rangée sous ce nom dans les $\bar{A} g a m a$. A la suite de É. Parlier-Renault, nous utiliserons ici le nom de Dakṣināmūrti par simple convention.

41. Voir R. Dessigane \& P. Z. Pattabiramin 1967, p. 6-9. Pour une description détaillée de ce phénomène d'assimilation tardive de ces deux aspects de Siva dans ce texte, voir V. Gillet (2006, p. 71 , note 132 , et à paraître).

42. D. Goodall (2004) pose quelques jalons pour la datation de plusieurs Āgama, en tentant essentiellement de déterminer les plus anciens. Selon H. Brunner-Lachaux (1998, p. iv-v; 1990), beaucoup de ces textes, notamment ceux qui contiennent des descriptions très détaillées des images appartenant au culte public, seraient postérieurs au $\times I^{\circ}$ siècle.

43. Il est remarquable que la figure du dicu enseignant assis sous un arbre banian dans les hymnes du Tévaram et celle qui apparaît pour la première fois sur les façades sud des temples pallava soient très proches. Nous citons ici, à titre d'exemple, la strophe 6 d'un poème de Cuntarar (Tè văram VII. 65) :

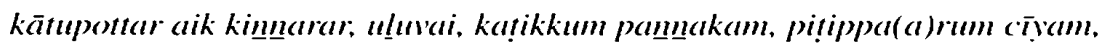

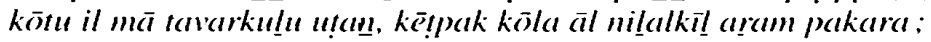

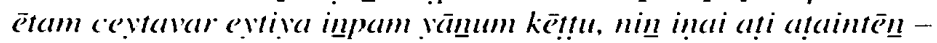

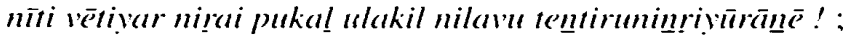

"Il prononce le dharma à l'ombre d'un beau banian, pendant que les beaux kinnara aux oreilles percées, le tigre, le serpent qui mord, le lion difficile à attraper et les grands ascètes sans défauts assemblés, l'écoutent; ayant entendu moi aussi la joie obtenue par ceux qui ont accompli des fautes $j$ 'atteins ta paire de pieds il est celui de la Tiruninniyūr du Sud, répandant dans le monde la renomméc accomplie des brahmanes. ")

Selon le regretté T. V. Gopal lyer, ètam ceytavar renvoic aux sages qui ont commis des fautes pouvant être rachetées par l'apprentissage des Veda après avoir reçu l'enseignement du dieu. Suivant son interprétation. ce passage mettrait également en valeur le fait que même eux, malgré leurs fautes, ont acè̀s aux Veda. Notons qu’à plusieurs reprises dans le corpus du Té̀ăram, les sages qui approchent l'Enseignant ont l'esprit troublé (1. 53.6, I. 101.4, VI. 14. 4, II. 30. 1).

Pour une traduction moins littérale de cette strophe, nous renvoyons à D. Shulman (1990, p. 420) : "Those who cover their ears, lordly kinnaras, a tiger, a venomous serpent, a lion too wild to be caught. 
Kāma et les images pallava de Dakṣināmūrti nous apparaît ainsi comme la surimposition d'un lien postérieur sur une représentation plus ancienne qui ne l'illustre pas ${ }^{+4}$.

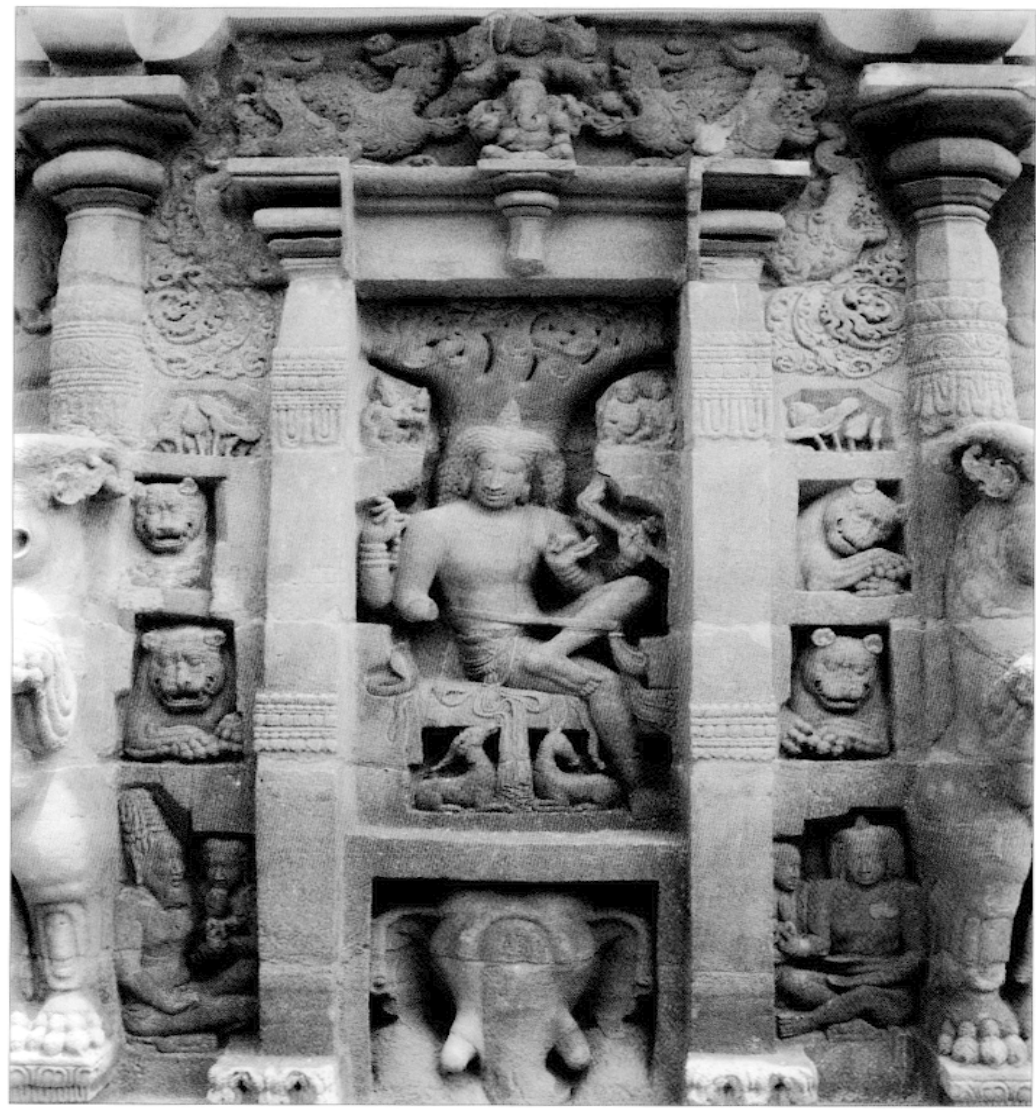

Fig. 1

Daksināmūrti, face sud du Kailāsanātha de Kāñcipuram, début du VIII" siècle (cliché : Emmanuel Francis).

Par ailleurs, le rapprochement que É. Parlier-Renault effectue entre l'image de Dakșināmūrti chez les Pallava et le mythe de l'Ekāmbaranātha, un temple proche du Kailāsanātha ${ }^{45}$, ne fonctionne plus si l'on élimine l'association de cette divinité pallava

a group of perfect sages - these were his audience when he taught dharma beneath the great banyan tree. When I learned of the joys attained even by those who have done harm, I came to your feet, lord of Tiruniñiyūr in the south, its fame established through the world by righteous Vedic Brahmins. "

44. À notre sens, la figure de Dakșināmūrti chez les Pallava, où elle apparaît probablement pour la première fois, s'est forgée en partie sur la base d'un emprunt au bouddhisme et d'une figure divine sud-indienne mal définie, le dieu au banian; voir V. Gillet (2006, p. 52-86, et à paraître) et sur le dieu au banian du pays tamoul, Ch. Schmid (2005b, p. 89-97).

45. Le temple de l'Ekāmbaranātha ou Ekämranātha, à Kāñcipuram, est à moins d'un kilomètre du Kailāsanātha. On y a retrouvé un pilier inscrit d'une série de biruda attribués à Mahendravarman Ior $\left(I P n^{\circ} 21\right)$, qui laisse alors supposer qu'un temple avait déjà été érigé en ce lieu au début du vil ${ }^{e}$ siècle. Il semblerait même que ce temple était déjà nommé Ekāmra à cette époque, puisque, si l'on accepte que Mahendravarman $I^{\text {er }}$ fut l'auteur du Mattavilāsa, un monument est ainsi désigné dans cette pièce (I. 69). Voir l'édition de M. Lockwood \& A. V. Bhat (p. [7]) et également P. C. Bisschop (2006, p. 222). Dans l'enceinte actuelle de ce complexe, un petit sanctuaire est également assigné à la période pallava, de par la présence d'un relief́a fond de la cella représentant Siva et son épouse assis (ce 
avec le cycle narratif de Kāma. La mythologie de l'Ekāmbaranātha se développe en effet, entre autres, autour d'un manguier. Cet arbre est l'emblème de Kāma et É. ParlierRenault suppose que l'arbre banian peut également faire référence à celui-ci (p. 179-182 et 187). Aucun élément des représentations pallava ne permet cependant de lier le Śiva enseignant aux mythes de ce temple ${ }^{46}$. En outre, le manguier lui-même n'est clairement intégré dans aucune légende précise des textes les plus anciens ${ }^{47}$.

Jalandharasamhāramūrti. L'image principale de la façade nord du sanctuaire, qui répond systématiquement à celle de Dakșināmūrti, représente la mise à mort du démon Jalandhara par Śiva ${ }^{48}$ (fig. 2). É. Parlier-Renault qui avait, en 2000 , identifié ce relief comme la mise à mort de Kāma, se range ici à l'identification de la Jalandharasaṃhāramūrti. Cependant, elle continue de lier cette image à la destruction de Kāma (p. 183-187). Remarquant que la présence du disque dans l'épaule du démon « ne paraît guère laisser de doute : il renvoie à l'épisode de la destruction de Jalandhara » (p. 184), elle propose néanmoins de considérer ce Śiva, qu'elle appelle alors Yogadakṣiṇāmūrti, comme « renvoyant plus spécifiquement à la mise à mort de Kāma » (p. 185). En effet, il «n'enseigne pas, mais médite, comme le fait Śiva lorsque Kāma le dérange » (p. 185) ${ }^{49}$. Les deux

relief est en territoire pallava et c'est sous les dynasties pallava et pändya seulement que le mur du fond de la cella est occupé par une Somāskandamūrti ou un couple divin). Nous avons découvert, non loin de ce sanctuaire, la partie inférieure d'une Dakșināmūrti et un Nandin, taillés dans le grès jaune caractéristique des temples pallava du vIII" siècle. Une légende majeure liée à ce site est l'embrassement de Śiva ou du linga par Pārvatī lorsque le dieu fait déborder la rivière Kampai (voir É. ParlierRenault 2006, p. 165-166). Mais d'autres légendes sont attachées à l'Ekāmbaranātha, notamment celle justifiant la présence du vénérable manguier au ceeur du temple. É. Parlier-Renault (2006, p. 180), qui cite le chapitre 62 du Käñcipurāna (cf. R. Dessigane, P. Z. Pattabiramin \& J. Filliozat 1964), la rapporte. Śiva, après avoir mis à mort le démon Bhaṇa, décide de recréer le monde à l'ombre d'un manguier qui n'est autre que les Veda transformés. Ayant pris la forme d'un liriga, il crée, de sa partie gauche, la déesse Lalitā, renommée plus loin Kāmakaṇṇi (Kāmākṣī), qui créera à son tour dieux et mondes.

46. Nous pensons que la déesse est absente ici, malgré les perroquets perchés au-dessus du dieu au banian sur la façade sud du sanctuaire principal du Kailāsanātha, que É. Parlier-Renault considère comme « une allusion voilée à la figure de la déesse absente et à la présence invisible et proche de Kāma » (p. 182). Pour nous, les oiseaux traduisent l'aspect sauvage de cette figure qui évolue dans la forêt.

47. Dans le Manavilāsa (1. 69), l'Ekāmra (Fhamıva) désigne simplement le nom du lieu dans lequel

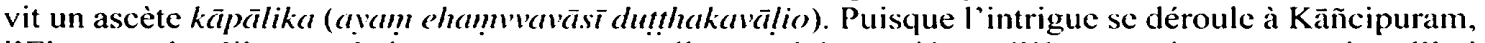
l'Ekāmra tel qu'il apparaît dans ce texte a naturellement été associé au célèbre temple portant aujourd'hui le nom d'Ekāmranātha. Le Tēíăram comprend douze hymnes consacrés au temple de l'Ekāmbaranātha à Kāñcipuram (I. 133; II. 12; III. 114; IV. 7, 44 et 99; V. 47-48; VI. 64-65; VII. 61). Seul un hymne de Campantar évoquerait, peut-ètre, un manguier. En effet, les termes ammā ennnum kacuc ị̂ul (II. 12. 10b) se comprendraient soit comme « dans Kacei appelée Mère (ammā) " soit, tel que l'envisage V. M. S. Ayyar (cf. Digital Të̀äram), comme « dans Kacci appelée le manguier (ammä pour le sanskrit ämra) ». De nombreux poèmes (I. 76. 4: IV. 60. 7; V. 32. 1; VI. 1. 8, 20, 30. 7, 31. 2, 37, 44. 5, 50, 2, 59. 9, 62. 6, 63. 8, 74. 4, 79. 5, 80. 4, 81. 1) dédiés à des temples divers, évoquent également le dieu Ekampan (ou Kampan ou encore Kampam, qui signifie le pilier ou le poteau), mais sans jamais mentionner de manguier. Que l'on considère done le Mattanilâsa ou le Tévérram, aucune légende intégrant le manguier ne nous est parvenue. De fait, il semblerait que, dans le Té̀ $\bar{r} r(m$, seule la légende de la déesse s'accrochant à son époux lorsque la rivière déborde (sup)ra, note 45 ) soit évoquée en des termes à peu près explicites.

48. Voir K. V. Raman \& B. Sasi Sekaran (1992), R. Nagaswamy (1988) et V. Gillet (2004-05: 2006, p. 193-201 : à paraître).

49. Cette simple remarque démontre à elle seule que l'association du mythe de Kàma et de l'image de Dakṣiṇāmūrti ne fonctionne pas pleinement, puisque ce dernier enseigne. 
images pourraient, selon certains $\bar{A}$ gama, avoir des traits communs ${ }^{50}$. Mais il faut avouer. comme le fait d'ailleurs l'auteure (p. 184), que l'apparence du personnage vaincu, clairement démoniaque, est très éloignée de celle d'un séduisant Kāma. Là encore, il nous semble hasardeux d'établir, sur la base de textes postérieurs, une relation entre deux mythes qu'aucun élément archéologique n'indique ${ }^{51}$.

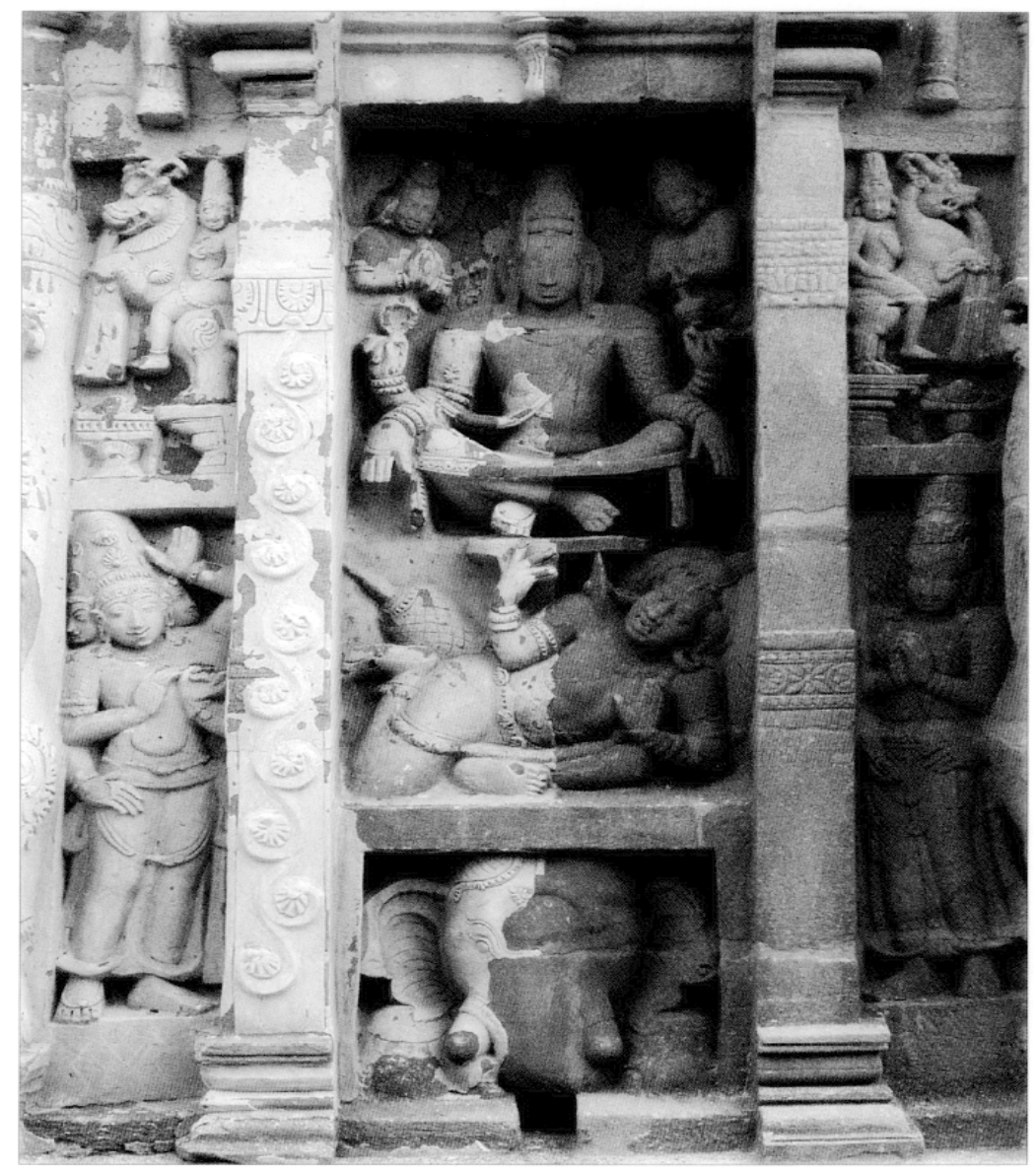

Fig. 2

Jalandharasaṃhāramūrti, face nord du Kailāsanātha de Kāñcipuram, début du VIII ${ }^{\mathrm{c}}$ siècle (cliché : Charlotte Schmid).

50. Il s’agirait essentiellement de la posture de Śiva. Voir T. A. G. Rao (1914, vol. II, part 2, Appendice B, p. 75), qui présente quelques vers de l'Uttarakāmikāgama LVII. É. Parlier-Renault (p. 183, note 152) évoque le Pürvakāranāgama XI et le Mayamata (p. 399 [de l'édition publiée par B. Dagens, 19701976]). Śiva n'a cependant, dans ces deux derniers textes, rien de commun avec la Yogadakṣināmūrti, puisque, dans le premier, il doit avoir les caractéristiques de la Vyākhyānamūrti, et dans le deuxième, il semble assis en paryarkabandhāsana (cf. note 75 de B. Dagens, p. 399 de son édition du Mayamata). Par ailleurs, pour une description de Jalandharasamhāramūrti dans les Āgama qui correspondrait, plus ou moins, avec nos images, Bruno Dagens nous a renvoyé à l'Ajitägama, Paṭala 36, v. 274-277ba.

51. Certes, la posture du dieu et la composition du relief sont inhabituelles pour la représentation de la mise à mort d'un démon. Si É. Parlier-Renault propose la légende de Kāma en tant que thème axial à partir duquel se distribuent la Dakșināmūrti et la Jalandharasaṃhāramūrti, nous opterions pour une influence partielle du bouddhisme. En effet, on pourrait rapprocher cette dernière image de la victoire du Buddha sur Māra, ce qui expliquerait son lien avec l'image du Śiva enseignant, dont la composition est empruntée aux représentations du premier sermon du Buddha. Sur l'étude des images de Dakṣināmūrti et de Jalandharasamhāramūrti, et des diverses influences qu'elles subissent, voir V. Gillet (2006, p. 63-82 et 199-201: à paraître). 
Les inscriptions. Pour justifier dans les bas-reliefs pallava une présence en filigrane des légendes liées au dieu Kāma, É. Parlier-Renault utilise également des textes contemporains de son corpus de sculpture, les inscriptions sanskrites des Pallava et, plus précisément, celles de Narasimhavarman II, fondateur du Kailāsanātha : « les inscriptions de Narasimhavarman II semblent bien se référer au contexte mythologique qui s'est dessiné à travers l'ensemble de ces textes [qui évoquent la légende de Kāma], tous liés de façon plus ou moins étroite à Kāñcipuram. Le thème de la victoire de Śiva sur Kāma a visiblement revêtu une importance centrale pour Narasiṃhavarman II » (p. 174). Dans ces inscriptions (p. 174-178), le terme kāma est souvent employé dans le sens bien attesté par ailleurs de désir ${ }^{52}$. Le roi, associé à Śiva, est parfois aussi comparé à Kāma ${ }^{53}$. Mais ne s'agit-il pas là plutôt d'une convention que d'une allusion fondée sur un mythe précis? Le roi n'est-il pas, depuis les premiers éloges royaux gravés en Inde, une figure séductrice, dont la beauté évoque celle d'un Kāma ${ }^{54}$ ?

Nous rejoignons l'auteure lorsqu'elle envisage (p. 175), en citant la première strophe de $I P \mathrm{n}^{\circ}$ 48-49 (supra, note 52), que le terme kāma renvoie aux désirs des sujets que le roi doit combler, illustrant ainsi l'une des fonctions royales les plus importantes, le don. Mais l'usage de kāma fait essentiellement écho à l'aspect séducteur d'un roi qui prend les traits de Kāma. La récurrence du terme dans les textes n'établit pas pour autant, à notre sens, l'importance de la légende du dieu Kāma dans la sculpture pallava 55 .

52. Ce serait le sens de l'un des biruda royaux, Atyantakāma, que l'on pourrait traduire par « Celui dont le désir est infini ». Voir aussi la strophe 4 de l'inscription de fondation du Kailāsanātha $\left(I P \mathrm{n}^{\circ} 54\right)$ que cite É. Parlier-Renault (p. 174). Le composé kāmādyantaścarāriprasabhavijayinām, que S. Brocquet (1997, p. 553) traduit comme «Qui par la force soumirent leurs ennemis intérieurs, à commencer par leurs désirs ", s'applique aux rois pallava en général, et semble bien signifier que les souverains sont maîtres d'eux-mêmes. Lorsque les termes kāmamardana ou kāmasūidana apparaissent, c'est souvent avec un double sens qu'il faut interpréter ces composés, comme si la référence au mythe n'était pas première : bhūyād atyantakāmāya jagatām kāmamarddanah (IP $\mathrm{n}^{\circ} 48-49$, strophe $\left.1 \mathrm{~b}\right)$, « Puisse-t-il procurer satisfaction aux désirs infinis des êtres - lui, le destructeur des désirs (/le meurtrier de Kāma) » [traduction de S. Brocquet 1997, p. 534]. Comme le signale É. Parlier-Renault (p. 175), le même double sens se retrouve dans le composé de la même inscription, strophe $6:$ sañkarah kāmasūdanah, « le bicnfaitcur qui détruit Ics désirs (/Śamkara, qui occit Kāma) » [traduction de S. Brocquet 1997, p. 535].

53. Voir la strophe 6 de l'inscription de fondation du Kailāsanātha (IP $\left.\mathrm{n}^{\circ} 54\right)$, citée par É. Parlier-Renault (p. 175) : kalācaturayoșitām rahasi rañjane manmathas, « S'agissant de séduire les femmes riches en talents artistiques, il est Manmatha » [traduction S. Brocquet 1997, p. 554].

54. C'est un topos que l'on rencontre dans un grand nombre d'inscriptions royales, en Inde mais aussi dans l'Asie indianisée, antérieures aux Pallava. Voir, par exemple, Inscriptions of the Vákātakas, $\mathrm{n}^{\circ} 25$ (à Ajaṇtā), strophe 17 (p. 108 et 110), où le Vākāṭaka Hariseṇa est comparé, entre autres, à Kāma (Smara).

55. Rares sont les allusions claires au mythe de Kāma dans les inscriptions pallava. Nous retiendrons ici les deux occurrences qui nous semblent pertinentes parmi celles que relève É. ParlierRenault. À la dernière ligne de la strophe 16 des tablettes de Kacākūti ( $I P \mathbf{n}^{\circ} 77$; de Nandivarman II ; deuxième moitié du vıII" siècle), Śiva est désigné comme «l'ennemi de Manmatha », sans autre précision : aśvatthāmā manmathaśatror avatārah̆, "Aśvatthāman, l'incarnation de l'ennemi de Manmatha " [traduction de S. Brocquet 1997, p. 656]. Dans la strophe 6 de la même inscription, nous lisons :

[drlstvā lall $\bar{a}^{*}$ lte nayanam bh(r)iveva

kämo nā [lire na] yầm iśvara li ity upäste I

vișnol $h^{*}$ J svasā sä bhagavaty alaksmìm

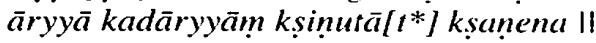


Ainsi, nous ne considérerons pas que le cycle des légendes de Kāma structure le programme iconographique d'un Kailāsanātha où le dieu Kāma n'est jamais représenté, pas plus que dans les autres temples pallava. Seul un relief (niche $n^{\circ} 47$ du mur d'enceinte au Kailāsanātha) pourrait renvoyer à l'épisode dans lequel Kāma retrouve un corps grâce à l'intervention de son épouse Rati auprès de Śiva ${ }^{56}$. Le stuc recouvrant des éléments essentiels de l'image, dont la bannière au makara qui constitue l'unique élément d'identification de Kāma ici, rend cependant incertaine la présence du dieu. Les Pallava illustrent leur idéologie par des images très explicites telles que Gañgādharamūrti, Kālārimūrti ou Tripurāntakamūrti. Si le cycle mythologique de Kāma jouait un rôle essentiel dans leur système de représentation, se seraient-ils contentés de vagues allusions ${ }^{57}$ ?

Une déesse Kāmākșì au Kailāsanātha? É. Parlier-Renault présente par ailleurs la " déesse » comme l'un des axes principaux du programme iconographique du Kailāsanātha. Dès l'ouverture de son étude sur ce monument, elle annonce l'importance que revêt cette figure, souvent présente aux côtés de Śiva et sur le porche d'entrée. Elle suppose que " si la forme féminine a pris tant d'importance dans le programme iconographique de ce temple, c'est certainement parce que Kãñcipuram était déjà à l'époque pallava un des principaux centres du culte de la déesse » (p. 142).

Pour l'auteure, la figure féminine de Kāmākșī ( "Celle dont l'œil est désir [kāma] ») est étroitement liée à Kāma (p. 178-179) ${ }^{58}$. Si le cycle de légendes de Kāmākṣī, tel qu'on le rencontre dans des textes postérieurs au ${\mathrm{V} I I \mathrm{I}^{\mathrm{e}}}^{\mathrm{e}}$ siècle (Lalitāmāhätmya du Brahmānda

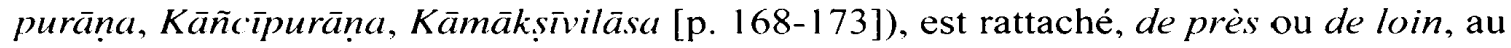
mythe de la mise à mort de Kāma, en revanche, les rares fois où cette figure féminine est

«Comme terrifié à la vue de l'œil sur son front,

Kāma ne s`approche pas d’elle. croyant voir İ́vara :

Puisse la sœur de Viṣnu, la bienheureuse Āryā [la Noble].

A l'instant détruire l'infortune cupide [plus exactement : ignoble (kad-ārva)| ! »

[Traduction de S. Brocquet 1997, p. 653 ; nos ajouts entre crochets droits.]

E. Parlier-Renault (p. 176-177) reconnaît dans ces vers une évocation de la «longue tradition liée à Kāmākșī ». Cependant, il nous paraît clair qu'il s'agit tout simplement de la déesse que l'on retrouve dans les temples pallava dès le vII siècle, souvent couplée avec « Gajalakșmī » d'ailleurs évoquée dans la strophe précédente (voir Ch. Schmid 2005a, p. 502-505). Kāma sembie n'être mentionné que pour souligner l'aspect terrible et puissant de cette figure féminine.

56. C’est ainsi que l'a identifié, en premier lieu, R. Nagaswamy (1969, p. 24).

57. Avant la dynastie des Pallava, les représentations mythologiques çivaïtes existent mais leur éventail est restreint. Voir, entre autres, D. M. Srinivasan (1984, p. 38-39) et Ph. Granoff (2003 et 2006) qui discutent la réticence du courant çivaïte à mettre en scène le dieu sous forme humaine et active, autant dans les textes que dans les images, au moins jusqu'à l'âge gupta. Les représentations de Kālārimūrti, de Tripurāntakamūrti et de Jalandharasamhāramūrti, reflets de la fonction royale qui est l'un des thèmes chers à leur iconographie royale, apparaissent pour la première fois chez les Pallava. D'autres figures telles que la Gañgādharamūrti, la Liñgodbhavamūrti, le Śiva mendiant et le Śiva dansant ont été représentées avant le vIII siècle, mais les Pallava les reprennent sur un mode qui leur est propre. Ces images qui expriment, selon nous, soit la fonction royale soit le principe d'incarnation divine autant parmi les dieux que parmi les hommes, sont les axes que nous considérons comme centraux dans le programme iconographique des temples pallava. Pour plus de détails, voir V. Gillet (2006, p. 269-272 et 304-309, et à paraître).

58. C"est sans doute après avoir noté la récurrence des figures féminines que l'auteure construit sa théoric de la présence de Kāma (supru, p. 269). 
évoquée dans les hymnes du Tēvāram ${ }^{59}$, elle n'est jamais associée à ce dieu. Le terme Kāmākṣī (Kāmāṭci en tamoul) n'apparaît pas dans ce corpus d'hymnes. C'est une déesse nommée Kāmakōtții, ultérieurement associée à Kāmākṣī, qui est mentionnée dans deux poèmes ${ }^{60}$. Un hymne de Cuntarar évoque par ailleurs un kämakkōttam, c'est-à-dire un temple de Kāma, résidence du désir ou de la beauté, etc., à Kacci où la fille de la montagne a été placée, pour le bien des mondes ${ }^{61}$. Rien dans ces lignes ne nous paraît renvoyer à la légende de Kāmākși : le nom du lieu s'explique, à notre avis, par le fait que la déesse est belle et désirable ou serait désirante. À peu près à la même époque, le caractère également vague de la première mention d'un kāmakkôttam dans l'épigraphie

59. Le Têvāram est un texte qui nous paraît jouer un rôle essentiel dans la discussion sur la présence de la déesse. Il est en effet daté généralement entre les $\mathrm{VII}^{\mathrm{C}}$ et $\mathrm{i} \mathrm{X}^{\mathrm{C}}$ siècles et contient plusieurs poèmes dédiés à Kāñcipuram. Kāmākṣī n'y serait-elle pas évoquée si elle avait une place prédominante sur la scène religieuse de la ville à cette époque?

60. kolum pavalaccenkañivāyk kāmakkōtni konkai inai amar porutu kōlam koṇ̣a

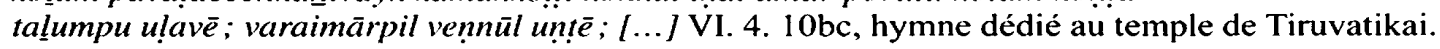
«Il y a la poitrine [de Śiva] au cordon blanc, [semblable à une] montagne; elle porte les marques qui ont pris la beauté de l'union des deux seins de Kamākkōṭti à la bouche de fruit mûr et de riche corail. »

Ce passage semble faire référence à la légende liée à l'Ekāmbaranātha de Kāñcipuram que développent le Kãñaīpurāna, le Periyapurānam et le Skandapurāna de la Veñkațeśvara Press (voir É. Parlier-Renault 2006, p. 165-167), dans laquelle la déesse embrasse le linga si fort qu'elle y laisse l'empreinte de ses seins, lorsque la rivière vient à déborder de son lit. Ici, néanmoins, c'est la poitrine de Śiva qui porte les marques, non le symbole divin. Le nom de Kāmakōtți pourrait être interprété comme le féminin de Kāmakōttam, « le temple ou la résidence de Kāma ». Cependant, il est aussi possible d'envisager le terme de kāma comme désignant le désir ou la beauté. Dans ce cas, Kāmakōtți signifie « Celle qui est le lieu de résidence du désir ou de la beauté » et ce nom n'aurait aucune relation avec la figure divine de Kāma et de sa légende - une relation qui n'apparaît pas dans le Tévāram. L'hymne de Cuntarar (VII. 61) que cite É. Parlier-Renault (p. 164-165) est le seul parmi les douze hymnes dédiés à l’Ekāmbaranātha qui évoque cette légende, et l'épouse de Śiva n'y est pas nommée. Si la réduction en cendres de Kāma est mentionnée (VII. 61.3), elle apparait, nous semble-t-il, au même titre que la célébration de tous les autres exploits de Śiva (avaler le poison et vaincre le dieu de la mort en VII. 61. 1; détruire les trois cités et se couvrir de la dépouille de l'éléphant en VII. 61. 3 ; chanter et expliquer les textes sacrés en VII. 61. 7; détruire le sacrifice de Dakșa en VII. 61.9), sans que l'on puisse établir de lien avec le mythe particulier au temple.

Un deuxième hymne évoque également une certaine Kāmakkoti à Kacci : kac‘ippoli kāmakkotiyutan $k u ̄ t i c$ (II. 36. 4b : « uni avec Kāmakkoți célébrée à Kacci »; hymne dédié au temple de Tiru Irumpūlai). Ce nom signifierait « la bannière du désir ou de l'amour » ou « la liane de l'amour », et il n'est pas possible de déterminer quelle est la forme divine qui apparaît ici ni à quelle légende elle pourrait être reliée.

61. vār iruñkulal, mai vā!netunikan, malaimaka! - matu vimmu koṇ̂ait

tār irun tatamārpu nīnkāt taivalāl - ulaku uvva vaitta.

kār irum polil, kacci mütūrk kāmakkōttam untạka, nür pōy

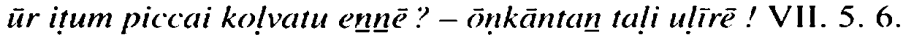

«Here is the Kămakkōttam in the ancient town of Kacci, its grove dark with clouds, where you placed the Lady who never leaves your broad chest covered with honcy-rich konrai [fleur associée spécifiquement à Śiva et dont est tressée sa guirlande], the Mountain Girl with flowing dark hair and eyes long as swords. You placed her here so the world would prosper. Why, then, do you travel the villages looking elsewhere for alms, you who are in Ōnkāntantali? » [traduction de D. Shulman 1990, p. 32].

Nous acceptons ici l'interprétation que propose D. Shulman du participe passé vaitta (transitif) qui aurait pour sujet Śiva, à la dernière ligne ( Toi qui résides dans le temple d'Ōnnkāntan »), contra V. M. Subramanya Aiyar qui suggère $k a ̄ r$ (nuage) comme sujet et prend ce verbe comme un intransitif («big gardens in which clouds crawl for the people to lead a life without worries ».) Il est vrai que la traduction de V. M. Subramanya Aiyar respecte l'ordre des mots (participe passé, puis sujet), mais celle de D. Shulman a l'avantage de justifier l'introduction de la ligne consacrée à la déesse, qui devient le complément d'objet direct. 
tend à confirmer le fait que ce terme n'est pas relié à la déesse Kāmākșī : il semble désigner un sanctuaire, peut-être dédié à la déesse ${ }^{62}$. Ainsi, ni les hymnes du Têvāram ni l'épigraphie pallava n'indiquent, selon nous, que Kāmākṣī jouait, dès le vill" siècle, un rôle majeur à Kāñcipuram. Nous remarquons enfin qu'aucune image, aussi bien au Kailāsanātha que dans les autres temples pallava, ne semble se rapporter à Kāmākṣī ou à son mythe ${ }^{6.3}$. Si ceux-ci avaient eu, à cette époque, tant d'importance, les Pallava ne les auraient-ils pas représentés?

Au plus près des images. Ces quelques remarques inspirées par l'évocation d'un cycle de la légende de Kāma ou de la déesse nous amènent à insister sur l'importance d'une observation in situ. Nous conclurons ainsi sur le débat qu'ouvre l'identification d'une scène unique dans l'art indien, abritée par la chapelle $\mathrm{n}^{\circ} 11$ du mur d'enceinte du Kailāsanātha. É. Parlier-Renault propose d'identifier ce relief comme une représentation du combat de Triśiras contre Indra (p. 204, fig. 122) ${ }^{64}$. Un personnage à trois têtes retient le bras d'un Indra brandissant son foudre. Ses trois têtes, ses quatre bras et le vase à eau qu'il porte dans la main supérieure gauche nous permettent de l'identifier comme un Brahmā et non comme un Triširas. Quant à l'adversaire d'Indra, il n'apparaît pas sur la photographie publiée par É. Parlier-Renault mais se trouve pourtant face à lui, debout sur un lotus. C'est un petit personnage au ventre rebondi; ses quatre bras tiennent un arc et des flèches dont il se sert pour attaquer le roi des dieux. Il est entouré de cinq figures volantes semblables -.. si ce n'est qu'elles ont deux bras - qui attaquent aussi Indra

62. Voir $I P \mathrm{n}^{\circ} 74$, une inscription du Pallava Nandivarman II à Caattamankalam dans la deuxième moitié du vil" siècle. Le terme "Kāmākọtțam » y figure, que l’on peut envisager ici comme le « Temple du désir ". et qui apparaît alors comme le nom générique de tout sanctuaire dédié à la déesse : il ne se présente pas lié exclusivement à Kāñcipuram et à Kāmākșī, divinité féminine de cette ville. C"est également ainsi que le terme est utilisé dans l'épigraphie postérieure à la période pallava. En effet. Uthaya Veluppillai nous informe qu'aux $X I I^{\circ}$ et $X I V^{2}$ siècles, on le rencontre dans deux inscriptions du temple de Tiruvaṇnāmalai ( $n^{\circ} 197$ et 285 ) où il renvoie à la demeure de la déesse Uṇnāmulai. Il est possible que la première évocation du kămakkōttam comme sanctuaire de la déesse Kāmākșī de Kāñcipuram se rencontre dans une inscription de Tripuräntakam, dans le district de Kurnool, en Andhra Pradesh, que cite C. R. Srinivasan (1979, p. 250) et que nous a signalée Leslie Orr. D’après le résumé de l’inscription $A R E$ 1905, $\mathrm{n}^{\circ} 217$ (ARE 1906, p. 14), l'épigraphe enregistre une donation par le roi, seigneur de Kāñcipuram et dévot de Kāmakōtyambikāa.

63. Nous n'avons rencontré aucune représentation du mythe de cette déesse embrassant le linga ou la forme humaine du dieu lorsqu'elle est menacée par les flots de la rivière. Nous n'identifierions pas, quant à nous, les déesses qui se tiennent au côté de Śiva à l'époque pallava comme des Kāmākșī, sur le simple constat que celle-ci est, à partir du XI" siècle sans doute, une figure prééminente à Kāñcipuram. La seule image de déesse qui pourrait prétendre à une telle identification serait celle qu'abrite la chapelle $n^{\circ} 7$ du mur d'enceinte du Kailāsanātha. N'ayant pas été identifiée de manière satisfaisante jusque-là, l'aspect inhabituel de cette figure féminine, dont des formes semblables apparaissent entre les niches du mur d'enceinte (infía, p. 291), n'a jamais été justifié. É. Parlier-Renault (p. 203) la nomme Durgā assise. Cependant, elle paraît confondre cette figure avec celle, debout, qui se trouve deux chapelles avant, et une troisième, assise entre les chapelles $n^{\circ} 20$ et 21 : la déesse $n$ 'a que deux bras au lieu des huit mentionnés, la tête de buffle décrite n'est pas présente et il n'y a qu'un seul dévot agenouillé, et non pas deux. Sans pouvoir nommer cette déesse, nous la considérerions comme paisible, l'aspect guerrier de la divinité féminine étant pris en charge par la déesse de la chapelle $n^{\circ} 5$. Ces deux déesses encadrent la figure du prince, futur roi. le Skanda qui trône dans la chapelle $n^{\circ} 6$. Elles illustrent, à notre sens, deux concepts attachés à la royauté et mis en scène dans ce temple. l'aspect guerrier et l'aspect apaisé.

64. L’auteure ne décrit alors que la partie gauche de l’image, la seule qui apparaisse dans l'illustration quelle fournit. 

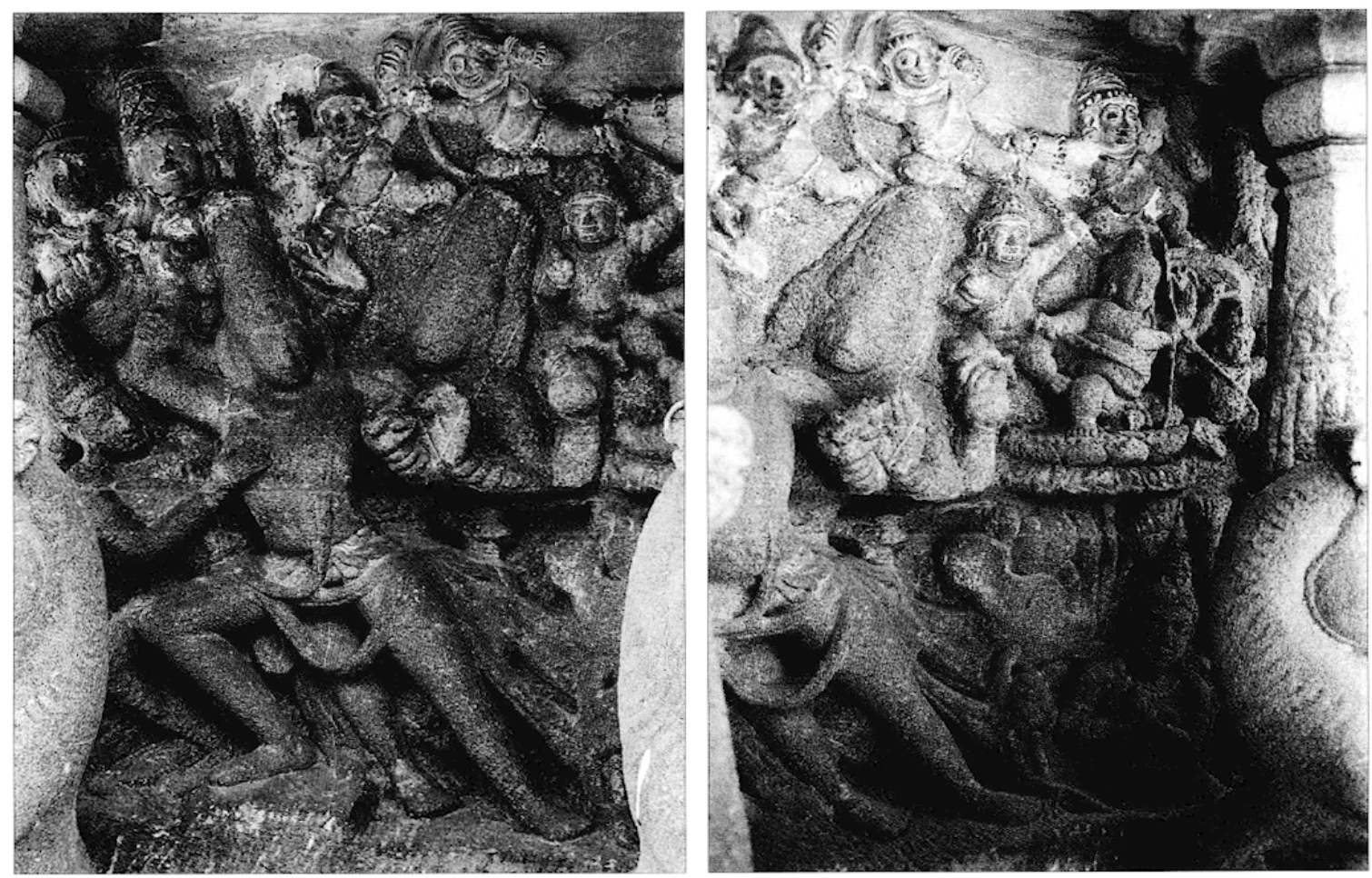

Fig. 3a et 3b. Le combat d'Indra contre Skanda, chapelle ${ }^{\circ} 11$ du grand präkāra du Kailāsanātha de Kāñcipuram, début du vıı̄ siècle (cliché : Emmanuel Francis).

(fig. 3a-b). Sous le lotus, un personnage pourvu d'un nez en forme de bec, d'une paire d'ailes et de deux seins se tient assis, les deux mains jointes.

Le Mahābhārata [ci-après Mhh] III. 213-218 et le Paripätal V. 48-70 permettent de proposer une identification qui rende compte de tous les éléments de la scène ${ }^{65}$. Il s'agit, à notre sens, de l'attaque menée par Indra contre Skanda, lors de la naissance de ce dernier. Dans les textes, les dieux, Brahmā en tête, tentent de retenir leur roi. Le personnage au bec d'oiseau représenterait Garuḍī, forme prise en $M b h$ III. 214. 8-10 par Svāhā, la mère du jeune dieu qui quitte la forêt après s'être unic à Agni. Elle revient ensuite auprès de son fils, en prière, pour se faire reconnaître en $M b h$ III. 215. 4.

Malgré ces désaccords avec l'auteure, on rendra hommage à son entreprise, ambitieuse et originale, qui compare des milliers d'images, dont bon nombre sont mises à la disposition du lecteur. Cet ouvrage apparaît alors comme une base très utile, voire indispensable, à toute recherche sur l'iconographie sud-indienne et sur celle du Deccan ${ }^{66}$.

65. Pour une étude détaillée du relief, voir V. Gillet (2006, p. 274-279, et à paraître), qui explique, notamment, qu'un Skanda à six corps serait ici représenté par la figure à quatre bras et par les cinq autres corps volant autour de lui.

66. Nous signalons ici l'ouvrage d'llisabeth Beck, Pallana Rock Architecture amel Sculphure (2006), publié par la Sri Aurobindo Society en association avec Last West Books. I e texte reprend, pour l'essentiel, les thèses les plus communes sur l'art pallawa sans les discuter: les reproductions sont d'excellente qualité et illustrent parfois des détails qu'on n'a guère l'occasion de voir ailleurs (nous pensons notamment au Dharmarājaratha de Mahābalipuram). 
Peter C. Bisschop, Early Śävism and the Skandapurāna, Sects and Centres, Groningen, Egbert Forsten (Groningen Oriental Studies n ${ }^{\circ} 21$ ), 2006 , VII et 368 pages. ISBN 90-6980-150-7; sans indication de prix.

Si nous nous sommes penchés sur le volume de Peter C. Bisschop, Early Saivism and the Skandapurāna, Sects and Centres, c'est qu'il contient des éléments permettant de renouveler l'approche d'un des mythes fondateurs de l'Inde méridionale dont les représentations sculptées pallava sont parmi les premières connues. On le nomme habituellement "Mythe de la forêt de pins ». De nombreux Purāna, tout d'abord sanskrits et originaires du Nord de l'Inde, comme les textes qu'édite P. C. Bisschop, content comment Śiva s'en va mendier dans la forêt de cèdres déodars ${ }^{67}$. Le dieu est souvent alors appelé Bhiksătana ( « [celui qui fait sa] tournée d"aumônes"), dans la littérature secondaire. Nous l'appellerons ici Séducteur en marche parce que les bas-reliefs pallava sont organisés autour d'un Śiva en marche, provoquant l'adoration des femmes et la colère des rs $i^{68}$ (fig. 4).

Troisième volume paru d'une série consacrée à l'édition critique d'un Purāna çivaïte, intitulé Skandapurāna dans les manuscrits mais différent de celui que la Śrīveńkațeśvara

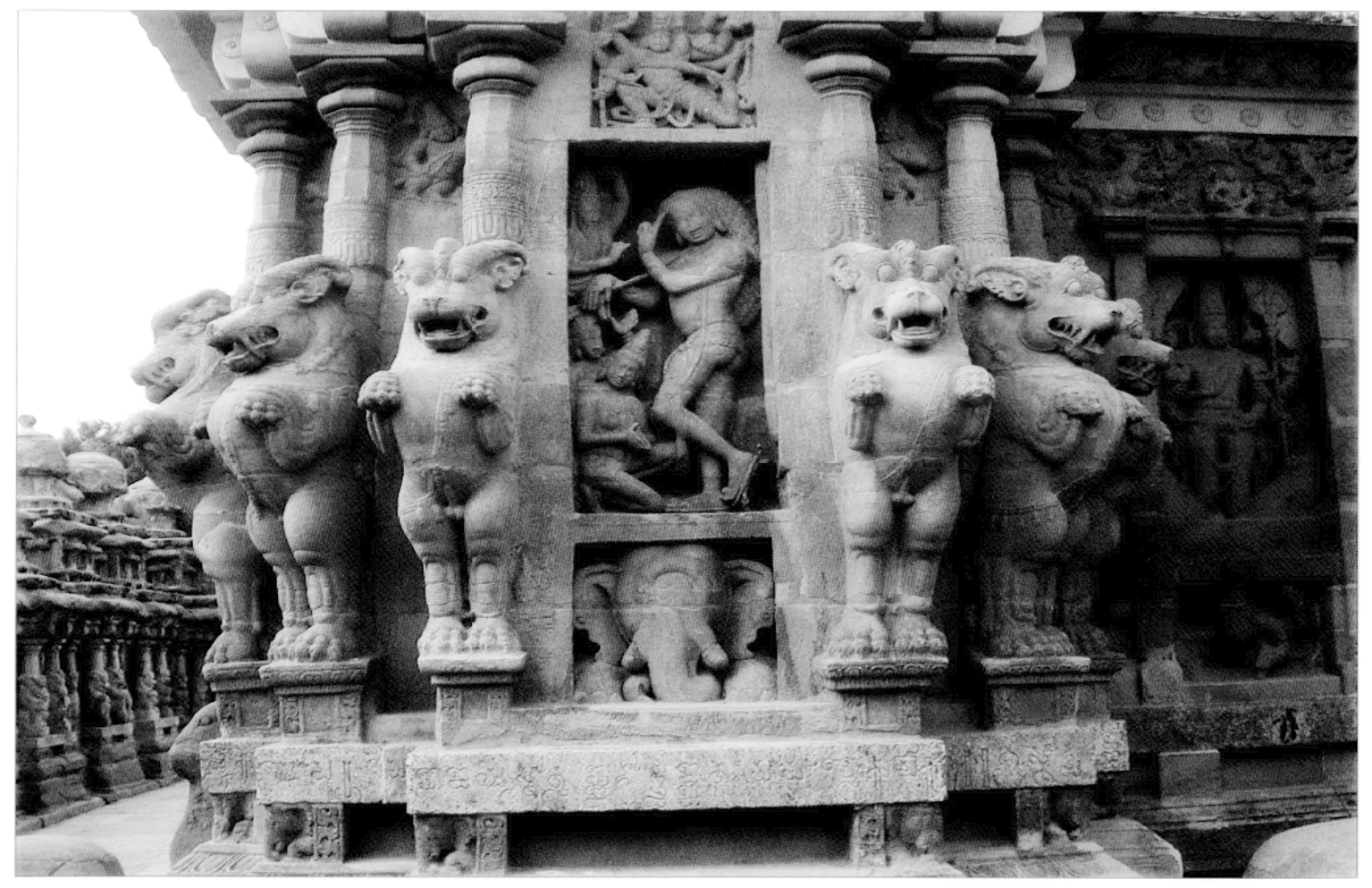

Fig. 4. Le Séducteur en marche, face sud du Kailāsanātha de Kāñcipuram, début du vıII siècle (cliché : Charlotte Schmid).

67. Pour une typologie précise de cette forme de Śiva, voir V. Gillet (à paraître).

68. Aucun élément des sculptures pallava ne situe l’intrigue dans une forêt: les versions du mythe marquées par le contexte méridional, comme celles qui se développent autour du site de Citamparam. font d’ailleurs de la forêt un espace très urbain. Le dieu y mendie d'une " rue " de la forêt à l'autre... 
Steam Press publia sous ce titre en $1910^{69}$, le livre de P. C. Bisschop sera pour nous l'occasion d'évoquer l'intérêt d'un tel projet pour nos études, en mettant l'accent sur ce qui s'avère un thème majeur de l'iconographie pallava. Nous soulignerons ici les richesses de l'ensemble à travers l'utilisation que peuvent en faire ceux qui étudient l'histoire religieuse et culturelle de l'Inde ${ }^{70}$. Il ne s'agira que d'un bref éclairage sur l'usage d'un travail philologique dans le domaine des images; sur l'axe culturel unissant le Nord et le Sud du sous-continent indien; sur la contribution, enfin, que peuvent apporter les données de l'iconographie pallava à l'étude du çivaïsme. Les versions sud-indiennes du mythe de la forêt de pins sont plus récentes en effet. Elles transforment en danseur la figure mendiante du dieu, selon des modalités auxquelles les images sculptées pallava apportent une contribution qui, pour remarquable qu'elle soit d'inventivité et de maîtrise esthétique, demeure à ce jour pratiquement inconnue.

\section{Le projet du Skandapurāna et l'Inde méridionale}

Né du désir d'exploiter au mieux le matériel exceptionnel que constitue un manuscrit népalais daté de 810 , publié par Krṣṇaprasāda Bhaț̣arāī en 1988, le projet d'édition du Skandapurāna $[\mathrm{SP}]$ développé à Groningue est exemplaire ${ }^{71}$. La publication du SP est en effet accompagnée d'introductions développées et d'une annotation précise donnant accès, entre autres, aux critères qui ont présidé à l'établissement du texte présenté. Une édition critique est bienvenue dans le monde des études puraniques qui en manquent cruellement, mais les volumes déjà parus se présentent en outre comme des études du çivaïsme ancien. Dans une approche à la fois prudente et respectueuse de ses sources, l'ouvrage de P. C. Bisschop s'est plus particulièrement attaché à la géographie de ce mouvement, à partir des textes dont il propose l'édition critique : le $\mathrm{SP}_{\mathrm{S}}$, le plus ancien d'entre eux, et les cinq chapitres du $\mathrm{SP}_{\mathrm{RA}}$, recension plus récente (cf. Abréviations, p. 307). Les textes édités constituent en effet des variations autour d'une liste de lieux saints, depuis le $\mathrm{SP}_{\mathrm{S}}$ que son éditeur pense pouvoir placer au vi' siècle jusqu'à des recensions connues par des manuscrits postérieurs au $x \mathfrak{l}^{\mathbb{E}}$ siècle. Ces textes énumèrent divers sites où Śiva s'est manifesté, sanctuaires où le dévot peut obtenir d'être délivré du cycle des renaissances. L'un d'eux est le Devadāruvana, la forêt de cèdres déodars, qu'on appelle habituellement la forêt de pins. Śiva y entre en mendiant ithyphallique.

On touche ici à une figure majeure de l'Inde méridionale : le Séducteur en marche est le personnage central du mythe de Citamparam. Dans la mythologie bâtie autour d'un des plus fameux sanctuaires indiens, vers lequel affluent les pèlerins d'aujourd'hui, le dieu qui danse est le Śiva mendiant dans la forêt de pins qu'évoque un passage du texte édité par P. C. Bisschop. Dans la majorité des versions nord-indiennes du mythe, Śiva entre dans cette forêt, où des sages sont occupés à divers rituels. $\mathrm{Nu}$, le dieu séduit leurs femmes. En colère, les " voyants" frappent le linga de Śiva. Celui-ci tombe à terre et disparaît de l'univers qui, ainsi privé, sombre. Les sages devront reconnaître leur erreur

69. Rappelons que la Venkateśvara Press a constitué un texte à partir de khanda dispersés dans plusieurs manuscrits qui les attribuent à un « Skandapurāṇa ».

70. Peut-être répondrons-nous ainsi au souhait des éditeurs du volume II $\wedge$ du Skandaparäna, qui notent ( $p$. vii) que certains chercheurs ont commencé à utiliser les données de cet ancien Purāna pour leurs propres investigations.

71. Après l'annonce à la neuvième World Sanskrit Conference d’une édition critique du SP (R. Adriacnsen, H. T. Bakker \& H. Isaacson 1994), on se reportera pour les détails de l'histoire de cette publication aux préfaces de R. Adriaensen. H. Bakker et H. Isaacson $(1998 ; 2004)$ et à celle de P. C. Bisschop pour son propre ouvrage. 
et. pour que le monde retrouve son sens. y fonder un culte au linga. À Citamparam. Śiva entre dans la forêt de pins, séduit les femmes et provoque la colère des sages qui célèbrent un rituel pour détruire le mendiant nu. Celui-ci révèle alors toute la puissance de Śiva en entamant une danse de victoire devenue le symbole du dieu de Citamparam - et grâce, entre autres, aux commentaires śaivasiddhāntin qui inspirèrent certains indianistes du $\mathrm{xx}^{\mathrm{C}}$ siècle, une sorte de symbole contemporain de l'indianité.

La place qu'occupe ce mythe en Inde du Sud a été récemment mise en valeur par le livre de Don Handelman et David Shulman, Siva in the Forest of Pines, An Essay on Sorcery and Self-Knowledge (2004). Les auteurs s'y appuient, pour explorer ce qui est " the richest and most complex of all narratives about Śiva and, as such, provides scopes for sustained interpretation nourished by many distinct vantage points and different strands of the tradition "), sur quatre textes, sélectionnés parmi bien d'autres ${ }^{72}$. La traduction de trois textes tamouls (le Kantapurānam, Takṣakāṇtam 6. 13, 30-127 [Purāna tamoul centré sur la mythologie de Skanda]; le Koyirpurānam 2.1-78, 3. 38, 4l-52 [1'un des textes fondateurs du mythe de Citamparam]; le Tirunèlvelittalapurānam, Tārukāvanaccarukkam [Sthalapurāna du site]) ouvre la discussion des trois premiers chapitres de l'ouvrage. La traduction du Haravilāsamu 5. 3-68, "Le Jeu de Śiva », poème télougou du Xve siècle, est insérée dans le quatrième chapitre qui explore la folie de Śiva, à partir de la forme divine du site de Lepākși ${ }^{73}$. La traduction du Kürmapurāna II. 37, un texte sanskrit, est présentée en appendice. Aucun des quatre textes sud-indiens structurant le livre n'est antérieur au $\mathrm{XI}^{\mathrm{C}}$ siècle. Les auteurs ne s'intéressent pas en effet aux origines du mythe considérées sous un angle historique classique, mais aux valeurs qui le fondent, perdurant dans le corpus qui se constitue peu à peu autour du site de Citamparam et connaissant de nombreuses efflorescences dans d'autres lieux saints çivaïtes du Sud de l'Inde. Cette perspective leur fait mettre de côté la plupart des données antérieures, en particulier le large corpus de sculptures représentant le dieu dansant ou mendiant, dont Marguerite Adicéam souligna, dès 1965 , la grande richesse comme le caractère divers - ses figures ne correspondant en outre pas toujours aux descriptions agamiques ${ }^{74}$. D. Handelman et D. Shulman revendiquent néanmoins une approche non structuraliste et citent l'anthologie tamoule dévotionnelle du Tềvāram, qu'on date aujourd'hui entre le viI et le $\mathrm{IX}^{\mathrm{e}}$ siècle. Publié après le leur, l'ouvrage

72. Chacun reconnaît la forme du mendiant et la rattache à un mythe bien connu dans de multiples versions textuelles, comme le soulignent les deux auteurs, évoquant « the hundreds of texts that fit the narrative pattern » (D. Handelman \& D. Shulman 2004, p. vi), et comme l'illustrent, dans leur ouvrage, les mythes rattachés à deux sites différents, Citamparam et Tirunēlveli.

73. L'article de J. Törzsök (2004), «Śiva le fou et ses dévots tamouls dans le Tèvāram », rejoint parfois les propos de ce chapitre; les trois auteurs mènent ainsi la même analyse sémantique des termes dénotant la folie dans leur corpus textuel, avec pittu/pittam, signalant les origines sanskrites du terme et l'envisageant sous l'angle médical d'une des humeurs du corps humain. Voir D. Handelman \& D. Shulman 2004, p. 175-181 (ces auteurs mentionnent le Téväram [p. 176, note 33] et citent le plus tardif Tiruvācakam); J. Törzsök 2004, p. 7-10. On notera le parallèle systématique tracé par Campantar entre pittar, les fous, et puttar les bouddhistes que signale J. Törzsök : le poète çivaïte critique bouddhistes et jaïns en leur appliquant une épithète qu'on s'attend à rencontrer pour Śiva. Un tel rapprochement trouve dans le Séducteur en marche pallava une équivalence plastique remarquable car ce dernier reprend le profil du Buddha (ou du Jina) prêchant (pour des illustrations du Buddha en marche prêchant, voir Robert L. Brown 1990).

74. Voir M. Adicéam 1965a et 1965b. La littérature secondaire sur la forme dansante de Śiva à Citamparam est trop abondante pour être évoquée ici. On en trouvera un aperçu dans le volume collectif consacré au site de Citamparam édité par V. Nanda \& G. Michell (Chidambaram. Home of Nataraja, 2004). Des cinq représentations sculptées évoquées (et illustrées) par D. Handelman \& D. Shulman (2004), trois datent peut-être du XvII" siècle et les deux autres du XIX" 
de P. C. Bisschop qui dresse un état des lieux critique sur le mythe dans les textes sanskrits ne leur était pas accessible.

La confrontation de matériaux relevant de champs géographiques et documentaires très éloignés en apparence - les textes présentés par P. C. Bisschop et les sculptures pallava - jette un jour nouveau sur la trame narrative de la forêt de pins, renouvelant ainsi, entre autres, l'histoire du mythe de Citamparam dont H. Kulke posa les bases en 1970, dans son étude du Cidambaramāhātmya. La complémentarité d'ouvrages « textualistes » très différents, une édition critique accompagnée d'une étude basée sur les données philologiques (Bisschop) et un travail d'une poésie parfois cabalistique privilégiant la traduction de textes plus récents portant sur une mythologie très vivante (Handelman \& Shulman), est évidente. Les figures sculptées pallava nous permettront de l'aborder, pour proposer de considérer les débuts du çivaïsme ancien en Inde tant septentrionale que méridionale autrement qu'à travers le prisme des textes.

\section{Figures Pallava : la marche du Séducteur}

Les temples çivaïtes construits pallava offrent plusieurs représentations illustrant le mythe de la forêt de pins. La figure d'un mendiant en marche, vers lequel se tournent des femmes, certaines agenouillées, tandis que des sages, dont barbes et hauts chignons assurent l'identification, lèvent leurs poings, est la plus manifeste (fig. 4 et 5). Śiva n'a que deux bras, ce qui est exceptionnel dans le corpus des figures çivaïtes pallava; il porte de longs cheveux dénoués qui tombent jusqu'à sa taille; la main gauche est refermée autour du manche d'un chasse-mouche porté en travers de l'épaule tandis que le bol du mendiant semble y coller ${ }^{75}$; le personnage lève l'index de la main droite vers le ciel en un geste qu'aucun autre des Śiva pallava n'esquisse. Cinq représentations occupant des emplacements et des directions distincts dans le complexe du Kailāsanātha de Kāñcipuram en font l'une des formes majeures de ce temple. En suivant la pradaksina $\bar{a}$, la première figure de séducteur conclut le programme iconographique de l'élévation sud du vimāna (fig. 4); la seconde ouvre la face ouest du même vimāna, mais dissimulée à l'intérieur d'une des neuf chapelles qu'il déploie (fig. 5); la troisième est abritée par l'une des niches du mur nord du prākāra, faisant face au sud donc; la quatrième fut sculptée sur l'une des chapelles extérieures du complexe, face à l'ouest et la cinquième, très monumentale, marche, face au nord, à l'intérieur du sanctuaire annexe fondé par Mahendravarman III.

Le même personnage se rencontre dans tous les temples construits pallava de Kāñcipuram : Iravāttāneśvara et Piravāttāneśvara, Mātangeśvara et Mukteśvara. À l'arrière du temple (face ouest), la représentation de l'Iravāttāneśvara est différente de toutes les autres (fig. 6). Le dieu est vu de trois quarts, presque de face. Sages et femmes rendent pourtant certaine une identification, qui fait alors hésiter sur celle d'autres figures en mouvement qu'on rencontre sur le site pallava de Mahābalipuram et dans les temples de Kāñcipuram. Proche du Séducteur avec lequel elles partagent une posture en marche et les cheveux dénoués, les figures en question ne sont pas entourées par les personnages secondaires permettant d'identifier le mythe de la forêt de pins. Celui que nous appelons pour le moment « Le Marcheur » est, de surcroît, représenté vu de face (proche donc de l'atypique séducteur de l'Iravāttāneśvara) et seule l'une de ses représentations n'offre que deux bras (Kailāsanātha, face nord de la huitième chapelle extérieure). Les autres présentent quatre bras (Dharmarājaratha de Mahābalipuram, troisième niveau, face sud : ressaut faisant face à l'ouest du mur nord du vimānct du Kailāsanātha; mur nord du

75. Karine Ladrech nous a fait remarquer ce détail surprenant des représentations pallara. 


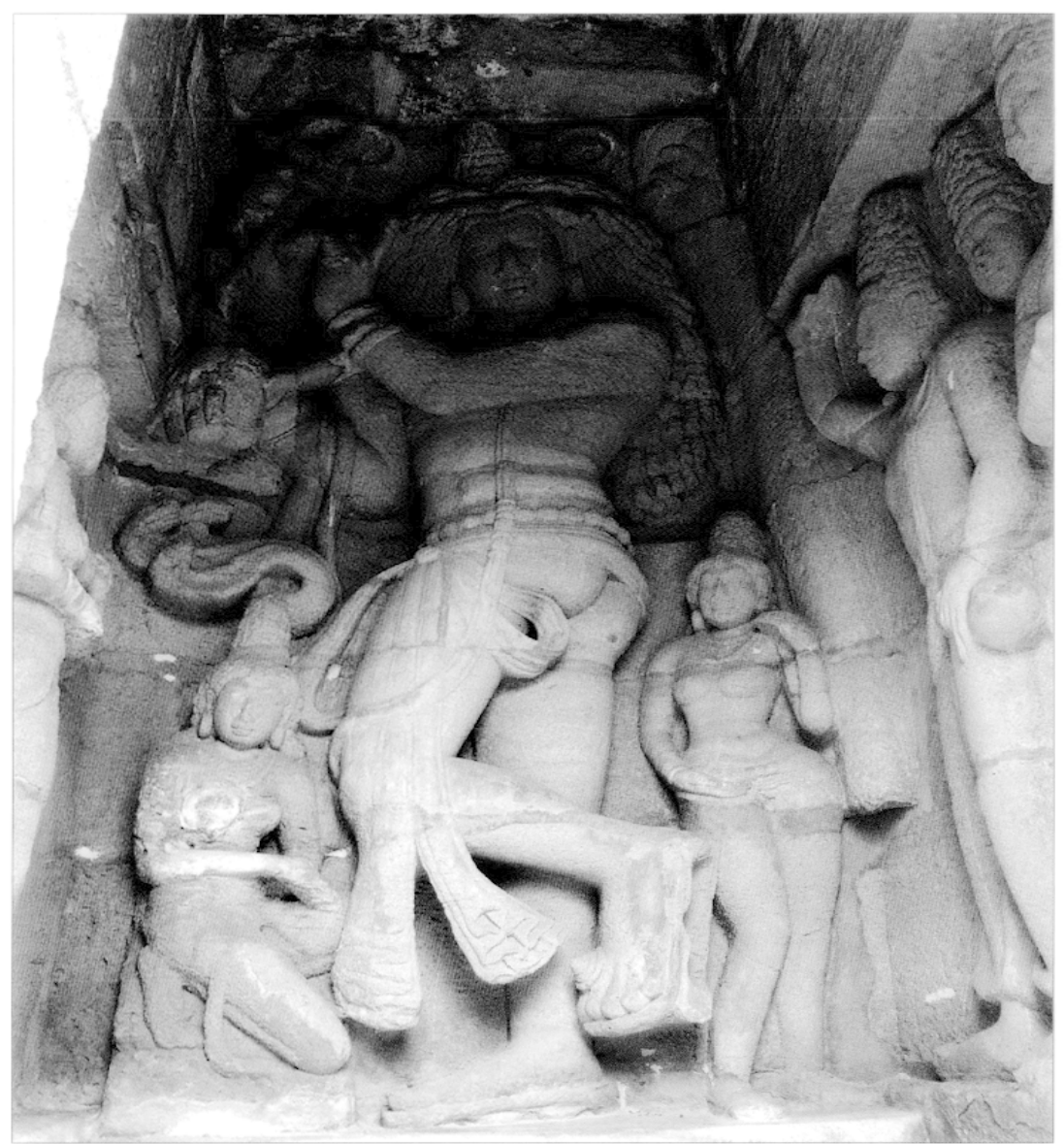

Fig. 5. Le Séducteur en marche, chapelle de l'angle sud-ouest du Kailāsanātha de Kāñcipuram. début du VIII" siècle. Cliché : Emmanuel Francis.

Fig. 6. Le Séducteur en marche, face ouest de l'lravāttāneśvara de Kāñcipuram, vIII"-IX" siècle (cliché : limmanuel Francis).

Fig. 7. Le «Marcheur», chapelle $\mathrm{n}^{\circ} 52$ du grand präkära du Kailāsanātha de Kāñcipuram, début du VIII" siècle (cliché : Valéric Gillet).
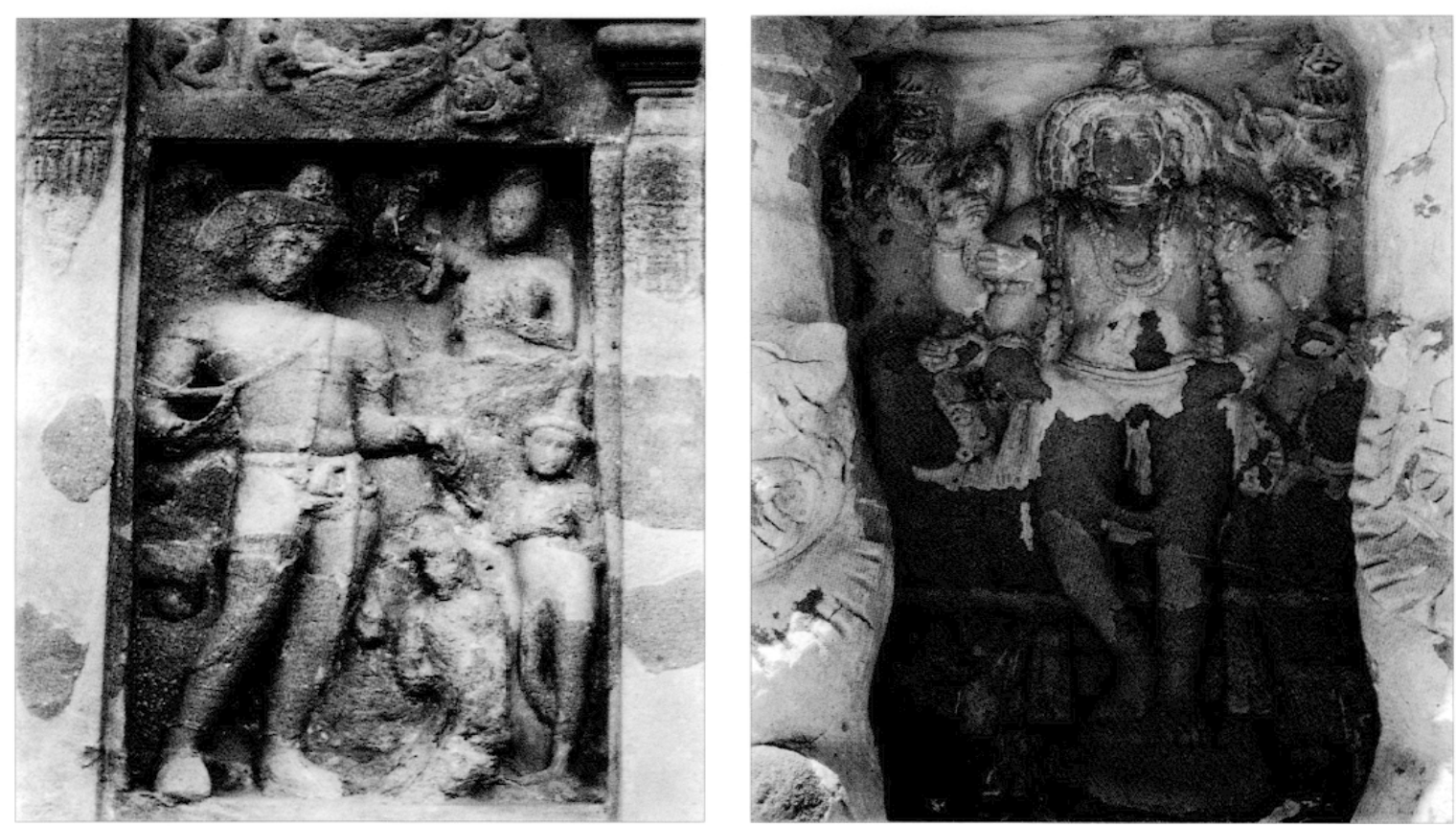

Fig. 6

Fig. 7 
vimāna du Mātangeśvara) ou même huit (représentation d'une des chapelles du mur nord du prākāra du Kailāsanātha, fig. 7). Sur le plan qu'elle donna du Kailāsanātha dans son ouvrage sur l'iconographie de Skanda au Tamil Nadu, Françoise L'Hernault (1978, plan $\mathrm{n}^{\circ}$ 1) légenda les Marcheurs de ce temple comme des Bhairava ${ }^{76}$.

Ultérieurement, en contexte $c \bar{l} \underline{l} a$, le Séducteur en marche reprend le modèle présenté par l'Iravāttāneśvara, en lui ajoutant une paire de bras (fig. 8). Dorénavant plus proche donc des « Marcheurs » pallava, le dieu est vu de face ou légèrement de trois quarts; il porte toujours à gauche chasse-mouche et bol de mendiant; la main supérieure droite est pourvue d'un tambour et la main inférieure caresse le museau d'une antilope. Les femmes et les sages sont souvent représentés à ses côtés. Mais ils ne sont pas toujours là et l'échelle de représentation insiste sur leur caractère secondaire. Le tambour évoque la musique au rythme de laquelle danse le Śiva de Citamparam, qui tient, de même, cet instrument dans sa main supérieure droite.

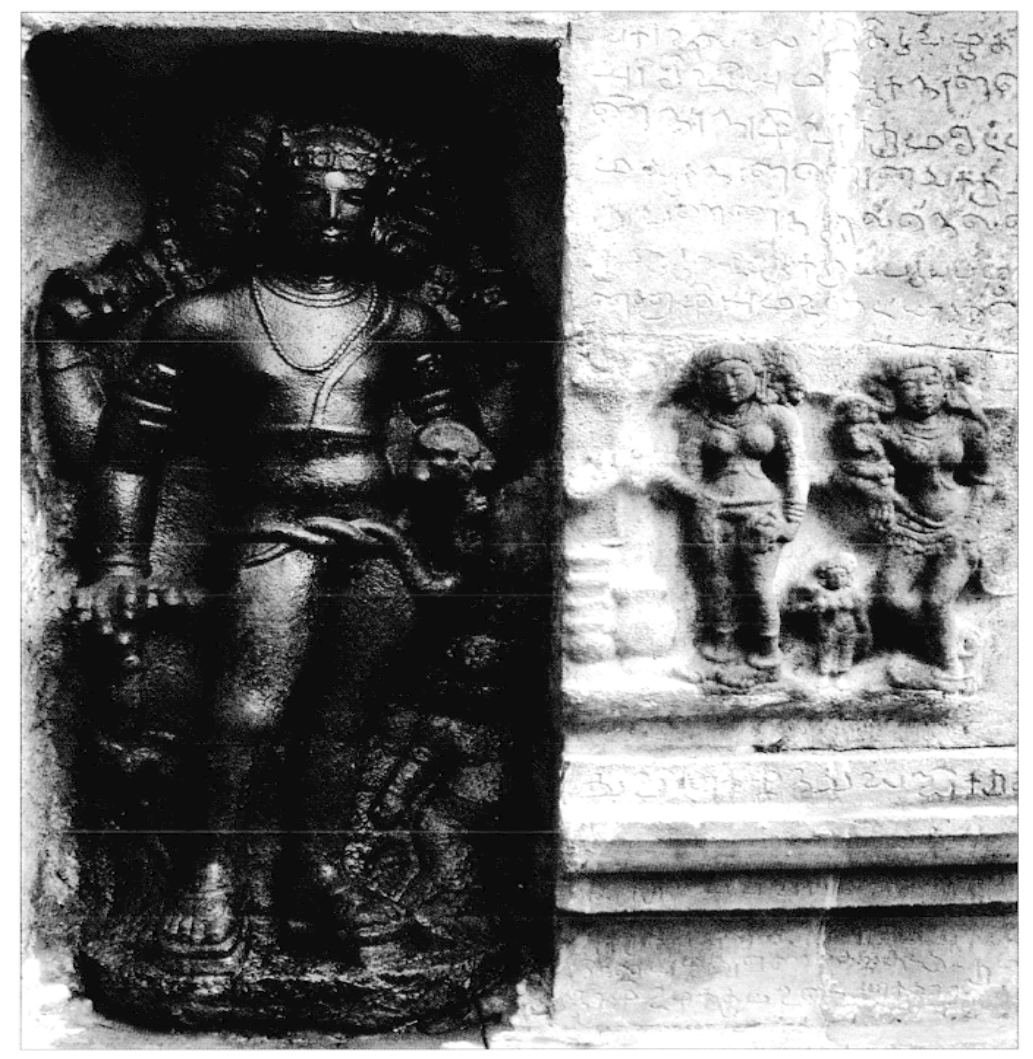

Fig. 8. Śiva dans la forêt de pins, époque cōla, temple de Kovintaputtūr, face nord, $x^{*}$ siècle (cliché : (harlotte Schmid).

76. É. Parlier-Renault (2006. p. 158-159, 237 ; légendes des figures 116 et 160 dont la seconde illustre le «Marcheur " du Mātangeśvara) reprend cette identification pour considérer, en définitive, qu’on a affaire à une forme de Śiva ascète. Pour notre part, nous distinguons plusicurs formes de Marcheurs, certains plus ascétiques et paisibles, et d’autres où l'accent est mis sur l'aspect terrible du dieu (que nous étudions plus spécifiquement dans cette chronique). Pour une typologie et une mythologie des Marcheurs, voir V. Gillet (à paraître). 
Pour des raisons qui nous échappent, l'article fondateur de Marguerite Adicéam sur les formes mendiantes de Śiva (1965b) ignore presque toutes les représentations pallava ${ }^{77}$. Celles-ci sont ensuite passées inaperçues des spécialistes. Les Séducteurs pallava relèvent pourtant clairement de l'histoire du mythe de la forêt de pins. Avec les Marcheurs, ils pourraient participer également de celle de Bhairava, l'Effroyable, forme de Śiva très adorée en Inde méridionale, où on considère, généralement, qu'elle apparaît au $x^{1}$ siècle $^{78}$. Pour D. Handelman et D. Shulman, la figure du mendiant errant n'est, en effet, que l'une des phases de la biographie de Bhairava, perspective dans laquelle s'inscrivaient déjà les recherches de M. Adicéam (1965a et 1965b) et qui est, d'une certaine façon, celle du Kürmapuräna dont D. Handelman et D. Shulman (2004) citent en annexe le chapitre II. $32^{7 \%}$. Posant un «Bhairava-Beggar prototype» (p. 95), ces auteurs en font le lien unissant un Śiva mendiant, un Śiva dansant et un Śiva terrible, ou Bhairava. Les récits puraniques pourraient bien leur donner raison. Ils font en effet de Bhairava une figure effrayante condamnée à errer en mendiant parce qu'elle a coupé l'une des têtes de Brahmā. Le Kürmapurāna II. 31 décrit ce mendiant comme un ascète d'un extraordinaire éclat, accompagné par des sages et par une troupe de femmes séduites par son apparence physique $^{80}$. Le motif est donc le mème que celui du dieu de la forêt de pins qui, dans le cadre du mythe de Citamparam, signifie sa victoire sur les sages par la danse si souvent représentée en bronze dans le Tamil Nadu. Pour D. Handelman et D. Shulman, l'organisation de l'espace cultuel du Citamparam d'aujourd'hui atteste également le rôle fondamental de Bhairava sur le site. Une statue de Bhairava d'une iconographie très conventionnelle ( $\mathrm{I}^{\circ}$ siècle) trouve place en effet à l'intérieur du sanctuaire, alors que, formes gardiennes, les Bhairava de la période cōla sont habituellement relégués à l'extérieur du saint des

77. Les deux articles de 1965 sont les premiers de M. Adicéam sur les formes çivaïtes du Sud. Ils s inscrivent dans une série sur « L es images de Śiva en Inde du Sud», qu avait lancée Jean Filliozat avec un article sur « L'image de l'origine du linga (lingodbhavamūrti) » publié en 1961, où l'auteur n’évoquait aucune des représentations pallava, pourtant parmi les premières du genre. Au fur et à mesure que paraissent les articles de $\mathrm{M}$. Adicéam. les images pallara se font plus présentes pour être prises en compte dans la dernière étude, publiée en 1976 (sur la Gangāadharamūrti). L'ouvrage de ĺ. Parlier-Renault (2006) évoque les formes mendiantes, en renvoyant à l'article de M. Adicéam. Nous ne trouvons dans celui-ci, cependant, qu'une référence à un cliché d'un "relief de Māmallapuram (Cinkalpet) ), qui serait peut-être une Kańkālamūrti à quatre bras, avec une main mutilée et deux indistinctes (Adicéam 1965 b, p. 100).

78. Nous renvoyons pour l'iconographie de cette figure en lnde du Sud au Cd-rom publić par K. Ladrech (2005) et à son ouvrage à paraître, auquel nous empruntons la traduction de Bhairava comme l'Fffroyable.

79. Sur le Kürmapurāna et l’association de Bhairava et de la forêt de pins dans la littérature secondaire. voir infra, note 103. Cette perspective était déjà celle de T. A. G. Rao en 1914 (vol. II, part 1, p. 307): on la retrouve récemment dans les études de T. Donaldson (1986), de D. Smith (1997, p. 186-192) et de N. R. Bhatt (2000, p. 105).

80. Le lien entre les deux formes du Séducteur et de Bhairava n'est pas explicite dans D. Handelman $\&$ D. Shulman 2004. C'est nous qui le reconstituons à partir des textes et des images. Les femmes sont également mentionnées dans le récit mythologique du Śivarahasva (IV, XXVI-XXVII) cité par K. Ladrech (à paraître). Soulignons la difficulté que présente l'adjectif vikrta dans le passage puranique que nous résumons ici (" après avoir revêtu un costume hideux (/ bien orné ?) / un déguisement, resplendissant

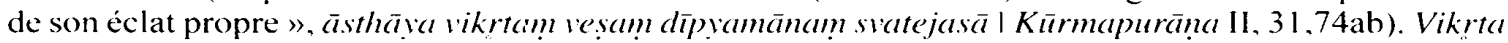
signifie difforme ou orné. Le premier sens est plus courant et c'est celui que les traducteurs adoptent ici, le dieu serait hideux et beau à la fois. Il pourrait cependant s`agir de signaler que le dieu se déguise. endossant un costume qui le dissimule. Nous penchons pour cette dernière hypothèse qui fait sens dans le contexte mythologique. 
saints - dans lequel on trouve également, à Citamparam soulignerons-nous, les sandales qui sont la marque du Séducteur en marche dans les représentations tant cōla que pallava.

Bhairava apparaît dans l'ouvrage de D. Handelman et D. Shulman comme celui qui prend et qui emporte : coupant les têtes, il est le gardien; mendiant, il poursuit sa marche dans un espace au-delà duquel il se situe. Ces auteurs en font ainsi une sentinelle engagée dans une ronde perpétuelle autour du monde. Nous pouvons les avoir mal compris : l'usage fréquent des métaphores et des symboles qui structurent leur analyse et la présentation de celle-ci ne facilite pas l'accès à l'ouvrage. Face à leur pensée poétique, qui se détache d'autant plus aisément des documents sur lesquels elle prend assise que le texte d'origine n'est, sauf exception, pas donné, les annotations de P. C. Bisschop apparaissent d'une grande concision ${ }^{\$ 1}$. Pour ce dernier, le $\mathrm{SP}_{\mathrm{S}}$, texte le plus ancien de ceux dont il offre l'édition critique, donnerait accès à la plus ancienne version connue du mythe de Bhairava (strophes 64-69). Le dieu assume en un lieu appelé Mahābhairava une forme effrayante qui fait peur à la déesse. Nulle trace ici, souligne l'éditeur, du haut fait qui fonde la légende de Bhairava, à savoir qu'il coupa la cinquième tête de Brahmā pour en rabattre l'orgueil ; nulle trace non plus, on le voit, d'une séduction exercée par le corps nu du dieu, ni de la marche du mendiant. Pour P. C. Bisschop, ce passage du $\mathrm{SP}_{\mathrm{S}}$ renouvelle donc la vision qu'on peut avoir des débuts de l'aspect de Śiva nommé Bhairava.

Nous commenterons les sculptures pallava à la lumière des documents et des analyses tant de P. C. Bisschop que de D. Handelman et D. Shulman. Notre réflexion s'organisera autour du thème des femmes adorant le Séducteur en marche et de la figure de Bhairava, que sa course pourrait mener dans la forêt de pins - portant dans sa main en guise de bol de mendiant le crâne de Brahmā dont il coupa la cinquième tête et affolant femmes et sages sur son passage.

\section{Les femmes des sages}

L'ouvrage de P. C. Bisschop offre deux versions du mythe de la forêt de pins. Elles mettent en valeur son développement, d'un bref passage dans le $\mathrm{SP}_{\mathrm{S}}$ (strophes 72-80, cf. Annexe I) au beaucoup plus tardif $\mathrm{SP}_{\mathrm{R \Lambda}}$ 3. 36-109. Le tableau qui place en regard, dans l'introduction, les versions des mythes du $\mathrm{SP}_{\mathrm{S}}$ et celles du $\mathrm{SP}_{\mathrm{RA}}$ (1-5) permet de constater d'un coup d'œil que le mythe d'un lieu qu'on ne peut guère situer que dans les montagnes himalayennes (Bisschop 2006, p. 195) est celui qui a connu le développement le plus important de tous. Constitué de 191 strophes, le $\mathrm{SP}_{\mathrm{S}}$ est daté au plus tard de 810 , date du manuscrit le plus ancien l'attestant $\left(\mathrm{S}_{1}\right)$. Les versions tardives comptent quant à elles pas moins de 411 vers : l'ouvrage de $\mathrm{P}$. C. Bisschop donne les matériaux d'une petite fabrique mythologique dont l'auteur s'attache à démonter la mécanique dans l'annotation qu'il fournit.

Cette fabrique est celle des textes. C'est la transmission puranique que l'on nous donne à observer, dans une forme scrupuleusement scientifique, pourvue de l'apparat critique qui fait défaut à la grande majorité des éditions de Purāna. Ce faisant, P. C. Bisschop ouvre aux philologues le champ d'une discussion informée ${ }^{82}$. Signalons qu'un non-sanskritiste

81. Les traductions de textes sont d'autant plus bienvenues que ceux-ci sont souvent difficiles à trouver en Oecident. Il reste que sans le texte original on ne peut guère les discuter et qu'elles semblent parfois former la base de la réflexion menée par D. Ilandelman \& D. Shulman (2004). Pourtant, lorsqu“ils citent le Téväram, en strophes prélevées sur des hymnes brês, D. Handelman et D. Shulman donnent le texte et justifient leurs traductions dans l'annotation...

82. Nous renvoyons au compte rendu de W. Cox (2008). 
ne tirera pas tout le profit possible de son ouvrage : les résumés donnés sont fort utiles. mais plus partiaux encore qu'une traduction. L'annotation qui met en valeur ce qui a paru d'intérêt à l'éditeur du texte les complète avec bonheur. Les analyses présentées sont, cependant, l'une des interprétations possibles du texte; le non-sanskritiste se gardera de les considérer comme un miroir où il pourrait lire ce texte.

Clairement, l'ouvrage de P. C. Bisschop, comme ceux de l'ensemble de l'équipe de Groningue, s'adresse en effet à un cercle assez restreint de spécialistes. Être exigeant vis-à-vis de son lecteur peut fonder un principe d'édition. Le risque est grand cependant de restreindre la portée, voire la bonne compréhension des découvertes, alors même que celles-ci sont l'occasion, au moins, de repenser les débuts du çivaïsme et que telle est, en tout cas, l'une des ambitions de P. C. Bisschop. Comme l'indique dès l'abord le titre Early Saivism and the Skandapuräna, Sects and C'entres, on n'a pas en effet affaire seulement à l'édition d'un texte. Les passages ici édités permettent d'explorer des pratiques pásúuata, ainsi que l'expose parfaitement P. C. Bisschop, pour qui le çivaïsme ancien serait pour l'essentiel, comme le $\mathrm{SP}_{\mathrm{S}}$, pāśupata.

Nous nous demanderons cependant si le $\mathrm{SP}_{\mathrm{S}}$ éclaire les débuts du çivaïsme et non simplement du çivaïsme páśupata. La présentation du mythe de la forêt de pins nous permet d'être plus précis sur ce point. La courte version du $\mathrm{SP}_{\mathrm{S}}$ ne comporte aucune mention des femmes des sages. Pour P. C. Bisschop il s'agit de la version la plus ancienne que nous ayons du mythe lui-même ${ }^{83}$. On considère habituellement qu'un vers de la Vulgate du $M b h$, rejeté en appendice par l'édition critique ( $M b h$ XIII, app. I. 4, 1. 66-67), en serait l'attestation la plus ancienne. Śiva y apparaît aux femmes et aux filles des sages, le sexe dressé, nu, le regard torve (à moins qu'il ne dissimule son troisième cil ou même sa propre personne) ${ }^{84}$. Toutes les versions puraniques autres que le $\mathrm{SP}_{S}$ évoquent les femmes des sages que le dieu séduit. Il s'agit du nœud mythologique puisque c'est par jalousie que les sages font tomber le linga du dieu en contexte nord-indien ${ }^{85}$. La mythologie bâtie à Citamparam reprend et développe encore cet aspect du mythe. C'est un Śiva musicien qui s'en vient enchanter les épouses des voyants; le désir que provoque sa nudité est métaphore d'une forme d'adoration sans retenue propre au contexte du Tamil Nadu et qui apparaît déjà comme telle dans les poèmes du Tềvăram. Dans son étude du Cidambaramāhātmya, H. Kulke (1970) en concluait, entre autres, que les femmes avaient dès l'origine fait partie du mythe. Pour P. C. Bisschop, le texte qu'il édite montre qu'il n'en est rien. Absentes

83. Pour les points de l'introduction évoquant le mythe, voir Bisschop 2006, tableau p. 6 et p. 11-12; pour le résumé du texte du $\mathrm{SP}_{\mathrm{S}}$ (version la plus ancienne), p. 67-68; pour le texte, p. 98-99; pour le commentaire, p. 195-196. Le mythe se retrouve dans le $\mathrm{SP}_{\mathrm{RA}} 3$ : résumé p. 79-80; texte p. 135-145; commentaire p. 254-270. La mention de l'ancienneté du mythe présenté dans la version du $\mathrm{SP}_{\mathrm{S}}$ mériterait un point de synthèse, permettant d'exposer, entre autres, les enjeux d'une telle affirmation.

84. Après $M b h$ XIII. 14. 84, la Vulgate insère le passage rejeté en appendice I. 4. Dans les lignes 66-67, on lit : krị̣ate rșikanyäbhir rșipatnībhir eva ca | ürdhvakeśs mahāsepho nagno vikrtalocanah̆, «Il s'amuse avec les filles des voyants tout comme avec leurs épouses, les cheveux dressés, le pénis grand, nu, l'œil torve ". Là encore on pourrait comprendre vikrtalocana différemment; peut-être s'agit-il de signifier que le dieu est dissimulé; le vers s'insère entre d'autres constats conventionnels à propos des différents aspects que le dieu adopte. Le composé pourrait même signifier "à l'éclat déguisé ». On peut aussi considérer, comme le font, entre autres, D. Handelman et D. Shulman (2004, p. xxx), Mbh X. 17. 6-26, où le linga se sépare du dieu de par sa propre volonté, comme l'une des origines du mythe de la forêt de pins dans son caractère étiologique. Il s'agit en effet de fonder le culte du linga.

85. La note 239, p. 196 de P. C. Bisschop 2006 n'est guère convaincante à cet égard, qui postule que la jalousie des sages se manifesterait parce que le mendiant nu serait « a rival or intruder », sans que les femmes jouent aucun rôle dans cette jalousie. 
du SP$_{S}$, les femmes n'auraient joué aucun rôle dans le mythe originel, où les sages seuls seraient la cible du dieu. P. C. Bisschop remet aussi en cause (p. 196) la date assignée par $\mathrm{H}$. Kulke au mythe de la forêt de pins, que cet auteur plaçait au VII" ou au $\mathrm{IX}^{\circ}$ siècle. Il suppose en effet, par ailleurs, que la liste topographique du $\mathrm{SP}_{\mathrm{S}}$ pourrait remonter au $V^{\prime \prime}$ siècle (p. 14).

Le mythe de la forêt de pins ne fait pas partie du Puränapañcalakșana. Il est inspiré de la mythologie védique d'Agni, comme d'autres mythes çivaïtes, dont celui de la naissance de Skanda auquel le lient les femmes des sages - troupe indistincte que séduit le dieu et épouses singulières qui adoptent Skanda. On se reportera pour les détails de son histoire philologique aux études de H. Kulke, de D. Handelman et D. Shulman et surtout de P. C. Bisschop pour une vision née de l'état actuel de la documentation ${ }^{86}$. Le $\mathrm{SP}_{\mathrm{S}}$ ne nous semble pas cependant infirmer la présence originelle des femmes dans le mythe de la forêt de pins, ni rajeunir considérablement la première attestation de la légende. Les représentations sculptées nous font en effet interpréter le passage du $\mathrm{SP}_{\mathrm{S}}$ en question différemment de son éditeur.

Les premiers bas-reliefs connus figurant le mythe de la forêt de pins apparaissent au viI $^{\mathrm{e}}$ siècle, au Madhya Pradesh et en Orissa ${ }^{87}$. Les représentations pallava ne sont sans doute pas antérieures au début du vIII" siècle et si elles se présentent, la plupart du temps, très différemment de cette tradition iconographique, elles en relèvent aussi puisque le bas-relief de l'Iravāttāneśvara en constitue une variante. Ces représentations comportent toujours des femmes. Celles du Madhya Pradesh et de l'Orissa sont lascives, au contraire de celles de l'art pallava, très retenues et qui offrent des figures d'adorantes idéales. Les représentations ultérieures du Tamil Nadu, y compris celles du site de Citamparam, exploitent souvent le caractère lascif des femmes. Les images pallar'a innovent donc et, comme parfois, constituent un exemple isolé, particulier, d'un mythe ${ }^{ }$. Sans spéculer sur les motifs's d'une telle originalité, constatons qu'elle prouve que le mythe est connu dans une part importante du territoire indien dès le $\mathrm{VII}^{\circ}$ siècle, dans des versions différentes les unes des autres mais qui toutes comportent des femmes. Seul le $\mathrm{SP}_{S}$ fait exception. Les bas-reliefs pourraient constituer des intermédiaires chronologiques entre ce texte et des versions puraniques et sculptées, ultérieures. L'accord quasi unanime des témoignages tant textuels qu'archéologiques ainsi que le caractère ouvertement pā́supata du SP $\mathrm{S}_{\mathrm{S}}$ nous font, cependant, proposer une autre interprétation des données.

86. On consultera aussi l'étude antérieure de W. Jahn (1915-1917) et, pour l'analyse mythologique, celle de W. Doniger ()Flaherty (1993, p. 219-265), qui souligne le caractère éminemment päśsupata du Śiva de ce mythe.

87. Th. Donaldson (1986) a publié les images de l'Orissa. Celles du Madhya Pradesh, dans les environs de la ville de Malhar (site de Deur Mandir), ne sont à notre connaissance disponibles que sur le site internet de l'American Institute of Indian Studies (http://dsal.uchicago.edu/images/aiis/) : nous n'avons malheureusement pas eu acè̀s aux quelques publications locales qui évoquent aussi ce site.

88. Notre analyse diffère jei de celle de É. Parlier-Renault 2006 (p. 157), pour qui le Séducteur de Kailāsanātha reprend des prototypes cälakya et pallaver. Les datations actuelles du temple d'Alampur et du site de Mahābalipuram qui nous paraissent sous-entendues en l'oceurrence ne sont pas suffisamment établies, en effet, pour qu'on puisse en considérer les reliefs comme des prototypes de ceux du Kailāsanātha (supra, p. 268). Leschéma iconographicue est de toute façon très différent. Celui d'Alampur correspond en effet au bas-relief de l'Iravāttāneśvara tandis que la figure du Dharmarājaratha de Mahābalipuram est entièrement isolée durant la période (peut-être participa-t-elle en revanche de la constitution de l'iconographie du Séducteur de la période cōla 
Le $\mathrm{SP}_{S}$ ne nous apparaît pas, en l'occurrence. comme un noyau originel; il présenterait un bref résumé du mythe, postulant la connaissance de versions plus longues. Le résumé supprimerait certains éléments, présents dans toutes les autres versions connues et dès les premières sculptures. On peut raisonnablement poser l'hypothèse d'une version qui a abrégé le mythe, jusqu'à le rendre peu compréhensible. Le texte du $\mathrm{SP}_{\mathrm{S}}$ a peu de sens en effet. Il n'est pas dit pourquoi les sages font tomber le linga du dieu. La $\bar{i} r s \bar{a}$, jalousie (stance 75a), des sages n'y est pas justifiée. Le dieu entre dans la forêt ; les sages le voient avec son membre dressé qu'ils font tomber «par jalousie ». Le contenu est étrange, la forme aussi puisque, comme permet de le voir l'édition de P. C. Bisschop (au contraire de l'editio princeps de $\mathrm{K}$. Bhatțarāī 1988), on se réfère au linga, au terme de l'épisode (st. 79c), par un démonstratif masculin (alors que le mot linga est neutre) ${ }^{89}$. Nous supposerons, pour notre part, un résumé du mythe prenant pour base des versions comportant l'élément féminin, dont l'étude de D. Handelman et D. Shulman montre à loisir la nécessité mythique ${ }^{\% 0}$.

Une telle hypothèse s'accorde avec la nature même du $\mathrm{SP}_{\mathrm{S}}$, qui se présente comme une litanie de lieux saints, dont il serait logique qu'elle abrège les mythes qui y sont rattachćs. Elle s'accorde aussi avec le fait que nombre de Purāna aient été réécrits dans une optique sectaire. On peut penser aux Purāna originellement vishnouites dans lesquels Rajendra Chandra Hazra (1975 [1940]) a parfois isolé des réécritures, dont certaines sont, précisément, pāśupata comme le serait le $\mathrm{SP}_{\mathrm{S}}$. Relevant de l'atimārga, la voie extrême, le mouvement pāśsupata exclut non seulement les femmes, mais aussi les maîtres de maison (A. Sanderson 1988, p. 664-665). Le vers de la Vulgate du Mbh mentionne les femmes et les filles des sages; les versions puraniques du mythe mettent en scène les épouses des sages et, parfois, leurs fils (l'un d'eux frappe le linga du dieu sur un bas-relief du Paraśurāmeśvara de Bhubaneśvar). Ainsi, non seulement les femmes sont-elles présentes, mais les sages apparaissent aussi comme proches de maîtres de maison, un aspect du récit que les versions méridionales mettent en valeur lorsqu'elles organisent la forêt comme un espace urbain ${ }^{91}$. Ne correspondant pas à un contexte pāsupata, femmes, filles et fils auraient été écartés d'un résumé d'esprit pāśupata. Ainsi, bien que le $\mathrm{SP}_{\mathrm{S}}$ soit assurément plus ancien que les recensions tardives éditées par P. C. Bisschop, le constituer en

89. Le changement de genre pourrait refléter le statut particulier du linga, signe de la présence du dieu puis manifestation du dieu lui-même. Le passage du SP $\mathrm{S}_{\mathrm{S}}$ nous intéressant semble jouer sur les différentes acceptions du terme linga ( marque, signe; sexe masculin; genre grammatical ») : le dieu entre ithyphallique et son sexe est désigné par le terme mehana (st. 74d), sans ambiguïté ; puis le terme linga apparaît (st. 75a); sa chute entraîne la disparition de toute masculinité (y compris au sens grammatical peut-être : il n'y aurait plus de genre masculin). Remarquons enfin qu'en $\mathrm{SP}_{\mathrm{S}} 79 \mathrm{c}$, le tam drstvā où tam renvoie au linga du dieu correspond à bien des débuts de vers dans les textes puraniques mettant Śiva en scène, dont, évidemment, les versions étendues du mythe de la forêt de pins (voir, par exemple, Kürmapurāna II. 31. 76c).

90. L'un des propos majeurs de D. Handelman \& D. Shulman est de montrer que le dieu qui se manifeste dans la forêt de pins est une figure incomplète et figée. L'Autre, c'est-à-dire la déesse, Viṣnu, les sages et leurs femmes, tous des figures de dévots, doivent remplir et compléter la forme du dieu pour qu'elle retrouve le mouvement qui en assure l'existence même.

91. Supra, note 68 ; voir la forêt de la version du mythe de Lepākși présentée par D. Handelman \& D. Shulman 2004, p. 194, où «Each clan of women had its own quarter, marked by a decorated flag [...]. Every house has its walls painted with exciting stories », et où Śiva " went begging for alms in the courtesans" streets $"$. 
texte de référence fait, à notre sens, problème ${ }^{92}$. Il suppose, à nos yeux, un autre texte nécessaire à la compréhension des données résumées; $s$ 'il est impossible de reconstituer ce dernier, l'incohérence même du $\mathrm{SP}_{\mathrm{S}}$ dans ce cas précis nous semble indiquer que le mythe d'origine mentionnait les femmes dont la présence fait débat ${ }^{93}$.

Par ailleurs, la date supposée par $\mathrm{P}$. C. Bisschop pour le $\mathrm{SP}_{\mathrm{S}}$, le $\mathrm{VI}^{\mathrm{E}}$ siècle, s'appuie essentiellement sur le fait que deux toponymes du $\mathrm{SP}_{\mathrm{S}}$ apparaissent dans des inscriptions d'Andhra Pradesh, remontant à la fin du II $^{\mathrm{e}}$ siècle et au IV $\mathrm{V}^{\mathrm{e}}$ siècle. L'argument est ténu en soi et les chronologies permettant de situer ces inscriptions dans le temps sont un objet de controverses ${ }^{94}$. Il semble d'autant plus raisonnable de poser le vil' siècle au plus tôt comme date de la liste de lieux saints ici donnée qu'on ne connaît aucune représentation du mythe antérieure à cette date. Les versions puraniques du mythe de la forêt de pins

92. P. C. Bisschop réserve ainsi un sigle aux émendations dont le $\mathrm{SP}_{\mathrm{S}}$ est la base dans son édition des autres recensions du texte (p. 56). Lorsqu'il déclare que les recensions $R$ et $A$ « not only contain additional material but in fact transmit a completely revised text " (p. 52), le $\mathrm{SP}_{\mathrm{S}}$ est aussi la référence. Certes le $\mathrm{SP}_{S}$ est beaucoup plus ancien que ces deux recensions. La discussion détaillée des p. 56-57 apporte la preuve d'une relation entre elles et le $\mathrm{SP}_{\mathrm{S}}$. Mais le $\mathrm{SP}_{\mathrm{S}}$ nous semble également un texte révisé, même si c'est avec d'autres buts et méthodes : faut-il en faire l'archétype du mythe? On notera à cet égard que P. C. Bisschop, dans son article de 2007 sur la description de Śivapura, suppose également une réécriture pāśspata dans le SP d'un prototype, dont le Vãyupurâna serait, en l'occurrence, plus proche.

93. Le parallèle entre ce passage du $\mathrm{SP}_{\mathrm{S}}$ et l'un des panneaux du site de Deur Mandir (American Institute of Indian Studies $n^{\circ}$ C7. 68/2 [cf. supra note 87]) fera peut-être mieux comprendre notre pensée. Sur ce panneau, seuls les sages attaquent Śiva. Les femmes ne sont pas figurées. Mais elles apparaissent dans les autres panneaux de la série, y compris dans un panneau où ce sont, cette fois, les sages qui sont absents.

94. L'introduction évoque le $\mathrm{VI}^{\mathrm{E}}$ siècle pour renvoyer à l'annotation du $\mathrm{SP}_{\mathrm{S}}$ à propos de deux toponymes. Le premier, Puṣpabhadra, apparaît dans une inscription datée en années de règne $i k s v a \bar{k} k u$. P. C. Bisschop se repose là sur la chronologie des Ikșvāku que propose H. Sarkar (1985). Signalons que celle adoptée par D. C. Sircar (D. C. Sircar \& K. G. Krishnan 1960; Sircar 1963), éditeur du corpus épigraphique sur lequel s'appuient les discussions, place les Ikșvāku cinquante ans plus tard (sur cette controverse, E. Rosen Stone 1994). L'autre toponyme, Citraratha, se retrouve dans le nom de la divinité tutélaire (Citrarathaśvāmin) des Sālañkāyana, dynastie d'Andhra Pradesh que les Viṣnukuṇụin ont supplanté, probablement au début du $\mathrm{vI}^{\mathrm{e}}$ siècle (ni la chronologie absolue des Śălañkāyana, ni celle des Viṣnukuṇ̣in ne sont fixées avec certitude). Ces toponymes détermineraient selon P. C. Bisschop un terminus post quem pour le $\mathrm{SP}_{\mathrm{S}}$. Poser ce dernier paraît prématuré, car la documentation, très lacunaire par nature, est actuellement peu accessible. Il ne s'agit en outre que d'argumentum e silentio : rien n'interdit que les toponymes en question aient été utilisés avant ces seules attestations, comme bien sûr rien n'interdit qu'ils aient commencé d'être utilisés bien après dans d'autres régions. Il s'agit, en effet, de données recueillies en Andhra Pradesh, qui constitue l'extrême limite méridionale de la géographie du $\mathrm{SP}_{\mathrm{S}}$ : on peut douter qu'elle lui soit centrale. Commentant la liste des quarante mondes constituant le dernier groupe des huit mondes des écritures çivaïtes, P. C. Bisschop fait par ailleurs remarquer que trente sur quarante d'entre eux se retrouvent comme toponymes dans le $\mathrm{SP}_{\mathrm{S}}$ et que les quatre noms de personne qu'elle comporte ont été spécifiquement regroupés en un site dans le $\mathrm{SP}_{\mathrm{S}}$, seul texte connu à procéder ainsi. Le site en question est Kārohana, d'où serait originaire le mouvement pāśúpata. La liste çivaïte de référence constituée de quarante noms est datée avant le $I X^{\circ}$ siècle et plus probablement du vil" siècle par A. Sanderson (2003-04, p. 405-406). Là encore, rien ne nous paraît confirmer une date dans le $V I^{\complement}$ siècle pour l'archétype dont dériverait le $S P_{S}$. De même, si le toponyme Prahasiteśvara du $S P_{S}$ se retrouve dans plusieurs inscriptions cambodgiennes du début du $\mathrm{VII}^{\mathrm{e}}$ siècle, cela ne nous paraît pas pour autant indiquer que le $\mathrm{SP}_{\mathrm{S}}$ lui-même leur serait antérieur, mais simplement que ce corpus épigraphique et le $\mathrm{SP}_{\mathrm{S}}$ pourraient, éventuellement, appartenir à la même mouvance sectaire (pāśspata?), ou relever d'un même espace géographique (le Nord-Ouest?). Sans doute P. C. Bisschop s'appuie-t-il aussi sur les travaux des membres de l'équipe de Groningue (tels ceux de Y. Yokochi [2005] selon qui le cycle de la déesse du SP serait antérieur au Devìmāhātmya et pourrait donc dater du vĩ siècle). Aucun élément de ces travaux ne nous semble cependant garantir une date dans le $v I^{\mathfrak{C}}$ siècle pour le témoignage qu'offrent les textes édités dans Bisschop 2006. 
ont été jusqu'ici datées par l'ensemble de la critique du vill ${ }^{\circ}$ siècle ou du $1 X^{\circ}$ siècle ${ }^{95}$ et le $\mathrm{SP}_{S}$ pourrait relever de la même mouvance $\%$.

Enfin. les épouses des sages de la forêt jouent un rôle important dans le mythe plus ancien de la naissance de Skanda, dont Agni est encore le père dans plusieurs de ses versions épiques et dont ces femmes sont des mères adoptives. Sur le prākāra du Kailāsanātha, les petites mères, $m \bar{a} t r k \bar{a}$, qui apparaissent également dans le $M b h$ comme mères de Skanda, font face aux adorantes du Séducteur en marche du vimāna du temple. Choix et position des images pourraient refléter ici l'importance de groupes féminins dans une mythologie çivaïte qui se met en place. Les femmes occupent en tout cas beaucoup de l'espace d'un sanctuaire où les déesses ont leur propre mandapa, pris, comme le vimāna, dans l'écrin d'un prākāra où une quarantaine de représentations de femme sur la montagne (Pārvatī'? les femmes des sages?) rythment les représentations des chapelles.

En résumé, il ne nous paraît guère possible de supposer un mythe originel de la forêt de pins sans femmes.

\section{Bhairava}

L'importance de l'élément féminin n'explique pourtant guère les figures du «Marcheur », ni leur lien éventuel avec le Séducteur. Notre interprétation de ces personnages s'appuiera sur l'ensemble des images et des textes dorénavant à notre disposition, en privilégiant les plus anciens d'entre eux. Là encore l'analyse des figures pallava nous entraîne dans une direction que les textes seuls ne feraient pas emprunter, vers un Bhairava errant et mendiant dont le SP permet d'entrevoir la profondeur historique.

Un autre détail ne fait guère sens en effet dans la version du mythe de la forêt du $\mathrm{SP}_{\mathrm{S}}$. Le dieu entre là sous prétexte de mendier. Quant à la raison de sa mendicité, elle n'est pas dite. Selon les autres versions puraniques connues, Śiva cherche ainsi à éprouver les sages. Le dieu adopte l'un de ses déguisements signifiants dont la littérature dévotionnelle est familière, depuis, par exemple, la Draupadī du $M b h$ qui marque son refus de peigner sa chevelure en choisissant un costume de coiffeuse, lors de la treizième année d'errance des Pānḍava qui doivent alors se dissimuler. La nudité ajoute une note ironique au costume absent de la divinité mendiante, qui symbolise, selon nous, la révélation d'un dieu incarné se mêlant aux hommes, pour les tester et établir son culte.

Dans un autre cadre mythique pourtant, l'errance du mendiant nu constitue la punition infligée à celui qui coupa la cinquième tête de Brahmā, Bhairava, "l'Effroyable » né de la colère de Śiva face à l'orgueil de Brahmā. La littérature puranique n'établit pas de lien direct entre l'épisode de la tête coupée de Brahmā et l'entrée d'une forme de Śiva

95. Le Kürmapurāna est actuellement placé au début du vilI ${ }^{\mathrm{e}}$ siècle (L. Rocher 1986, p. 186); pour R. C. Hazra, dont ]'argumentation est convaincante (1975 [1940], p. 57-75), il s'agit d'un document pāñcarātra réécrit par des dévots pāśupata. Le Lingapurāna aurait été composé dans son état actuel entre 800 et 1000 selon le même auteur (ibid., p. 95-96), qui nous paraît le plus raisonnable à ce propos et qui suppose une réécriture assez drastique d'un autre texte. Tel est aussi le cas du Vāmanapuräna (ibid., p. 77), dans lequel on rencontre deux fois le mythe de la forêt de pins. Dans les trois cas, le récit mythique nous intéressant se trouve dans la partie identifiée comme réécrite par R. C. Hazra.

96. L'accord chronologique entre textes et documents archéologiques ne saurait être nécessaire pour dater l'apparition d'un mythe. Nombre de mythes çivaïtes sont, dans l'état actuel des recherches, apparus dans les textes bien avant les premières représentations qu'on en connaisse. Mais le mythe de la forêt de pins n'apparaît pas dans les documents écrits, si donc on suit P. C. Bisschop, avant le SP, et. selon nos hypothèses, de toute façon pas avant des textes datés au plus tôt du vil" siècle. L'accord avec les témoignages archéologiques est ici assez étroit, quelle que soit la datation qu'on choisisse pour la premiere attestation textuelle du mythe. 
dans la forêt de pins. Tout au plus le Kūrmapurāna fait-il se succéder les deux mythes, la légende de Bhairava étant contée dans le chapitre II. 31 et le mythe de la forêt de pins occupant le chapitre II. 37 (entre ces deux chapitres s'intercalent des listes de lieux de pèlerinages, sans qu'intervienne de récit mythologique à proprement parler). L'art pallava ne paraît guère non plus établir de liens entre ces mendiants. A priori on a rcprésenté Bhairava dans au moins un sanctuaire pallava. En effet, si l'identification des Marcheurs en tant que Bhairava n'est pas évidente (d'autant que F. L'Hernault n'a pas commenté la légende qu'elle a donnée à une représentation de son plan $n^{\circ} 1,1978$ ), le prākāra du Kailāsanātha offre cependant l'unique bas-relief en pierre connu de l'art indien de la décapitation de Brahmā (fig. 9). Dans le Bhairava qui en est le héros, rien ne signale un lien avec le Séducteur, l'effrayante figure qui décapite possédant plusieurs bras et armes et étant coiffée d'un haut chignon.

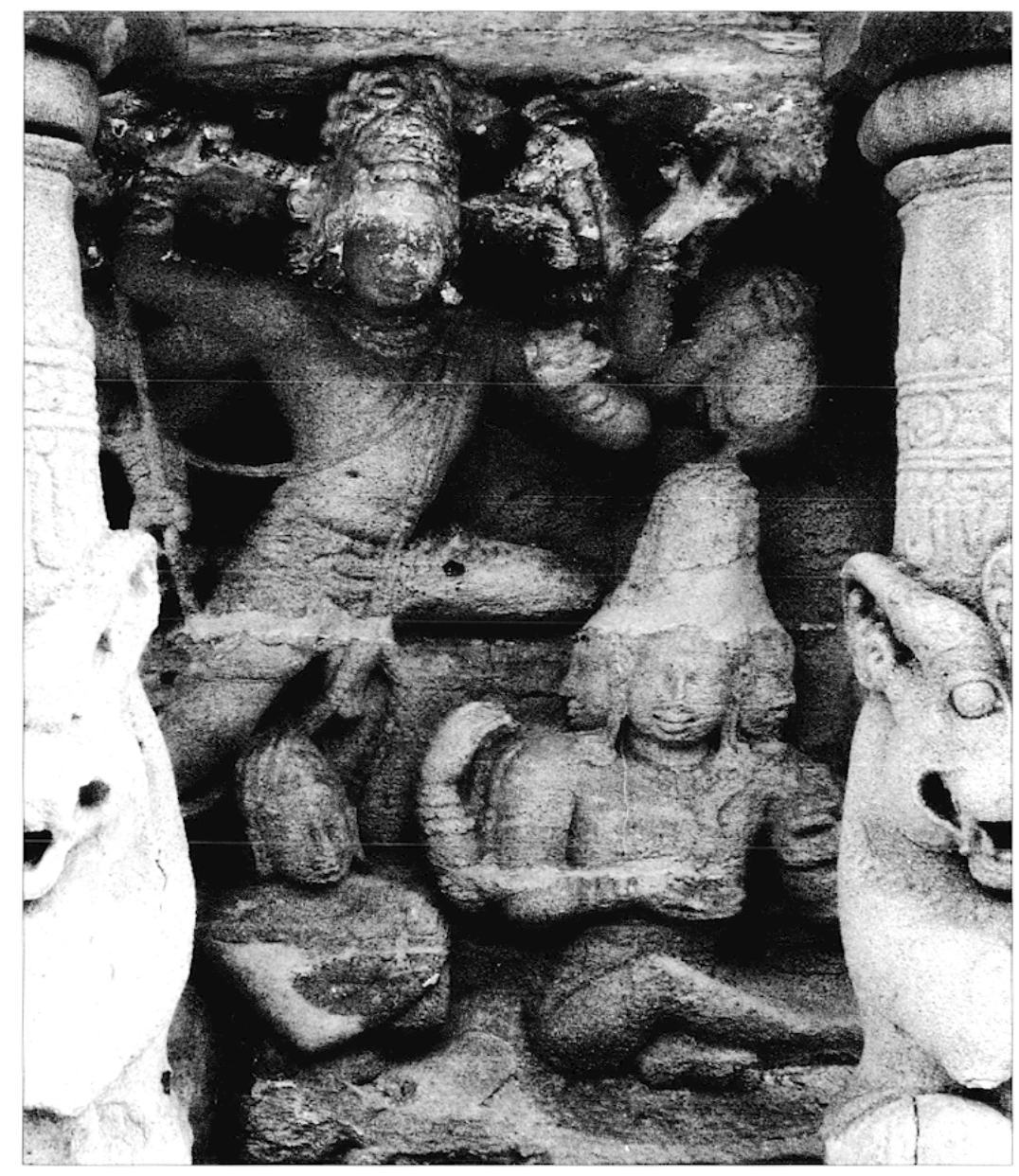

Fig. 9. La décapitation de Brahmā, mur sud (face au nord) du prākāra du Kailāsanātha de Kãñcipuram, début du vill ${ }^{e}$ siècle (cliché : Emmanuel Francis).

Par ailleurs, pour son éditeur, le SP, offrirait la version la plus ancienne du mythe de Bhairava, juste avant le mythe de la forêt de pins $\left(\operatorname{SP}_{S}\right.$ 64-69). Sur le site de «Mahābhairava », le dieu assume une forme terrible (bhairavam rüpam, $\mathrm{SP}_{\mathrm{S}} 65 \mathrm{c}$ ), par jeu (krị̂ăhetor, $\mathrm{SP}_{\mathrm{S}} 66 \mathrm{a}$ ), 
pour effrayer la déesse. Il reprend ensuite une forme normale. Il n'est pas question de décapiter Brahmā et P. C. Bisschop considère alors, contra Heinrich von Stietencron (1969), que le motif de la décapitation n'était pas originel dans l'émergence de la forme de Śiva qu'on appelle Bhairava.

La figure de l'Effroyable se fait ainsi fort évanescente et en dehors du hapax iconographique que nous venons de signaler, rien ne la rapproche de nos sanctuaires pallava. L'archéologie des textes et des sculptures pourrait cependant être organisée suivant un schéma plus complexe, faisant à Bhairava, ou plutôt à l'une des formes personnifiant l'effroyable, une place importante.

Tout d'abord, nous ne sommes pas certains que le $\mathrm{SP}_{\mathrm{S}}$ offre un ou le mythe originel de Bhairava. Bhairava n'est pas un nom propre avant la littérature tantrique et puranique, et cette chronique illustre, entre autres, les difficultés qu'on éprouve à dater ce type de textes. Si l'on veut par Bhairava désigner le dieu dont on connaît des centaines de représentations à l'époque médiévale, au culte duquel de nombreux textes sont consacrés et dont la mythologie est attestée par bien d'autres, le bref passage du $\mathrm{SP}_{\mathrm{S}}$ contant la légende du site (par ailleurs inconnu) de Mahābhairava où Śiva se fait terrible ne paraît pas s'y rapporter $^{97}$. On nous conte là simplement comment le Porteur de l'arc Pināka prend une forme effrayante. Ce n'est qu'à partir du ${ }^{\prime} I^{\prime \prime}$ siècle environ qu'on peut estimer que certains textes appellent Bhairava celui qui coupe la tête de Brahmā. La légende est alors intégrée dans un ensemble mythologique large qui constitue Bhairava en figure errante, le crâne de Brahmā collé à sa main gauche, jusqu'à Vārānasīi où le dieu se débarrasse de cet élément polluant. D'autre part, si le mythe de la décapitation de Brahmā fonde Bhairava, il ne s'ensuit pas que ce motif de la décapitation, que nous associons pour notre part avec l'errance et la séduction, soit apparu avec Bhairava.

Nous voyons d'autant moins de raisons de suivre ici P. C. Bisschop que le SP lui-même connaît un autre bourreau de Brahmā. En SP 5, celui qui décapite Brahmā est un étrange gana du nom de Nīlalohita ${ }^{\%}$. Phyllis Granoff lui a consacré plusieurs analyses (2003; 2004 ; 2006). Elle en a reconstitué la légende à partir des données védiques, épiques et puraniques. Nīlalohita est assurément l'un des prototypes majeurs de Bhairava, fondant lui-même l'existence d'une des formes de Śiva, selon une structure hypostatique, caractéristique peut-être du çivaïsme ancien, du moins dans certains espaces et à certaines

97. Peut-être pourrait-on aller plus loin dans l’analyse de la légende originelle et de sa recomposition dans le $\mathrm{SP}_{\mathrm{s}}$. On constate en effet qu'entre les deux lieux saints appelés l'un Mahābhairava et l'autre Devadāruvana, le $\mathrm{SP}_{\mathrm{S}} \mathrm{n}$ 'intercale que deux vers (consacrés à Rudrakoți). On se souviendra ensuite que dans le vers de la Vulgate du $M b h$ qui constitue l'une des attestations les plus anciennes de la légende de la forêt de pins, le dieu s'en vient jouer avec les femmes des sages (supra, note 84). C'est la même action qui est attribuée au Śiva de Mahābhairava («c'est là où, par jeu, Bhava [Śiva], après avoir effrayé la fille du roi de la montagne... ", krị̣̂ahetor bhavo yatra trāsayitvā girīndrajām $\mid \mathrm{SP}_{\mathrm{S}} 66 \mathrm{ab}$ ) en un mythe ailleurs inconnu. La version du mythe de la forêt de pins qu'atteste la Vulgate du $M b h$ n'aurait-elle pas été ici scindée en deux? Tout d'abord, le dieu joue avec la déesse, prenant une apparence particulière ; ensuite, il entre dans la forêt de pins, le sexe dressé. Les femmes ne seraient donc pas complètement écartées dans le $\mathrm{SP}_{S}$, où la déesse aurait remplacé les épouses des sages. L’insistance dans le $\mathrm{SP}_{S}$ sur l'apparence effrayante (bhairava) du dieu, à travers le nom du site entre autres, peut en tout cas s'expliquer par un lien ancien entre le thème de la séduction et celui de l'errance due à la décapitation, qui fonde le mythe de Bhairava, infra, p. 296-298.

98. Dans le SP lui-même, la décapitation est aussi liée au Mahākālavana d'Ujjain (Ph. Granoff 2006). Pour K. Ladrech (à paraître), qui évoque, en sus des antécédents épiques, les traités juridiques. le mythe de la décapitation de Brahmà se développe à partir d'un corpus ancien et composite. Deux légendes constituent des antécédents védiques précis du thème de la décapitation de Brahmā (conflit entre Prajāpati et Rudra: meurtre d’Indra par Rudra: cf. W. Doniger O’Flaherty 1976, p. 104-160. 274). 
époques ${ }^{\% 9}$. Une telle structure paraît en particulier s'appliquer dans le cadre pallava. Ce dernier suggère en effet, comme nous allons le voir, l'ancienneté d'un lien mythologique entre le Séducteur en marche et la décapitation, entre le héros de la forêt de pins et Bhairava. Mais qui est donc la figure représentée dans les bas-reliefs pallava? Śiva? Bhairava? Ou Nīlalohita?

Nous partirons des figures sculptées pallava: elles sont particulièrement suggestives en effet. Jambes de profil, l'une repliée et l'autre tendue, torse tourné vers le spectateur, un bras passant devant lui pour pointer l'index vers le ciel et l'autre replié en-dessous, le visage de face aux longs cheveux retombant sur les épaules, les Séducteurs pallava sont un calque des gardiens de porte des mêmes sanctuaires. Les figures sont semblables jusque dans la disposition des pans de tissu des vêtements et des guirlandes qui les décorent (fig. 10a-c). On commença de sculpter des gardiens de porte dès les premières grottes de la dynastie, alors que les Séducteurs n'apparaissent qu'avec les temples construits. Mais ce n'est qu'au moment où on sculpte ces premiers Séducteurs que la posture des gardiens de porte se fixe et se généralise, l'index pointé en l'air, «mudrā » originale qu'on ne rencontre pour les formes mendiantes de Śiva qu'en contexte pallava.
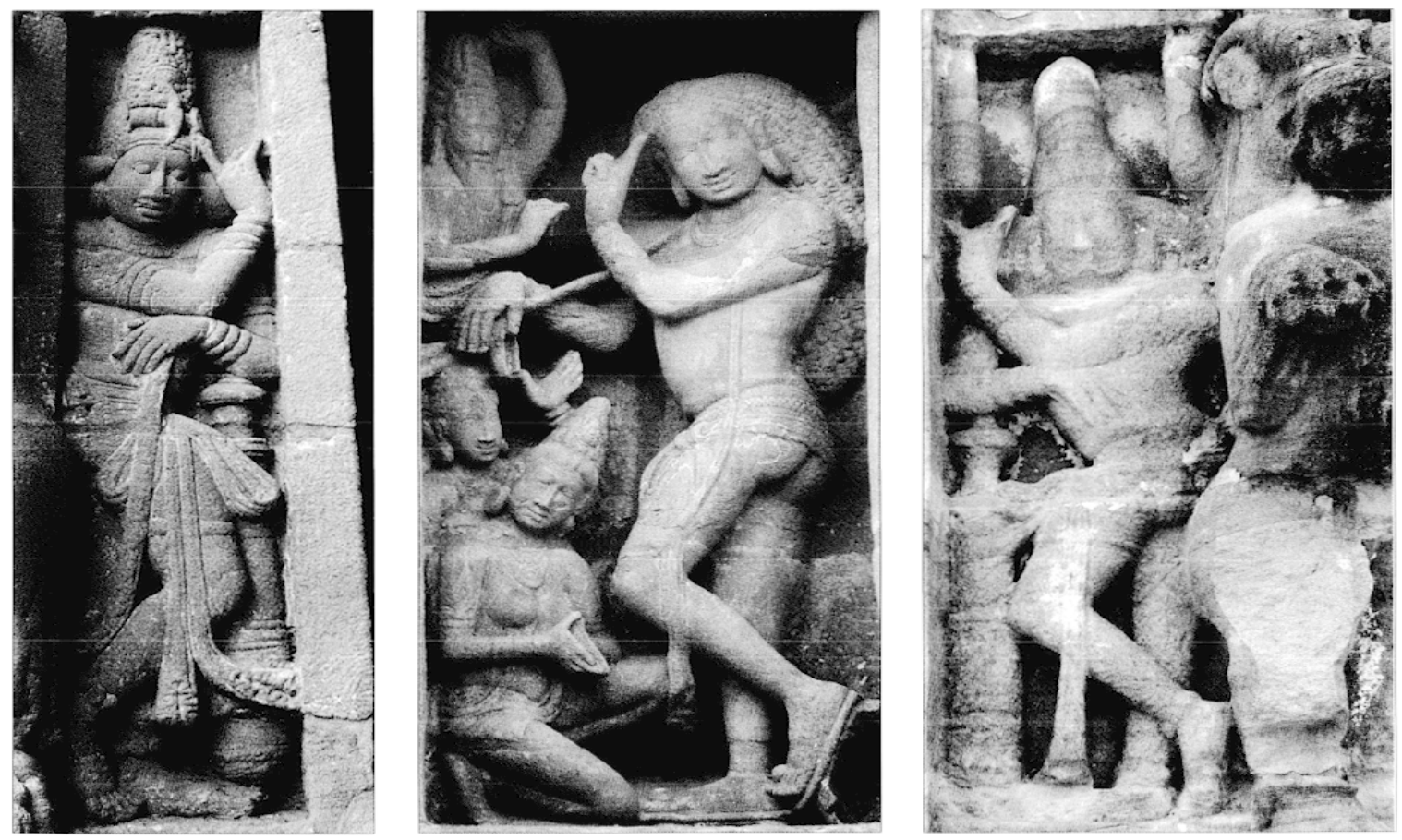

Fig. 10a. Dvārapāla, Kailāsanātha de Kāñcipuram, début du vıl゙ siècle (cliché : Emmanuel Francis). Fig. 10b. Le Séducteur en marche, Kailāsanātha de Kāñcipuram, début du vilı" siècle (cliché : Charlotte Schmid).

Fig. 10c. Dvārapāla, Mukteśvara de Kāñcipuram, vII̋"-IX“ siècle (cliché : Valérie Gillet).

99. Le passage du Puränapañcalaksana que cite II. T. Bakker (1996, p. 10) étudiant le svayanuara de Pārvatī paraît éclairer également la légende de ce gaṇa. C"est un kumāro nïlalohitahl en effèt qui apparaît dans le giron de Brahmā, lorsque Rudra engendre un fils semblable à lui-même. 
Par ailleurs, Ksetrapāla, le gardien du territoire. est l'un des noms les plus courants de Bhairava dans la littérature sanskrite. Celui qui le porte est en effet le gardien du temple de Śiva. En Inde méridionale. Bhairava est le Kṣetrapāla par excellence (K. Ladrech, à paraître). L'emplacement dévolu aux deux figures de Séducteur ornant le vimāna du Kailāsanātha de Kāñcipuram, à la fin et au début d'une face (angle sud-ouest), trouverait une explication dans ce rôle de gardien. Les Séducteurs de la forêt de pins sont ici assimilés, nous semble-t-il, à des ksetrapāla, gardant le territoire du temple. Les dvārapāla sont d'ailleurs souvent représentés sur les temples construits pallava, non seulement de chaque côté de la porte, mais aussi aux extrémités des murs d'élévation qui, articulant le temple avec l'espace, constituent des points de rencontre avec l'extérieur tout autant que les portes ${ }^{100}$. Fonction majeure de Bhairava à partir du $x^{\circ}$ siècle, l'activité de gardien du territoire du temple qui sera la sienne pourrait donc avoir été représentée dès les sanctuaires pallava avec ces figures du Séducteur en marche. Ultérieurement, durant la période $c \bar{l} l a$, le lien unissant gardien et séducteur serait mis en valeur dans le corpus de textes élaboré autour du site de Citamparam, qui réserve une place de choix au Séducteur marchant mais accorde aussi beaucoup d'importance à la figure du gardien Bhairava. Enfin, un tel lien pourrait être plus ancien que ce corpus méridional. Certains éléments des textes nord-indiens, dont le SP, semblent, en effet, associer eux aussi la forêt de pins et celui qui mutila Brahmā, la séduction et la décapitation.

Ainsi posée, l'idée paraîtra provocatrice. Pourtant, le gaṇa Nīlalohita dont le SP fait donc, dans l'état actuel des recherches, l'antique figure qui, avant Bhairava, décapitait Brahmā, transparaît en filigrane dans plusieurs des versions puraniques du mythe de la forêt de pins. Considérons d'abord celle du Kürmapurāna. Le Śiva qui en est le héros se rit des sages que fascine un Viṣnu transformé en Mohinī : "Alors le Porteur de l'arc, Nïlalohita, dit en riant, après avoir regardé l'origine du monde, [qui était] à son côté,

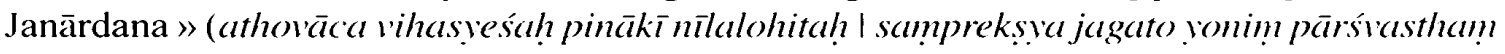
(a janārdanam II II. 37. 27). Pour choisir ici entre nülalohita adjectif qualifiant Pinākin, le Porteur de l'arc, qui serait «noir et rouge», ou un nom propre, Nīlalohita, assorti de l'épithète «porteur de l'arc pinäka», on se repose sur une connaissance du çivaïsme venue de la lecture d'autres textes et sur le contexte d'un récit à la gloire de Śiva. Qui est le dieu qui rit ici? Pinākin est l'un des noms anciens de Śiva, d'où une interprétation naturelle de nilalohita comme épithète. On ne voit pourtant pas ce qu'apporte ici l'adjectif, ni à quoi il fait allusion. Nous posons, quant à nous, l'hypothèse d'un élément que nous qualifierions de fossile. Il n'aurait pas d'usage narratif ou symbolique, mais témoignerait d'une relation ancienne, disparue, entre le gana Nīlalohita et le mythe du Séducteur de la forêt de pins ${ }^{101}$.

Qu'on retrouve nïlalohita associé au dieu qui entre dans la forêt du Lingapurāna renforce cette hypothèse. Accompagné ici de bhagavān, le terme s'interprète plus naturellement comme un nom propre : « [Je vais conter] comment il atteignit la forêt de cèdres, le souverain Nīlalohita, s'étant déguisé (vikrtam rūpam ästhāya), le sexe dressé, vêtu

100. On remarque tout particulièrement les gardiens qui encadrent les bas-reliefs de la face ouest de l'I İavāttāneśvara : l'un d’entre eux se trouve à côté du seul Séducteur du corpus pallara qui n’adopte pas l'allure d'un gardien. Indiquerait-il la différence de statut entre deux formes divines, l'une étant gardien de porte ou d'une entrée quelconque, l'autre veillant sur l'ensemble du territoire du dieu?

101. Dans le Dronaparvan du $M h h$ (VII. 57) que cite Ph. Granoff (20)3). Nīlalohita enseigne l'usage de l'are à Arjuna et à Krṣna. ('e gana serait-il plus particulièrement lié à l'are'? Il pourrait s'agir d'une forme d’arme animée. comme d'autres figures civaïtes. Fn Kürmapurāna 1. 10. 21. le Śiva qui remet un arc a Janaka est aussi dit (ou appelé) " nïlalohita". 
d'espace ", katham däruvanam prāpto bhagavān nülalohitah | vikrtam rüpam ästhāya cordhvaretā digambarah II (Lingapurāna I. 29. 2). En Vāmanapurāna 6. 66 également, le dieu qui entre dans la forêt est nīlalohita - ou Nīlalohita - : «Le linga du dieu tomba alors, en déchirant la terre; et il disparut, le Porteur de trident Nīlalohita (ou : le noir et rouge Porteur de trident; ou encore : Nīlalohita qui porte un trident) ", tatah papāta devasya lingạ̣ prthvīn vidārayan I antardhānam jagāmātha trisúülì nülalohitậ II.

Si l'on considère ces trois versions puraniques, le Séducteur de la forêt de pins n'aurait-il pas été, avant ces textes mêmes, Nīlalohita, le gana qui coupe la tête de Brahmā en SP 5 ? Avons-nous affaire à une simple épithète, à un nom propre ou à un nom propre ancien devenu épithète ? Enfin, Nīlalohita apparaît aussi en Kürrmapurāna II. 31, où l'on conte l'errance d'un Bhairava qui trancha la tête de Brahmā, et qui présente la particularité, signalée supra, d'être un séducteur 102. Dans ce chapitre, le terme nīlalohita revient à plusieurs reprises; le dieu qui remet à Bhairava la tête de Brahmā pour qu'il erre sur terre en tenant ce crâne porte ici le nom de Nīlalohita ${ }^{103}$. "Nïlalohita » n'est pourtant pas si courant dans le corpus puranique et nous n'y avons pas identifié pour le moment d'autres épisodes çivaïtes que ceux de la décapitation de Brahmā et de la forêt de pins auxquels le terme soit, ainsi, systématiquement associé.

À travers le personnage de Nīlalohita, cet ensemble documentaire vient souligner l'importance à date ancienne des gana çivaïtes que $\mathrm{Ph}$. Granoff met en évidence dans ses études. Ancêtre mythologique de Bhairava comme bourreau de Brahmā, Nīlalohita le serait-il aussi du mendiant séducteur de la forêt de pins? Sans le témoignage du SP, on ne distinguerait plus guère les contours de ce gana. Mais un tel profil amène à repenser l'ancienneté du lien entre décapitation de Brahmā, mendicité et séduction des femmes. Ces trois motifs ne sont pas toujours liés dans la mythologie de Bhairava qui n'est pas, en outre, la première à les connaître. Les figures pallava font poser l'hypothèse d'un lien

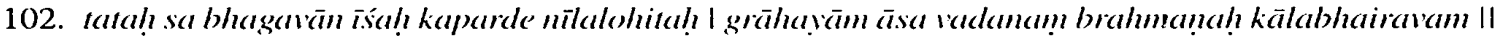
Kürmapuräna II. 31. 67. L'ensemble de ce chapitre contant la décapitation de Brahmā juxtapose les trois figures de Śiva, de Nīlalohita et de Bhairava. Portant un trident, Nīlalohita apparaît dans un cercle de feu à Brahmā qui le somme de prendre refuge en lui-même. İśvara envoie alors un être terrible (purusạn kälam bhairavam, Il. $31.29 \mathrm{~cd}$ ), un Kāla Bhairava qui coupe la tête de Brahmā. Ce dernier fait donc allégeance et I lara signifie alors au dieu Nīlalohita, qui se tient devant lui, que sa punition pour avoir coupé la tête de Brahmā sera d'aller mendier. Mais c'est ensuite Nīlalohita qui envoie Kālabhairava mendier avec la tête de Brahmā. Sur ce chapitre, voir aussi supra, note 79. Le Kürmapurāna utilise le terme nïlalohita au pluriel en I. 7.28 pour qualifier des rudra que Śiva fait émaner de lui-même, mais en I. 10. 32 c"est un Śiva nïlalohita qui fait émaner de lui-même des rudra tandis que, selon Kürmapuräna I. 38. 33ab, Śamkara Nīlalohita crée des avatära de lui-même (karisvaty avatäräni sánkaro nälalohitah). Le chapitre I. 37 met en scène un Nīlalohita-Śiva qui fait de Bäna le chef des gẹna. Il se rapproche ainsi de l'épisode du Harivamśs commenté par Ph. Granoff (2003), où Bāna est nommé chef des gana par Śiva, qui lui confère alors le nom de Mahākāla. Quant au Nīlalohita de 1. 19. 15, il est le petit-fils de Kṛ̣na, lui-même présenté comme père de Brahmā. Nīlalohita est donc fils de Brahmā (comme dans

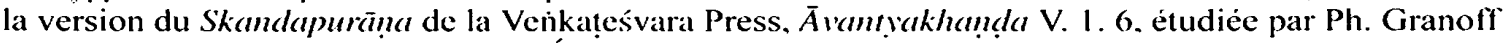
2003), mais c'est aussi une forme de Śiva.

103. Ce chapitre du Kürmapuräna est souvent cité par ceux qui ont étudié les formes mendiantes de Śiva et semble à l'origine des confusions faites dans la littérature secondaire entre le Séducteur de la forêt el Bhairava. S. Kramrish (1981, p. 287), dans le chapitre intitulé « The Supreme Beggar », juxtapose ainsi des passages du Kürmapuräna en constituant un mythe où Bhairava vient dans la forêt de pins. Le texte lui-même ne dit pas cela. On signalera cependant le lien intuitif que fait l'auteure entre deux figures mendiantes qui nous semblent liées à l'origine en effet. Remarquons que le déroulement qu'offre Kärmapurāna II. 31, où le mythe du liriga de feu précède la décapitation de Brahmā et l'errance de Bhairava qu accompagne un cortège de femmes, évoque tout particulièrement la face sud du Kailāsanātha, où la lirigodhhavamūrri est représentée, de même, avant le Séducteur en marche. 
ancien entre eux, puisque le Séducteur de la forêt de pins des bas-reliefs pallava est un gardien de territoire, qui endosse donc l'un des rôles de Bhairava. Dans les textes à notre disposition, la fonction de gardien et l'aspect séducteur ne sont liés que dans la mythologie de Bhairava. Celle-ci hérite elle-même du gana Nīlalohita, que nous « lisons » en filigrane dans plusieurs des versions du mythe de la forêt de pins : chacun des motifs est, au moins une fois, en contact avec l'un des deux autres.

Ces divers éléments nous amènent alors à poser l'antiquité du lien entre décapitation de Brahmā, mendicité et séduction dans le discours mythologique. Antérieur à la figure du dieu Bhairava, ce lien serait aussi ancien que Nīlalohita lui-même, terrible séducteur. Il se serait perdu peu à peu, peut-être à partir du moment où se constitue Bhairava qui emprunte partie (ou tout?) de sa légende à Nīlalohita ${ }^{104}$. Il aurait perduré en Inde méridionale sur le site de Citamparam, qui réserve une place singulière au coupeur de tête gardant le temple, en même temps que son mythe étiologique se fonde sur celui du Séducteur de la forêt de pins. Celui qui tranche la tête de Brahmā marche, mendiant, et entre, séduisant. dans la forêt de pins. Peut-être est-ce là une figure effrayante. Le sourire des Séducteurs en marche du Kailāsanātha s'ouvre sur les crocs parant toutes les formes de Śiva de ce temple; Nīlalohita apparaît lorsqu'il faut trancher la tête de Brahmā. Mais cette figure exerce une séduction certaine et les femmes tombent à ses genoux ${ }^{105}$.

Quant aux «Marcheurs » pallava, certains nous apparaissent comme des formes intermédiaires entre celle qui décapite Brahmā et les Séducteurs (V. Gillet 2006, p. 291). Ils sont triomphants en effet, adorés soit par Brahmā et Viṣnu, soit par des ascètes. Les dieux reconnaissent le pouvoir de Śiva Lingodbhavamūrti. Le mythe de la forêt de pins en constitue une variante et les ascètes, Brahmāà leur tête, Viṣnu de son côté, y adorent aussi Śiva. Parfois intégrée dans le mythe de l'apparition du linga, la décapitation de Brahmā qui est le lieu de l'apparition de Nīlalohita-Bhairava dans les textes en est une autre variante.

Les Marcheurs pallava avancent, vus de face, tels les Séducteurs du Madhya Pradesh, de l'Orissa et de l'Iravāttāneśvara pallava, et semblables aux Séducteurs de la période cōla. Leurs coiffures et leurs costumes sont ceux des Séducteurs pallava. Ils représentent ainsi à notre sens l'errance qui conduit une forme violente et puissante du dieu, sa colère personnifiée, qu'on l'appelle Nīlalohita ou Bhairava, dans l'univers divin où, adorée par Brahmā et Viṣnu, elle conserve bras et attributs (hache, trident, lien et serpent de celui qui décapite Brahmā se retrouvent sur le Marcheur à huit bras). Puis le Marcheur échange son apparence physique pour celle d'un ascète et s'en vient poser ses pieds, plus précisément ses sandales particulières, sur cette terre qu'il garde et parcourt - car qu'est cette dernière

104. Le fait même que les textes techniques distinguent clairement trois mürti, brahmaśiraśchedakamūrti. bhiksătanamürti et karkalamürti va dans le sens de notre interprétation. Ces documents enregistrent le fait qu'on représente des figures différentes, dont elles font des formes distinctes du dieu sans plus percevoir le lien entre elles. Ils n'en sont pas moins incapables de fonder leur différence sur le plan mythologique en liant chacune à un mythe différent. Les mythes se répètent, les formes permutent, les noms sont interchangeables : la confusion s'introduit dans toutes les explications autres que celles, matérielles, qui constituent uniquement trois formules iconographiques. On consultera sur ce point les deux articles de M. Adicéam ( $1965 \mathrm{a}$ et b) qui note la confusion sans l'expliquer ét conclut donc qu'il doit s'agir d'une même forme du dieu sous plusieurs aspects.

105. Peut-être la figure originelle avait-elle deux visages : Bhairava aurait hérité de l'aspect difforme et le Séducteur marchant dans la forêt d'une aimable apparence. Même si nous faisons l'hypothèse que less deux aspects du dieu pourraient avoir été déjà liés dans la figure de Nīlalohita, soulignons que nous ne voulons nullement dire qu iils étaient associés dès une chimérique origine, ni qu’ils le sont constamment. 
après tout, sinon un territoire cultuel ${ }^{106}$ ? Adoptant alors le déguisement d'un homme, nu, il provoque, après la dévotion des dieux, celle de femmes pieuses qui l'adorent les mains jointes et contemplent sa forme merveilleuse. Si les textes sont quasi unanimes pour dire que Bhairava n'est délivré du crâne qu'en atteignant Bénarès, le Kāñaīpurānam (34. 33-34; voir R. Dessigane et al., 1964, p. 42-43) fait évidemment de Kāñcipuram (la Kāśī méridionale) le lieu de cette délivrance. Au Kailāsanātha, entre la scène unique du prākāra du temple où Brahmā prie celui qui le décapite et les gardiens des murs du temple qu'adorent de belles femmes, les Marcheurs sillonnent l'espace. Adoré par Viṣnu et Brahmā, le plus puissant des Marcheurs déploie ses bras dans les huit directions de l'espace, sur la chapelle $\mathrm{n}^{\circ} 52$ du grand präkāra. En suivant la pradaksināa, il y précède immédiatement le dernier Séducteur en marche de ce chemin du dévot, signalant ainsi, de façon indiscutable, le lien entre deux formes : le mouvement même de la dévotion dans le temple fait apparaître le Séducteur comme issu du Marcheur.

Les sanctuaires pallava, et avant tout le Kailāsanātha de Kāñcipuram qui offre in situ une exceptionnelle variété de bas-reliefs, permettent, à notre avis, d'envisager les figures çivaïtes autrement qu'avec les seules données des textes, mais en accord aussi avec les plus anciens d'entre eux. I.e $S P_{S}$ ne paraît guère concerné par l'iconographie méridionale. Le Tamil Nadu n'appartient même pas à la géographie des textes édités par P. C. Bisschop (2006, p. 14). L'ancienneté des matériaux auxquels le projet d'édition du SP donne accès n'est pourtant pas le seul élément justifiant l'usage que nous en faisons. La relation entre textes prescriptifs et realia demeure délicate. Celle d'une littérature narrative rapportant les épisodes mythologiques représentés en picrre ct ces derniers est évidente; une telle relation ne témoigne-t-elle pas ainsi parfois d'un modèle différent de celui que diffusent la majorité des textes, brahmaniques, qui nous sont parvenus ${ }^{107}$ ? Construit par et pour Narasiṃhavarman II, le Kailāsanātha représente une idéologie royale autant qu'un modèle brahmanique. La marche de l'ascète est triomphale ici. Elle s'inspire

106. Cette hypothèse s'accorde avec une mythologie qui distingue plusieurs moments scindés par des espaces différents où le dieu marche; cf., par exemple, Varähapurāna 97. 20-22 qui distingue la dernière année d'errance du dieu (la sixième), où il devient un Kāpālika, un porteur de crâne, nu, impliquant qu'il n'était pas tel auparavant. Dans un passage du Skandapurāna de la Veñkaṭeśvara Press ( $\bar{A} v a n t y a-$ khaṇda, Caturaśñilirigamāhātmya 8. 10-12, cité par K. Ladrech, à paraître, p. 95-96), Śiva se déguise de même en käpälika nu pour égarer les brahmanes. La mention d'un déguisement implique une autre forme, différente de celle du Kāpālika. La forme déguiséc est celle qui s'en vient sur la terre : nu, le corps est le costume ultime choisi par le dieu pour dévoiler sa puissance, comme dans notre Séducteur en marche (sur ce mythème en contexte vishnouite, Ch. Schmid, à paraître). Sans développer ici par ailleurs le thème des chaussures particulières du dieu, signalons qu'il s'agit d'une invention pallara, et qu'elles seront au Tamil Nadu l'un des traits iconographiques qui distinguent le Séducteur et Bhairava à partir de la période cōla. Les Bhairava d'Andhra Pradesh et du Karnataka les portent : le type du séducteur en marche n existe pas dans ces régions et le port des chaussures y souligne l'identité de Bhairava et du Séducteur. Dans le pays tamoul, les sandales distinguent aussi le Séducteur des importantes catégories d'ascètes crrants que sont les jaïns et les bouddhistes dont les empreintes de pieds, nus, sont différentes de celles d'un Séducteur chaussé. On connaît les Buddha marchant et les huddhapācla; voici un Siva en marche, avec ses socques de bois. La relation avec le vishnouisme, puisqu'on connaît aussi des vismupāala, pourrait être d'ordre royal (cf. l'épisode des sandales symbolisant la puissance du roi que Rāma remet à son frère dans le Rämāyaṇa; à chaque fois que Bharata donne un ordre royal, il met d’abord ces chaussures [Rämăyana II. 107, 22 ; cité par H. T. Bakker 1991, p. 32]). Sur la relation entre marche, empreinte, royauté et bouddhisme, on consultera également, entre autres, R. L. Brown (1990), et sur les empreintes de pied de Śiva, le commentaire de P. C. Bisschop (2006, p. 177-179) à propos du toponyme de Mahālaya, site où Śiva laissa ses empreintes de pied.

107. Voir E. Francis $(2009, \$ 5.8)$. 
nettement de certaines représentations de cakravartin des sites bouddhiques méridionaux, où l'on représente celui-ci la jambe demi-pliée au-dessus d'une sorte de piédestal ovale (de même les Marcheurs pallava cheminent-ils au-dessus d'une sphère), tandis que des personnages en prière et la femme de ses trésors de roi universel le contemplent.

Le Séducteur en marche et les Marcheurs pallava constituent ainsi un Śiva-roi conquérant un territoire où chacun lui rend hommage. Au début du vill siècle, en Inde méridionale, Śiva se transforme au gré des mythes qui en permettent la représentation sur les temples. D'une figure furieuse à une forme triomphant des autres dieux, puis à un séducteur provoquant l'adoration de l'ensemble de la terre qu'il parcourt, la divinité royale adopte différents aspects, que l'iconographie et l'architecture du Kailāsanātha lient entre eux, soulignant la cohérence d'un discours mythologique sur l'origine première duquel on ne peut que spéculer ${ }^{108}$.

\section{Perspectives}

Au terme de l'examen de ces trois ouvrages, nous voudrions insister sur deux aspects: la relation entre texte et image; la nécessité de s'approprier les sources primaires par un examen de première main.

Texte et image. Soulignant les correspondances entre un texte, la Märīcisamhită, et un temple, celui d'Uttiramerūr, Gérard Colas (1986, p. 67-69) relevait le caractère pourtant vague de certaines prescriptions techniques, qu'on peine à retrouver dans le monde matériel. Dans un recueil d'articles consacré à la relation entre l'image mentale et l'image matérielle, Hélène Brunner-Lachaux (1990) s'interrogeait quant à elle sur l'absence de correspondance entre les figures concrètes et les textes qui les évoquent. Ces points de vue ouvrent des perspectives sur les voies de passage entre images faites de mots et sculptures du monde tangible, qu'illustre le cas des gardiens de porte en contexte méridional, où une correspondance quasi exacte entre représentation sculptée et texte peut aider à interpréter une image matérielle mais peut, également, induire en erreur.

Ainsi, l'on identifie encore aujourd'hui comme « horned dvārapäla », gardien cornu, l'un des àyudhapuruśsa, armes personnifiées, qui garde l'entrée des grottes çivaïtes pallava, pāntịya et āndhra ${ }^{109}$. On considère alors les pointes recourbées qui se déploient de chaque

108. Outre les études déjà signalées de Ph. Granoff, nous mentionnerons ici l'article publié sur la Toile par P. C. Bisschop (2008), portant sur une figure particulière du site de Mansar, que cet auteur identifie comme la première figure connue de celui qui décapite Brahmā. P. C. Bisschop songe aussi à faire d'une figure à l'identification controversée, du même site, une représentation de Nĩlalohita. L'identification comme un genre de nidhi ou de Kubera, développée par R. L. Brown (2004), nous paraît plus convaincante au regard des données méridionales (cf. E. Francis et al., Chronique des études pallava II, 2006, p. 449-452), mais nous n'avons pas examiné les pièces et il ne s'agit pas là d'art pallava.

109. Cette interprétation est toujours de mise aujourd'hui, comme le prouvent, par exemple, des cartels récemment mis en place au Government Museum de Madras et la reprise des commentaires de Calambur Sivaramamurti à propos du Ganeśaratha dans l'édition la plus récente (2006) de son Mahābalipuram. Dans cette nouvelle édition, B. Narasimhaiah reprend (p. 53-54) mot pour mot l'idée ancienne de C. Sivaramamurti (1952, p. $24 ; 1955$, p. 14-15), selon laquelle des dvärapāla cornus deviennent ensuite des triśūla personnifiés, une perspective déjà adoptée, entre autres, par F. L'Hernault (1987, p. 96). Dans son compte rendu de l'ouvrage de K. R. Srinivasan (1964), S. Kramrisch (1966) note quant à elle que " the suggested identification of the horned Dvārapāla figures with Nandi who is Srngi, the horned one, however has to be taken into consideration ". D. C. Barrett (1958. p. 5) parle des " curving horns and wig " des dvārapāla du site pallava tardif de Tiruttani. L’étude de V. R. Mani (1985) signale les tridents personnifiés qui gardent l'entrée des temples sud-indiens mais pour affirmer qu'il ne s`agissait pas là 

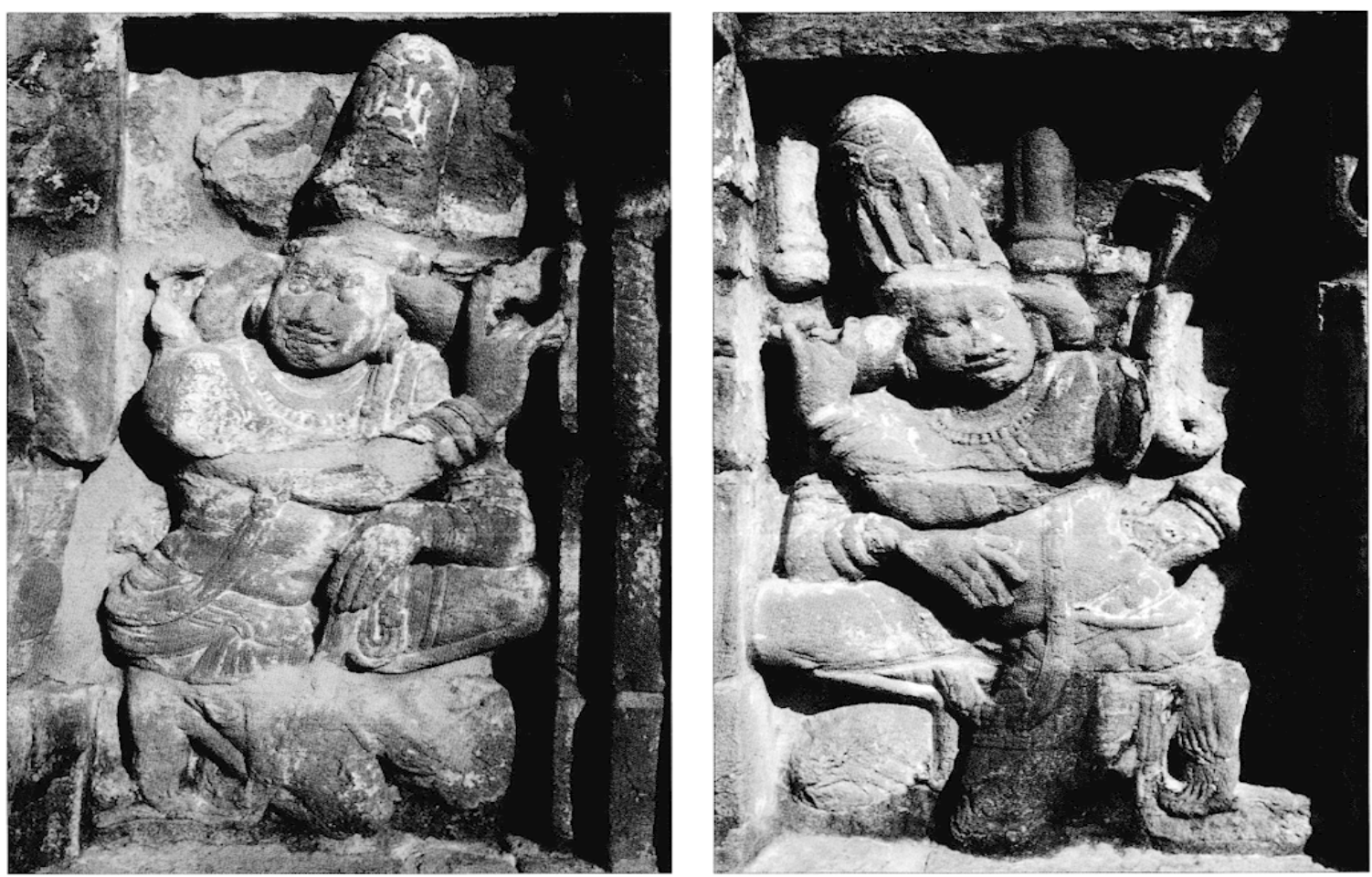

Fig. 11a, 11b. Gardiens de porte, petit prākāra du Kailāsanātha de Kāñcipuram, début du viı́ siècle (clichés: Emmanuel Francis).

côté du trident personnifié comme les cornes d'un taureau (fig. 11a). De fait, certains textes (l'Agnipurāna et le Viṣnudharmottarapurāna) mentionnent " Nandin » et " Mahākāla » comme gardiens des temples de Śiva, cependant que la littérature secondaire, certains Purāna çivaïtes et les dévots d'aujourd'hui donnent communément au taureau Vrṣabha, monture de Śiva, le nom de Nandin ${ }^{110}$. L'interprétation selon laquelle le taureau Nandin garderait les portes du temple paraît donc confortée par des Purāna çivaïtes. Cependant Gouriswar Bhattacharya (1977) a montré qu'il ne faut pas confondre Nandin et Vrșabha.

d'une figure courante de l'art pallava (ibid., p. 35), où ils sont pourtant des plus communs et figurent parmi les exemples les plus anciens. Enfin, l'étude de H. A. van Bemmel (1994) évoque les cornes des gardiens pallava qu'elle oppose aux armes personnifiées sculptées par les Cālukya aux portes de leurs sanctuaires... Il s'agit en réalité du même type d'armes personnifiées dans les deux cas (ce qui a, en l'occurrence, d'importantes conséquences sur l'analyse du processus d'indianisation de l'Indonésic). L'article de M. Lockwood, G. Siromoney \& P. Dayanandan (2001, dont une première version est parue dès 1970$)$ pouvait paraître conclusif pourtant. Après avoir analysé la confusion entre cornes et trident, les auteurs signalent les diverses formes de couvre-chefs des gardiens de porte, trident et hache en contexte çivaïte, répondant aux tiares ornées d'une conque ou d'un disque des gardiens de porte vishnouites. L. Giuliano (2004), dont l'étude documente ce type de dvārapāla, identifie néanmoins encore la hache comme un " ekaśüla », arme à une seule pointe, dans des temples du Maharashtra et du Karnataka, tandis que J. Guy $(2007$, p. 26) évoque au Tamil Nadu, dans la continuité de figures fantastiques combinant l"homme et le taureau, "the medieval form of the lesser god Nandikeśvara [...] in which the horned form reveals its other aspect, as Śiva's trident " puis « Nandikeśvara, a double-sided horned figure of Nandī » (ibid.. p. 37 et légende de la figure 38). Pour une synthèse des données archéologiques et des prescriptions âgamiques concernant Nandin et Mahākāla, voir D. Goodall et ai. (2005, p. 100-108).

110. Aucun des textes iconographiques mentionnant deux gardiens de porte çivaïtes sous ces noms n'est antérieur au vi" siècle. 
l. identification de la figure gardienne parée de pointes comme un Nandin-rrsabha un taureau ayant adopté une forme humaine. dont les cornes signaleraient l'identité par ailleurs animale nous paraît donc erronée et fondée sur une observation superficielle des figures sculptées. Le contexte de représentation est en fait nécessaire à l'identification des gardiens supposés " cornus" (fig. 1la). Ces derniers forment toujours paire avec d'autres, dont la tiare est parée d'une lame de hache (fig. 10a pour un exemple de gardien à une seule lame de hache; fig. $11 \mathrm{~b}$ où ce gardien porte plusieurs lames de hache les unes à côté des autres). Ces figures à la hache permettent de reconnaître dans leurs pendants une personnification du trident, dont les pointes latérales dépassent, telles des cornes, de chaque côté de la tête, tandis que la pique centrale en orne, parfois, le centre, ainsi que l'ont démontré, il y a plus de trente ans déjà, M. Lockwood, G. Siromoney \& P. Dayanandan (2001 [1970]).

Ainsi, l'usage des textes ne suffit pas, en soi, à justifier une identification et le décalage chronologique qu'on observe souvent entre les textes utilisés pour tenter d identifier une sculpture et cette sculpture même incite à la prudence : l'auteur du texte ne savait pas toujours mieux que nous aujourd'hui regarder une image.

Nous signalerons, à l'inverse du cas de nos gardiens, la convergence en revanche remarquable entre les figures d'une déesse guerrière, représentée sur des stèles et louée dans le Vettuva Vari (chant XII du Cilappatikäram, épopée tamoule qu'on date, généralement, entre le $I V^{C}$ et le $V I I^{\circ}$ siècle de notre ère). Les très nombreuses stèles où se dresse celle que nous appelons, à l'instar du Cilappatikāram, Korravai, sont disséminées sur une part importante du Tamil Nadu et datées de la période pallava ( $\mathrm{VII}^{\mathfrak{}-1 \mathrm{X}^{\mathfrak{C}}}$ siècle). La description de la déesse et de son culte que donne le poème épique correspond dans tous ses détails aux figures de pierre, sculptées à l'époque de la rédaction du texte. Dans la même région, au même moment, un matériel similaire offre pourtant un hiatus entre les deux types de sources considérées. Celle qu'on appelle Jyeșthā, la déesse à l'embonpoint bien marqué que l'on retrouve sur le même type de stèles, ne semble guère en effet correspondre à la déesse portant ce nom dans la littérature tardive relevant de certaines traditions védiques de l'Inde méridionale ${ }^{11 !}$.

Vérification des inscriptions. La prospection, le recensement et la mise à disposition de sources primaires nouvelles qui permettent d'élargir le corpus doit s'accompagner de la vérification de celles qui ont déjà été publiées ${ }^{112}$. Nous offrirons ici l'exemple significatif de l'inscription du pilier de Vāyalūr (début du viII" siècle) ${ }^{113}$. La littérature secondaire

111. Arlo Griffiths a lu pour nous les références à cette déesse dans ce corpus textucl. Sur Jyesțhā, voir E. Francis et al. (Chronique des études pallava II, 2006. p. 467-471). Chacune de ces deux déesses requiert une étude à part entière, et nous ne développerons donc pas ici ces deux exemples.

112. Signalons ici la publication par D. Dayalan de trois volumes (Computer Application in Indian Epigraphy, Delhi, 2005) inspirées des études statistiques menées dans le domaine cōla pour organiser les données épigraphiques. Y sont recensés les noms propres, les titres, les taxes, les temples, etc.. qu'on rencontre dans les inscriptions tant tamoules que sanskrites de la période pallava. L'appendice I, "Text of Recently noticed inscriptions » (vol. III. p. 1233-1328) peut être considéré comme une sorte de supplément aux $I P(1988)$. Il offre. en effet. ce qui est fort utile, quatre-vingt dix inscriptions de la période pallava (en sanskrit é en tamoul) qui n apparaissent pas dans les $I P$. L absence de vérification des données in sith amène cependant l'auteur à perpétuer. dans le corps de louvrage. des erreurs dorénavant connues.

113. Pour la lecture erronéc du terme silçkharena que I: Hult/sch proposa en éditant l’inscription de Trichy (SII I, n³3-34), au lieu de silaks sarena qu une observation in situ permet de lire. cf. E. Francis "l alii (Chonique des cencles pallava 1.2005 . p. 585 . note 10). 
se fonde sur l'édition de Hiranand Krishna Sastri (1926, EI XVIII. 18, p. 145-152) qui lit dans la dernière strophe le mot dvipalaksam. Ce dernier est considéré comme l'équivalent de laksadvippam (« la centaine de milliers d'îles », c'est-à-dire les Laquedives) et la strophe est interprétée comme une preuve de conquêtes outre-mer des Pallava (voir, par exemple, T. N. Subramaniam 1967, p. 14). Lors d'une visite in situ, nous avons pu constater que c'est le mot varsalaksam (« mille ans ») (fig. 12) qui est gravé sur une partie du pilier (partie qui n'apparaissait pas dans les fac-similés publiés par H. K. Sastri). Cette nouvelle lecture modifie considérablement la vision qu'on peut se faire de l'impérialisme maritime des Pallava : la seule mention concrète de l'outre-mer dans le corpus royal pallava s'évanouit en effet.

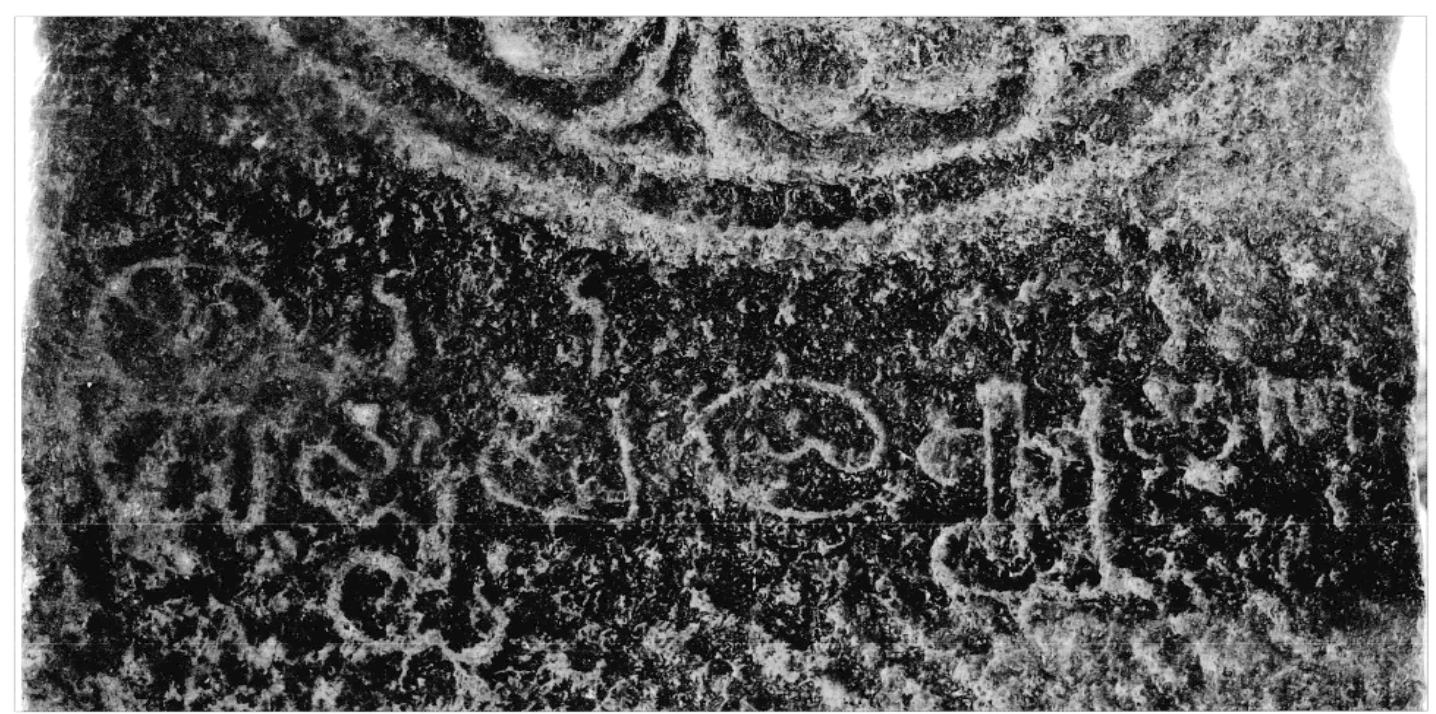

Fig. 12. Inscription de Vāyalūr, début du viII siècle (cliché : Emmanuel Francis).

"D. E. : Quelles impressions avez-vous ressenties, quand vous avez fait votre première expérience de terrain?

C. L.-S. : J'étais dans un état d'excitation intellectuelle intense. Je me seniais revivre les aventures des premiers voyageurs du $X V T^{\circ}$ siècle. Pour mon compte, je découvrais le Nouveau Monde. Tout me paraissait fabuleux : les paysages, les animaux, les plantes..."

Claude Lévi-Strauss \& Didier Eribon, De près et de loin, Paris, 1988, p. 34. 


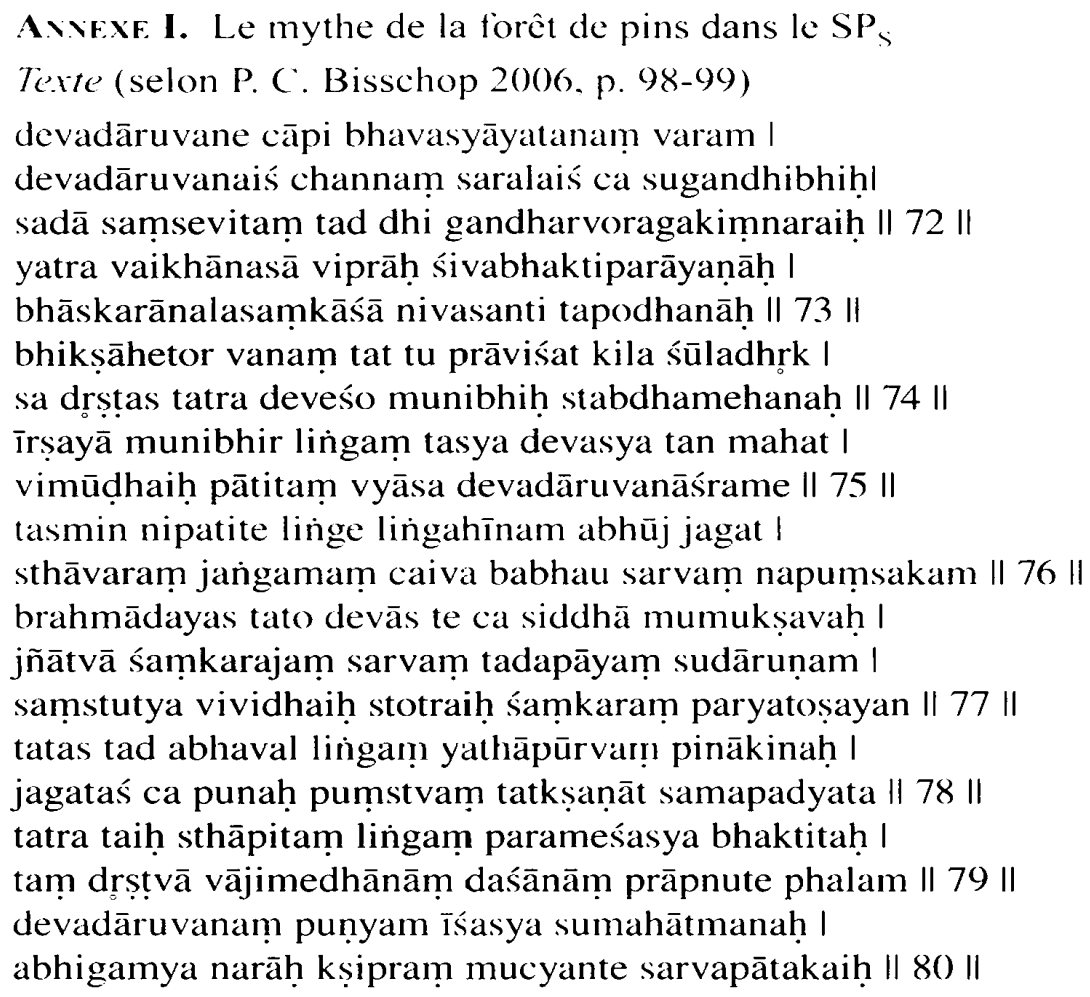

\section{Traduction}

Dans la forêt de cèdres, on trouve aussi un excellent sanctuaire $(\bar{a} \text { yatana })^{114}$ de Bhava; à l'ombre de forêts de cèdres et de pins au bon parfum, il est constamment fréquenté par des gandharva, des serpents et des kimnara.

C'est là que résident des brahmanes anachorètes (vaikhānasa) qui ont pour seul but la dévotion à Śiva, trésors d'ascèse qui ont l'apparence d'un feu éclatant.

L'on sait qu'afin de mendier, le Porteur de pique entra dans ce bois, et que des ascètes virent ce maître des dieux, son membre érigé.

De jalousie, les ascètes aveuglés abattirent le grand phallus de ce dieu, ô Vyāsa, dans l'ermitage de la forêt de cèdres.

Lorsque le phallus fut tombé, le monde fut privé de phallus : l'inanimé comme l'animé, tout apparut dépourvu de caractère masculin.

Alors les dieux, Brahmā en tête, et ces parfaits qui étaient désireux de se libérer, après avoir compris que cette perte totale, si cruelle, était l'œuvre de Śạ̣kara (le Bienveillant), le louèrent avec des hymnes divers et, ainsi, donnèrent satisfaction à Śamkara.

Alors ce linga de Pinākin (le Porteur de [l'arc] Pināka) fut comme auparavant; au moment même, la masculinité de l'univers fut alors rétablie.

Ils installèrent en cet endroit le linga du seigneur suprême avec dévotion.

En le voyant, on obtient le fruit de dix sacrifices du cheval.

Lorsque les hommes se rendent dans la forêt de cèdres au bon pouvoir (punya) du maître si magnanime, ils sont immédiatement délivrés de tout péché.

114. Sur le terme äyatana, voir P. C. Bisschop 2006, p. 173, annotant $\mathrm{SP}_{\mathrm{S}}$ 2a en donnant une bibliographie et en commentant son résumé du $\mathrm{SP}_{S}$ où il traduit le plus souvent âyatana par « sanctuary ». par opposition à sthäna, « abode». 


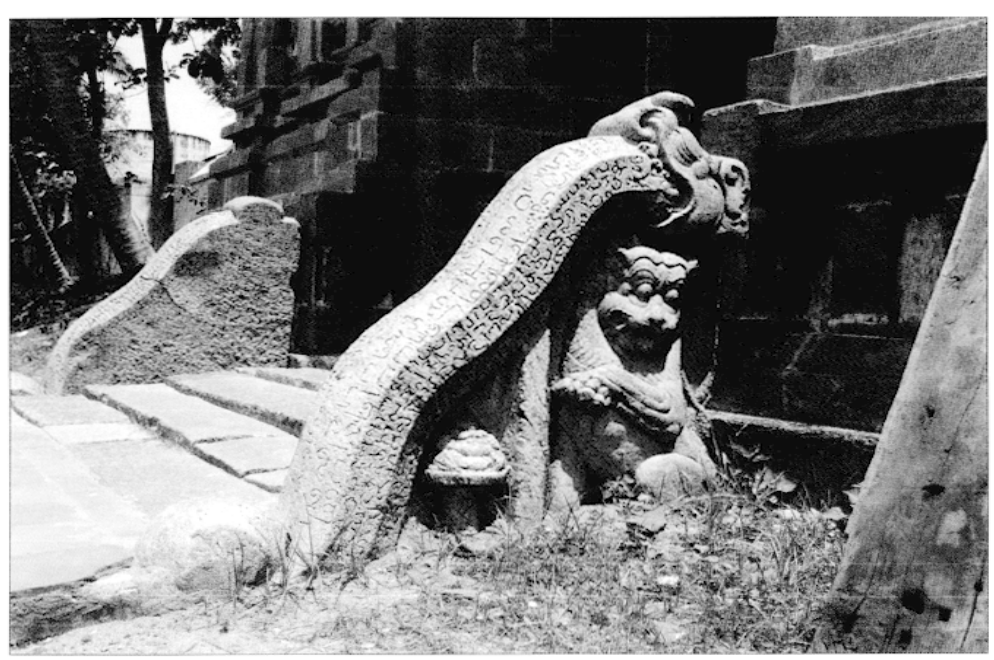

Fig. 13. Murs d'échiffre de Tirunāvalūr, Ix siècle (cliché : Emmanuel Francis).

Fig. 14. Monolithe de Tirunāvalūr, $1 x^{c}$ siècle (cliché : Emmanuel Francis).

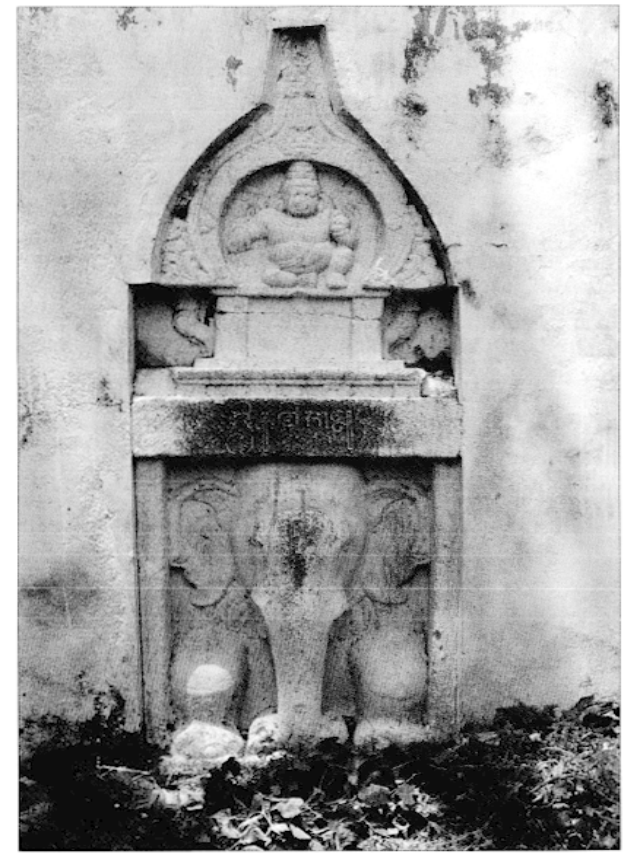

AnNexe II. Tirunāvalūr (un an après Taccūr)

Un mois après le dépôt du manuscrit des "Trésors " (E. Francis et al., Chronique des études pallava $I I, 2006$ ), nous avons pu consulter une publication récente de C. Paranan consacrée au temple de Tirunāvalūr (ou Tirunāmanallūr; taluk de Uḷuntūrpētṭai, district de Viluppuram) ${ }^{115}$. La photographic de la p. 163 de cet ouvrage présente un monolithe très semblable à celui du site de Taccūr (E. Francis êt al., Chronique des études pallava $I I, 2006$, p. 442-453, fig. 14-15, 18) ${ }^{116}$. Il est en effet sculpté pareillement, puisqu'on y trouve, de bas en haut. un éléphant, un bandeau inscrit et une lucarne ornée d'un petit personnage ventripotent que nous identifions comme Kubera ou comme un nidhi (fig. 14). T. V. Mahalingam signale par ailleurs sur ce site une inscription en pallava-grantha qui consiste en ce qu'il pense être le biruda d'un roi pallava d'une lignée mineure $\left(I P \mathrm{n}^{\circ} 263\right.$ $=A R E 1902, \mathrm{n}^{\circ} 376=S I I \mathrm{VII}, \mathrm{n}^{\circ} 1006$ : śrïkalinärai; voir $I P$ p. cxvii et $643^{117}$ ).

En septembre 2008 , nous nous sommes donc rendus sur le site de Tirunāvalūr pour $\mathrm{y}$ rechercher ce monolithe et cette inscription.

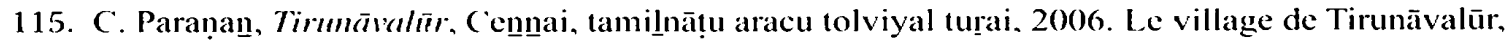
sur la National Ilighway 45 qui mène de Chennai à Trichy, se situe à $22 \mathrm{~km}$ au sud de Viluppuram et à $2 \mathrm{~km}$ environ à l'est de la rivière Kețilam.

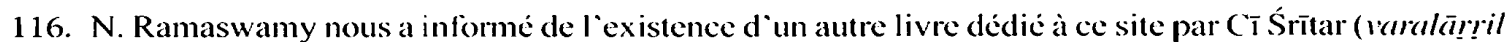

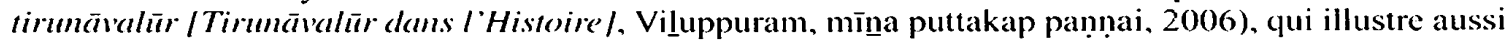
la pièce et la discute (p. 68, sous le titre yänai, "éléphant »).

117. T. V. Mahalingam décrit le support de cette inseription dans les termes suivants : "The sculptured stone which contains this record bears a kneeling elephant with a stout person mounted on its back » ( $I P \mathrm{n}^{\circ}$ 263, p. 643). Il s'agil d'une description imparfaite du monolithe portant la figure de Kubera. manifestement reprise de $A R E 1902$ (p. 4), où li. Hultzsch, qui ne disposait probablement que de l"estampage de l'inscription et d'une description du monolithe, attribuait śrikalinärai à un roi Pallava qu'il identifiait comme le personnage montant l'éléphant (notre Kubera/nidhi !). 
Le monolithe sur lequel est figuré Kubera ou un nidhi ${ }^{118}$ est encastré et maçonné dans la face intérieure du mur ouest de la première enceinte (fig. 14). Sa largeur $(83 \mathrm{~cm})$ est identique à celle de son homologue de Taccūr, mais sa hauteur est bien supérieure $(221 \mathrm{~cm}$ au lieu de $172 \mathrm{~cm}$ ). Coiffes et ornements des Kubera/nidhi de Taccūr et de Tirunāvalūr sont les mêmes; leurs poses sont identiques mais inversées : conque et lotus se trouvent à gauche et à droite de l'observateur à Taccūr, et sont intervertis à Tirunāvalūr.

Le bandeau de pierre sous la lucarne porte l'inscription śri kalinärai ${ }^{119}$. Qu'on interprète ce nom propre comme signifiant "Celui qui est une grue pour l'âge kali » (à comprendre dans le sens de "celui qui est le prédateur, le pourfendeur de l'âge kali », en référence à la description courante des rois comme restaurateurs de l'âge $k_{r} r a$ ), ou bien comme "Celui qui est une grue dans l'âge kali " ${ }^{120}$, nous suivrons ici Eugen Hultzsch et T. V. Mahalingam pour lesquels il s'agit d'un biruda qui s'applique à un roi ou à un roitelet pallava non identifié. Une inscription d'âge cōla du même site mentionne en effet par ailleurs une donation au seigneur du Kalinārīśvara (kalināriśvaramutaiyānn, ARE $1902, \mathrm{n}^{\circ} 365=S I I$ VII $\left., \mathrm{n}^{\circ} 995,1.2\right)$. Constatant que les villageois viennent de détruire le temple d'où provient le monolithe, E. Hultzsch en concluait, dans son introduction à l'ARE de 1902 (p. 4), que Kalinārai désigne le constructeur du sanctuaire dédié à un dieu dont le nom comporte celui du commanditaire, selon la règle que nous avons rappelée (supra, p. 256) ${ }^{121}$.

L'avant-train de l'éléphant sculpté sur la base de la pièce rappelle de fort près celui de Taccūr (jusque dans le collier orné de clochettes) et la comparaison avec le monolithe de Taccūr dont le bandeau est gravé d'une inscription de fondation appuie l'hypothèse d'E. Hultzsch.

Nous avons en outre constaté la présence à Tirunāvalūr de deux murs d'échiffre ornés de lions assis, analogues à ceux de Taccūr, disposés aujourd'hui de chaque côté de l'entrée du gopura (fig. 13) ${ }^{122}$. Nous supposons, comme nous l'avons fait dans notre chronique précédente, que ces murs d'échiffre encadraient le monolithe inscrit. Ils sont aujourd'hui gravés d'inscriptions datées du règne d'un « Parakesarivarman », probablement Parāntaka I ${ }^{\mathrm{er}}$, ce qui fournit un terminus ad quem dans la première moitié du $\mathrm{x}^{\mathrm{e}}$ siècle.

Le caractère analogue des dispositifs de Taccūr et de Tirunāvalūr, les inscriptions encore disponibles sur les deux sites et les vestiges de Taccūr font poser l'hypothèse d'un sanctuaire construit au $I X^{\mathbb{C}}$ siècle à Tirunāvalūr. Il s'agissait sans doute du temple

118. Pour l'identification de cette figure, voir E. Francis et al. (Chronique des études pallava II, 2006, p. 449-452).

119. Cette épigraphe mesure $32 \mathrm{~cm}$ de long. Sa paléographie permet de la dater, approximativement, du $\mathrm{I}^{\mathrm{C}}$ siècle; elle nous paraît quelque peu postérieure à celle de Taccūr. T. V. Mahalingam (IP), en lui attribuant le $n^{\circ} 263$, la considère aussi implicitement comme appartenant au ix siècle.

120. N. Ramaswamy nous signale des temples des environs de Kumbakonam où la grue est une figure du dévot de Śiva.

121. Le résumé de l' $A R E$ de 1902 enregistrant l'inscription du monolithe évoque " a shrine which has been recently demolished by the villagers ». Les inscriptions gravées sur les murs d'échiffre sont, sans doute significativement, regroupées à la suite de l'inscription du monolithe $\left(A R E 1902, \mathrm{n}^{\circ} 377-380=\right.$ SII VII, n 1007-1010).

122. Leurs dimensions sont également identiques, à quelques centimètres près $(109 \mathrm{~cm}$ de hauteur accessible sur $148 \mathrm{~cm}$ de largeur). 
d'origine des quelques pièces d'époque pallava aujourd'hui dispersées sur le site ${ }^{123}$. L'on aurait alors affaire ici à un autre de ces sanctuaires faits de matériaux périssables, brique, bois et mortier, que nous évoquions dans la Chronique des études pallava $I I$ : ces derniers semblent avoir été à date ancienne plus nombreux que ne le laisserait croire, de prime abord, le paysage archéologique actuel.

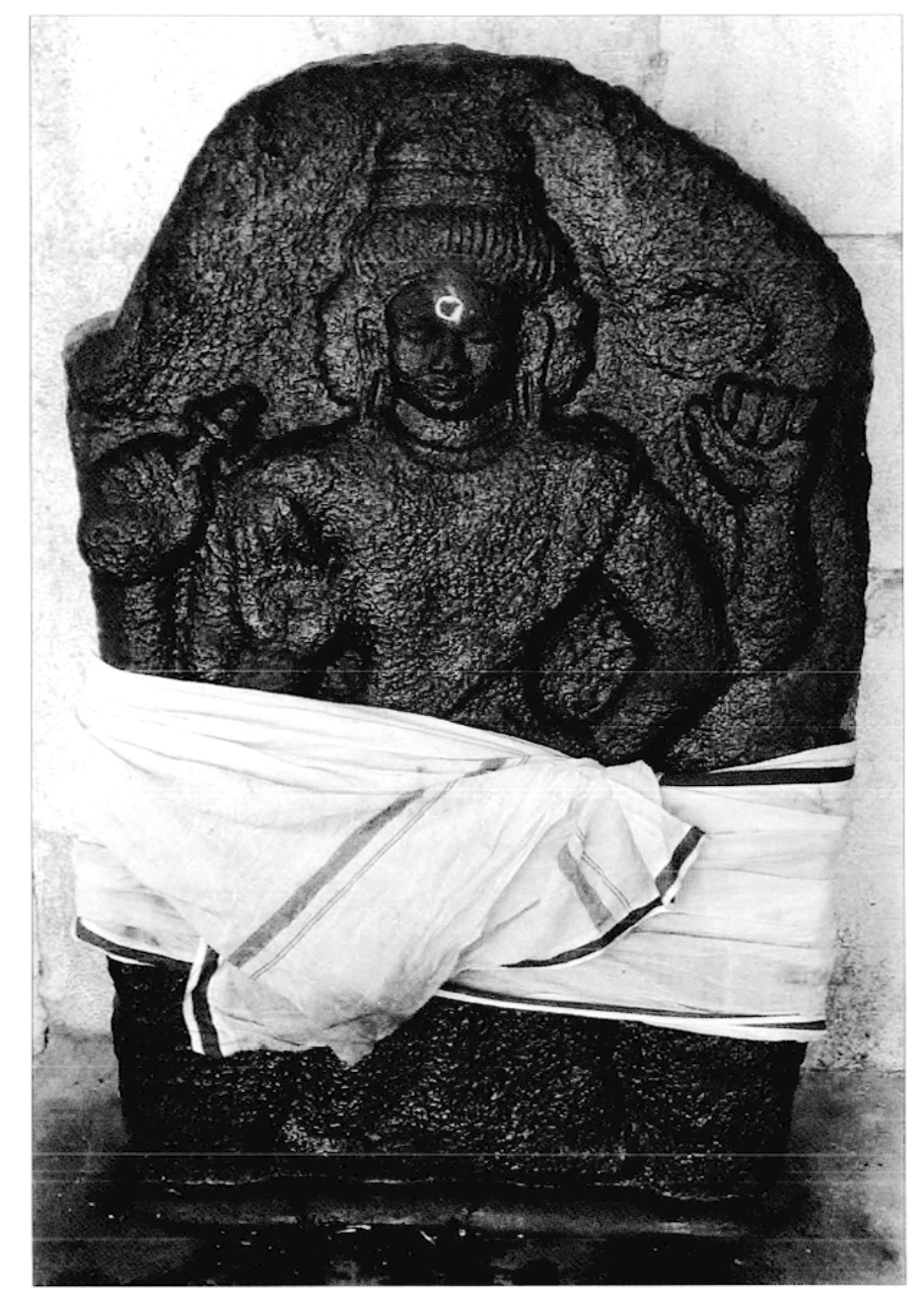

Fig. 15. Brahmā de Tirunāvalūr, Ix siècle (cliché : Emmanuel Francis).

123. Des stèles dont la facture correspond au IX“ siècle, représentant Viṣnu et Brahmā (fig. 1.5), de taille à peu près humaine, sont placées dans la galerie nord. On trouve aussi sur le site un Candeśa et un Ganeśa qui nous paraissent dater de la même époque, de même qu'un lingę et sa base qui sont des copies conformes de ceux de Taccūr. Nous supposerons, comme à Taccūr, que ces sculptures occupaient les niches extérieures d'un sanctuaire aujourd'hui disparu. 


\section{Bibliographie}

\section{Abréviations}

ARE : Annual Report on Eprigraph!.

EI : Epigraphia Indica.

IP: T. V. Mahaingiam, Inscriptions of the Pallavas.

Mhh : Mahābhārata.

SII : South Indian Inscriptions.

SP : édition critique du Skandapuräna publiée à (ironingue.

$S P_{S}$ : recension « $S$ » du chapitre 167 du Skandapuräna publié originellement à Katmandu par K. Bhaṭarāī (1988), et dont P. ('. Bisschop (2006) présente l'édition critique.

$\mathrm{SP}_{\mathrm{RA}}$ : recensions «Reväkhanda » et «Ambikäkhanda» du chapitre $167 \mathrm{du}$ Skandapurāna publiées originellement à Katmandu par K. Bhaț̣arāî ( 1988), et dont P. C. Bisschop (2006) présente l’édition critique commune.

\section{Sources primaires : textes (par titre)}

\section{A.mTincinMA}

Ajitägama. The great Tantra of Ajita. Critically edited. translated and annotated, par Niddodi Ramachandra BHATT, Jean FHLIII)/AT \& Pierre-Sylvain FII.III)/AT, 5 vol., New Delhi, Indira Gandhi National Center for the Arts \& Motilal Banarsidass, 2005.

CIIAPPATIKĀRAM

Illankōvatikalaruliceyta cilappatikāramülamum arumpatavuraiyum atiyārkkunallā-

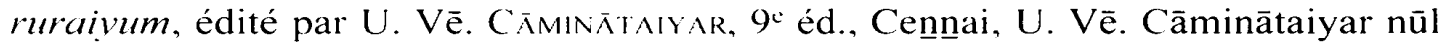
nilaiyam (U. Vē. Cāminātaiyar nūlnilaiya veliyịtu eṇ 58), 2001 [1 ${ }^{\text {re }}$ éd. : 1892].

KI:MARASAMBHAVA

Kumärasambhava of Kälidāsa. Edited with Introduction and English Translation, par C. R. Devadhar, Delhi, Motilal Banarsidass, 1985 [réimpression : 1997].

KÜRMAPURĀNA

The Kürmapurāna. With English Translation, édité par Anand Swarup Gupta et traduit par Ahibushan BHATTACHARYA, Varanasi, All-India Kashi Raj Trust, 1972.

LINGGAPURĀNA

Śrì vyāsamaharșiproktam śrilingamahāpurānam. With the Sanskrit Commentary Sivatoșin̄ī, édité par Ganeśa Nর̄Tu, Bombay, Venkatesvara Press, V. S. 1981 [1924] [réimpression : Delhi, Nag Publishers, 1989].

The Linga-purāna. Translated by a Board of Scholars, Delhi, Motilal Banarsidass, 1982 (Ancient Indian tradition and mythology series 5-6).

MAHĀBHĀRATA

The Mahähhärata. For the first time critically edited, par Vishnu S. Slkthankar, S. K. Brvalkar. Parashuram Lakshman Vardira et al. 19 vol., Poona. Bhandarkar Oriental Research Institute, 1933-1959. 
MatTaVILĀSA

«A farce of Drunken Sport (Matta-Vilāsa Prahasanam) by King Mahēndravarman », édité et traduit par Michael Lockwood \& A. Vishnu BHAT, dans Michael LocKwoOD \& A. Vishnu BHAT, Metatheater and Sanskrit Drama. Part Two, Madras, Tambaram Research Associates \& Delhi, Munshiram Manoharlal, 1995, p. 49-80.

Mayamata

Mayamata. Traité sanskrit d'architecture. Édition critique, traduction et notes, par Bruno Daglens, 2 vol., Pondichéry, Institut français d'indologie (Publication de l'Institut français d'indologie 40), 1970-1976.

PARIPĀṬAL

Le Paripātal. Texte tamoul. Introduction, traduction et notes, par François Gros, Pondichéry, Institut français d'indologie (Publications de l'Institut français d'indologie 35), 1968.

Purānapañ Calakșaña

Das Purāna Pañcalakṣana. Versuch einer Textgeschichte, par Willibald KIRfEL, Bonn, Kurt Schroeder, 1927.

RAURAVĀGAMA

Rauravāgama. Édition critique, par N. R. BHATT, 3 vol., Pondichéry, Institut français d'indologie (Publications du département d'indologie 18), 1961-1988.

Le Rauravāgama. Un traité de rituel et de doctrine sivaïtes. Introduction, traduction et notes, 2 vol., par Bruno Dagens \& Marie-Luce BARAZER-BILloret, Pondichéry, Institut français d'indologie (Publications du département d'indologie 89), 2002.

SKANDAPURĀṆA

Skandapurānasya ambikākānḍ̣h, édité par Krṣ̣naprasāda Bhaț̣̂RĀī, Kathmandu, (Mahendraratnagranthamālā 2), 1988.

The Skandapurāna. Volume I. Adhyāyas 1-25. Critically edited with Prolegomena and English Synopsis, par Rob AdrIAfNSEN, Hans T. BAKKER \& Harunaga IsAACson, Groningen, (Supplement to Groningen Oriental Studies), Egbert Forsten, 1998.

The Skandapurāna. Volume IIA. Adhyāyas 26-31.14. The Vārānasī Cycle. Critical Edition with an Introduction, English Synopsis \& philological and historical Commentary, par Hans T. BAKKi:R \& Harunaga IsAACSON, Groningen, Egbert Forsten (Supplement to Groningen Oriental Studies), 2004.

SKandaPURĀṆA de la Veñkateśvara Press

Śrīskandamahāpurānam, édité par Kṣemarāja ŚRīKRọ̦NADĀSA, 7 vol., Mumbai, Śrīvenkațeśvara Steam Press, 1910 [réimpression : Delhi, Nag Publishers, 1986].

TẼVĀRAM

Têvāram. Hymnes śivaïtes du pays tamoul. Têvāram. panmurai, édition établie par T. V. Gopal Iyer, sous la direction de François Gros, 3 vol., Pondichéry, Institut français d'indologie (Publications de l'Institut français d'indologie 68), 1984-1991.

Digital Têväram / Kaṇinit tềuaram. With the complete English Gloss of the late V. M. Subramanya Ayyar (IFP) and furnished with a full Concordance of the Tamil Text, par Jean-Luc Chevillard (éd. principal) \& S. A. S. Sarma (éd. associé), Pondichéry, IFP \& EFEO (Coll. «Indologie » 103), 2007. 
VARAHAPURAYA

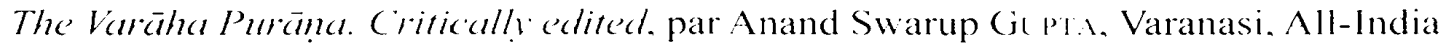
Kashiraj Trust. 1981.

\section{Sources primaires : inscriptions (par titre)}

Annual Report on Epigraphy [ARE], publié d'abord sous la forme de Government Order [G.O.], puis sous les titres successifs de Annual Report on Epigraphy, Annual Report on South-Indian Epigraphy et Archaeological Survey of India Annual Report on Indian Epigraphy, d'abord par le Government of Madras, puis par le Government of India et enfin par l'Archaeological Survey of India, 1885-1995.

Epigraphia Indica $[E I .42$ volumes. Calcutta puis New Delhi. Archaeological Survey of India, 1892-1992.

Inscriptions of Andhra Pradesh, Mahabühnagar District. Volume I, édité par N. S. RAMA(IIANIDRA MuRTHY \& P. Jogil NAIDU, Hyderabad, Department of Archaeology and Museums, Government of Andhra Pradesh, 2003.

Inscriptions of the Pallavas [IP], édité par T. V. MAIALINGiAm, New Delhi, Indian Council of Historical Research \& Agam Prakashan, 1988.

Inscriptions of the early Pạndyas (from c. 300 B.C. to 984 A.D.), édité par K. G. KRISHNan, New Delhi, Indian Council of Historical Research \& Northern Book Centre, 2002.

Inscriptions of the Vākatakas, édité par V. V. MirAsılı, Ootacamund, Government Epigraphist for India Archaeological Survey of India (Corpus Inscriptionum Indicarum. vol. V), 1963.

Pondicherry Inscriptions. Part I, compilé par Bahour S. KI'ppusamy et édité par G. VIJAYAVI:Nuciopal, Pondichéry, IFP \& EFEO (Coll. «Indologie» 83.1), 2006.

South Indian Inscriptions [SII], 27 volumes, Madras puis New Delhi, Archaeological Survey of India, 1890-2001.

Tiruvannamalai. A Saiva sacred complex of South India. Inscriptions, Edition, Translation, Indexes, Topography, volumes 1.1 et 1.2, par P. R. SRINIVASAN \& et Marie-Louise R:1Nicile, Pondichéry, Institut français de Pondichéry (Publications de l'Institut français d'indologie 75), 1990.

\section{Littérature secondaire (par auteur)}

ADICIAM, Marguerite

1965a «Les images de Śiva dans l'Inde du Sud. II. Bhairava ", Arts asiatiques 11, p. 83-112.

1965b « Les images de Śiva dans l'Inde du Sud. III-IV. Bhikṣātanamūrti et Kañkālamūrti ", Arts asiatiques 12, p. 23-44.

1976 "Les images de Śiva dans l'Inde du Sud. XV. Gañgādharamūrti », Arts asiatiques 12 , p. 83-112.

Adrialnsi:n, Rob, Hanls T. Bakki:k \& Harunaga ISAacson

1994 "Towards a Critical Edition of the Skandapurāna », Indo-Iranian Journal 37 , p. 325-331.

Aravamuthan, T. G.

1931 Portrait Sculpture in South India. London. The India Society. 
BAKKER, Hans T.

1991 "The Footprints of the Lord", dans Devotion Divine, Bhakti Traditions from the Regions of India, Studies in Honour of Charlotte Vaudeville, édité par Diana L. Eck \& Françoise MAlbison, Groningen, Egbert Forsten \& Paris, EFEO (Groningen Oriental Studies 8), p. 19-38.

1996 «Pārvatī's Svayamvara. Studies in the Skandapurāna I ", Wiener Zeitschrift für die Kunde Südasiens 40, p. 5-43.

Barrett, Douglas C.

1958 The temple of Virattanesvara at Tiruttani, Bombay, Bhulabhai Memorial Institute.

Bemmel, Helena A. van

1994 Dvārapālas in Indonesia, Rotterdam \& Brookfield, A. A. Balkema.

BHATT, Ramachandra Niddodi

2000 La Religion de Siva d'après les sources sanskrites, traduit de l'anglais par Pierre-Sylvain Filliozat, Palaiseau, Āgamāt.

BhatTACHARYA, Gouriswar

1977 " Nandin and Vrşabha ", Zeitschrift der Deutschen Morgenländischen Gesellschaft, Supplementa III.2, p. 1545-1567.

Bisscirop, Peter C.

2006 Early Saivism and the Skandapuräna, Sects and Centres, Groningen, Egbert Forsten (Groningen Oriental Studies 21 ).

2007 «The Description of Śivapura in the early Vāyu- and Skandapurāna. », dans Mélanges tantriques à la mémoire d'Hélène Brunner / Tantric Studies in Memory of Hélène Brunner, édité par Dominic GoOdnLl \& André PaDoux, Pondichéry, IFP \& EFEO (Coll. «Indologie » 106), p. 49-72.

2008 "The Skull on Śiva's Head. Preliminary Observations on a Theme in the Śaiva Art of Mansar ", dans Mansar: The Discovery of Pravaresvara and Pravarapura. Temple and Residence of the Văkataka King Pravarasena II. Proceedings of a Symposium at the British Museum, London, 30 June I July, 2008, édité par Hans BAKKER, Groningen, Library of the University of Groningen [http://mansar.eldoc.ub.rug.nl/].

BRocQuet, Sylvain

1997 Les inscriptions sanskrites des Pallava: poésie, rituel, idéologie, 2 vol., Villeneuve d'Ascq, Presses universitaires du Septentrion.

Brown, Robert L.

1990 "God on Earth: The Walking Buddha in the Art of South and Southeast Asia ", Artibus Asicue 50, p. 73-107.

2004 "Vākāțaka-Period Hindu Sculpture ", dans The Vākātaka Heritage. Indian Culture at the Crossrocids, édité par Hans T. BAKKr:R, Groningen, Egbert Forsten, p. 59-69.

BrunNer-Lnchaux, Hélène

1990 "L'image divine dans le culte agamique de Śiva. Rapport entre l’image mentale et le support concret du culte ", dans Limage divine. Culte et méditation dans l'hindouisme, édité par André PADoux, Paris, Éditions du CNRS, p. 9-29. 
1998 Somaśambhupaddhati. Rituels dans la tradition sivä̈te selon Somaśambhut. Quatrieme partic. Rituels optionnels : pratisthä. Textes, traduction et notes. Pondichéry. IFP \& EFEO (Publications du département d’indologie 25/4).

C(a:sis, G.

1947 Pour mieux comprendre Angkor, Paris.

ColAs, Gérard

1986 Le Temple selon Marīci. Extraits de la Marīci-samhitā étudiés, édités et traduits, Pondichéry. Institut français d'indologie (Publications de I'Institut français d'indologie 71 ).

1996 Viṣnu, ses images et ses feux. Les métamorphoses du dieu chez les Vaikhänasa, Paris, École française d'Extrême-Orient (Monographies 182).

cox, Whitney

2008 "Peter C. Bisschop, Early Saivism and the Skandapurana, Sects and Centres. $2006 »$, Journal of the Roval Asiatic Societ1 18, p. 94-97.

DAYALAN, D.

2005 Computer Application in Indian Epigraphy, 3 vol., Delhi, Bharatiya Kala Prakashan.

Dissigane, R. \& P. Z. Pattabiramin

1967 La légende de Skanda selon le Kandapuränam tamoul et l'iconographie. Pondichéry, Institut français d'indologie (Publications de l'Institut français d'indologie 31 ).

Dissigianf, R., Pattabiramin, P. Z. \& Jean Filliozat

1964 Les Légendes Śivaïtes de Käñipuram. Analyse de textes et iconographie. Pondichéry, Institut français d'indologie (Publications de l'Institut français d'indologie 27).

DONALDSON, Thomas

1986 «Bhikṣạtanamūrti Images from Orissa », Artibus Asiae 47, p. 51-80.

DONIGH:R O'FI.AHERTY, Wendy

1976 The Origins of Evil in Hindu Mythology, Berkeley \& Los Angeles, University of California Press [Édition indienne : New Delhi, Motilal Banarsidass. 1988].

1993 Siva érotique et ascétique, traduit de l'anglais par Nicole Ménant, Paris, Gallimard (Bibliothèque des Sciences Humaines) [Édition originale : 1981].

FII.IIO/.AT, Jean

1961 "Les images de Śiva dans l'Inde du Sud. I. L'image de l'origine du linga (Lingodbhavamūrti) », Arts asiatiques 8, p. 43-56.

1966 "New Researches on the Relations between India and Cambodia », Indica 3, p. 95-106.

FrANCIS, Emmanuel

2009 Le discours royal. Inscriptions et monuments pallava (I $\mathbb{K}^{\prime}-\mathbb{K}^{\prime}$ siecle), thèse de doctorat, Louvain-la-Neuve, Institut orientaliste, Université catholique de Louvain.

Fravers, Emmanuel, Gin.1:T, Valérie \& Charlotte S(rimis)

2005 "L'eau et le feu: chronique des études pallava », BEFEO 92, p. 581-611 [paru en 2007]. 
2006 «Trésors inédits du pays tamoul : chronique des études pallava II », BEFEO 93, p. 431-481 [paru en 2008].

Gali:y, Jean-Claude

1990 "Reconsidering Kingship in India: An ethnological Perspective ", dans Kingship and the Kings, édité par Jean-Claude GAlt:y, Chur, Harwood Academic Publishers, p. 123-187 [réimpression d'un article paru dans History of Anthropology 4/2 (1989)].

GILLET, Valérie

2004-05 «La création d'une image pallava : Jalandharasaṃhāramūrti », Bulletin d'études indiennes 22-23 (2004-2005), p. 227-248 [paru en 2007].

2006 La création d'une iconographie sivaüte narrative. Incarnations du dieu dans les temples pallava construits, thèse de doctorat, Paris III, Sorbonne Nouvelle.

à par. La création d'une iconographie śivaüte narrative. Incarnations du dieu dans les temples pallava construits, Pondichéry, IFP \& EFEO (Coll. « Indologie »).

GiUliano, Laura

2004 «Studies in early Śaiva Iconography. (I) the Origin of the Trišula and some related Problems », Silk Road Art and Archaeology 10, p. 51-96.

Goodall, Dominic

2004 Parākhyatantram. The Parākhyatantra. A Scripture of the Saiva Siddhānta. A critical Edition and annotated Translation, Pondichéry, IFP \& EFEO (Coll. "Indologie » 98).

Goodall, Dominic, Rout, Nibedita, Sathyanarayanan, R., Sarma, S. A. S., Ganfasan,

T. \& S. Sambandiansivacarya

2005 The Pañcāvaranastava of Aghorasivācārya: A twelfth-century South Indian Prescription for the Visualisation of Sadāsiva and his Retinue. An annotated critical Edition, Pondichéry, IFP \& EFEO (Coll. « Indologie » 102).

GranOFF, Phyllis

2003 «Mahākāla’s Journey: From Gaṇa to God », Revista degli Studi Orientali 77, p. 95-114.

2004 "Saving the Saviour: Śiva and the Vaiṣnava Avatāras in the Early Skandapurāna ", dans Origin and Growth of the Purānic Text Corpus. With Special Reference to the Skandapurāna, édité par Hans T. BAKKFR, Delhi, Motilal Banarsidass (Papers of the 12th World Sanskrit Conference held in Helsinki, Finland, 13-18 July 2003, volume 3. 2), p. 11-138.

2006 "Siva and his Gaṇas: Techniques of Distancing in Purānic Stories ", dans Voice of the Orient. A Tribute to Prof: Upendranath Dhal, édité par Ragunath PANISA et Madhusudan Mishr^, Delhi, Eastern Book Linkers, p. 77-103.

GuY, John

2007 Indian Temple Sculpture, London, V. \& A. Publications.

Handelman, Don \& David Shulman

2004 Siva in the Forest of Pines. An Essay on Sorcery and Self-Knowledge, New Delhi, Oxford University Press.

HAZRA, Rajendra Chandra

1975 Studies in the Puranic Records on Hindu Rites and Customs, Delhi, Motilal Banarsidass [ $1^{\text {re }}$ éd. : Dacca, University of Dacca, 1940]. 
Hr:RAS, Henry

1935 «The Royal Portraits of Mahābalipuram ». Acta Orientalia 13, p. 163-173.

HINC̈BER, Oskar von

2008 «Vincent Lefèvre, Commanditaires \& artistes en Inde du Sud. Des Pallava aux Nāyak (VI'-XVIr" siècle), 2006 », Indo-Iranian Journal 51, p. 71-77.

HIRsH, Marilyn

1987 «Mahendravarman I Pallava: Artist and Patron of Māmallapuram », Artibus Asiae 48, p. 109-130.

JAHN, Wilhem

1915-17 «Die Legende vom Devadāruvana », Zeitschrift der Morgenländischen Gesellschaft 69, p. 529-557: 70, p. 301-320:71, p. 167-208.

Kaimal, Padma

1996 "Early Cōla Kings and "Early Cōla Temples": Art and the Evolution of Kingship », Artibus Asiae 58, p. 33-66.

2002-03 "A Man's world? Gender, Family, and architectural Patronage in medieval India ", Archives of Asian Art 53, p. 26-53.

KrAMrISH, Stella

1966 Compte rendu de K. R. Srinivasan, Cave-temples of the Pallavas, 1964, Artibus Asiae 28, p. 319-321.

1981 The Presence of Śiva, Princeton, Princeton University Press [éd. indienne : Delhi, Motilal Banarsidass, 1988].

KuLke, Hermann

1970 Cidambaramāhātmya, Wiesbaden, Otto Harrassowitz.

1974 « Der Devarāja-Kult, Legitimation und Herrscherapotheose im AngkorReich », Saeculum 25, p. 24-55.

LADRECH, Karine

2005 Bhairava Sahasrapratimāvali. Iconographie de la forme terrible de Siva en Inde du Sud, avec la collaboration de N. Dejenne et K. Ramesh Kumar, Pondichéry, IFP \& EFEO (Coll. «Indologie » 95).

à par. L'iconographie de Bhairava dans le Sud de l'Inde, Pondichéry, IFP \& EFEO (coll. «Indologie »).

LEFĖVRE, Vincent

2006 Commanditaires \& artistes en Inde du Sud. Des Pallava aux Nāyak (VR'-XVIII siècle), Paris, Presses de la Sorbonne Nouvelle.

L'Hernault, Françoise

1987 Darasuram. Epigraphical Study. Étude architecturale. Étude iconographique, avec des collaborations de P. R. Srinivasan et de Jacques Dumarçay, Paris, EFEO (Mémoires archéologiques 16).

1978 L'iconographie de Subrahmanya au Tamil Nadu, Pondichéry, Institut français d'indologie (Publications de l'Institut français d'indologie de Pondichéry 59).

Lockwood, Michael

2001 «God-king Images and Cult Worship », dans Pallava Art, édité par Michael Lockwoon, Madras, Christian College, Tambaram Research Associates, p. 53-65 [dernière version d'un article publié pour la première fois en 1974]. 
Lockwood, Michael \& A. Vishnu BunT

2001 "The Philosophy of Mahēndra's Tiruchi Poem », dans Pallava Art, édité par Michael Lockwood, Madras, Christian College, Tambaram Research Associates, p. 91-102 [dernière version d'un article publié pour la première fois en 1976].

Lockwood, Michael \& Gift Siromoney

1992 "Studies on Mahabalipuram monuments ", dans Indological Essays. Commemorative Volume II for Gift Siromoney, édité par Michael Lo(KWOOD, Madras, Department of Statistics, Madras Christian College, p. 203-212.

Lockwood, Michael, Siromoni:y, Gift \& P. Dayanandan

2001 "Pallava Dvārapālas and the Mahishamardinī Cave-Temple », dans Pallava Art, édité par Michael LoCkwoOd, Madras, Christian College, Tambaram Research Associates, p. 7-20 [dernière version d'un article publié pour la première fois en 1970].

MANI, Vaidyanathan Raja

1968 «A Pallava Metal Image: Epigraphical Evidence», dans Seminar on Inscriptions 1966. Speeches and Papers, édité par R. Nagaswamy, Madras, Books (India).

1985 The Cult of Weapons. The Iconography of Ayudha Purusas, Delhi, Agam Kala Prakashan.

Meister, Michael W. (éd.) \& M. A. Dhaky (coord.)

1983 Encyclopaedia of Indian Temple Architecture 1.1. South India. Lower Drāvicudèśsa. 200 B.C. - A.D. 1324, 2 volumes, New Delhi, American Institute of Indian Studies \& Philadelphia, University of Pennsylvania Press.

Mi:vissi:N, Gerd J. R.

1994 "Political Geography as a Determinant in South Indian Temple Art? A Case Study of Tripurāntakamūrti », dans South Asian Archaeology 1993, édité par Asko Parpola \& Petteri Koskikallio, Helsinki, Suomalainen Tiedeakatemia (Annales Academiae Scientiarum Fennicae, Ser. B, n² 271), p. 483-495.

2006 "Early Stone Sculptures of Tripurantaka in South India », dans Hari Smriti: Studies in Art. Archaeology and Indology (Papers presented in Memory of Dr: H. Sarkar). Volume I, édité par Arundhati BANERJI, New Delhi, Kaveri Books, p. 122-142.

Naciaswamy, R.

1960-62 «New Light on Mamallapuram ", Transactions of the Archaeological Society of South India 6 (1960-1962), p. 1-50.

1969 The Kailāsanātha Temple. A guide, Madras, The State Department of Archaeology, Government of Tamil Nadu.

1988 "Innovative Emperor and his personal Chapel. Eight Century. Kanchipuram ", dans Roval Patrons and Great Temple Art, édité par Vidya Dıнıл^, Bombay, Mārg Publications, p. 37-60.

NANiDA, Vivek \& Georges MichFi.I.

2004 Chidambaram. Home of Nataraja, Mumbai, Mārg Publications.

OGiurA, Yasushi

1998 "The Changing Concept of Kingship in the Cóla Period: Royal Temple Construction, ca A.D. 850-1279 », Acta Asiatica 74, p. 39-58. 
1999 "The changing Concept of Kingship in the Cọla Period: Royal Temple ('onstructions, C. A.D). 85()-1279 ", dans Kingship in Indian Histor\%, édité par Noboru Karashima. New Delhi. Manohar (Japanese Studies on South Asia $\left.\mathrm{n}^{\circ} 2\right)$, p. $119-142$.

Orr, Leslie C.

2006 "Preface », dans Pondicherry Inscriptions. Part I, compilé par Bahour S. Keppusamy et édité par (j. Vuayavinugopal. Pondichéry. IFP \& EFEO (Coll. «Indologie » 83.1).

2007 "Cholas, Pandyas, and 'Imperial Temple Culture' in Medieval Tamil Nadu», dans The Temple in South Asia, édité par Adam HARDY, London, British Academy, p. 83-104.

P.ARLII:R-RINALIT, Édith

2000 "La légende de Käma dans les inscriptions et l’iconographie Pallava ». Indologica Taurinensia 26, p. 121-141.

2006 Temples de l'Inde méridionale ( $1 \mu^{\prime}-1+1 f^{\prime}$ siècles). La mise en scène des mythes. Paris, Presses de l'université Paris-Sorbonne (coll. "Asie »).

RAB1:, Michael

1996 «The Māmallapuram Praśasti: a Panegyric in Figures », Artibus Asiae 57, p. 189-241.

2001 The Great Penance at Mämallapuram. Deciphering a visual Text. Chemmancherry (Chennai), Institute of Asian Studies.

RAMAN, K. V. \& Si:karan, B. Sasi

1992 "Some rare Sculptures from the Pallava Temples at Kāñcīpuram », dans Indological Essavs. Commemorative Volume II for Gift Siromoney, édité par Michael Lo(kwoon, Madras, Department of Statistics, Madras Christian College, p. 86-93.

RAO, T. A. Gopinatha

1914 Elements of Hindu Iconography, 2 vol., Madras [réimpression : Delhi, Motilal Banarsidass, 1997]

Rocht:R, Ludo

1986 The Purānas, Wiesbaden, Otto Harrassowitz (A History of Indian Literature ${ }^{\circ}$ II.3).

RoSIN STONF, Elizabeth

1994 The Buddhist Art of Nāgārjunakonḍa, Delhi, Motilal Banarsidass (Buddhist Tradition Series 25).

SANDERSON, Alexis

1988 "Śaivism and the Tantric Traditions", dans The World's Religions, édité par Stewart R. Sutherland, Leslie Houlden, Peter Clarki: \& Friedhelm Hardy, London, Routledge \& Kegan Paul, p. 660-704.

2003-04 "The Śaiva Religion among the Khmers, Part I », BEFEO90-91, p. 349-463.

SARKAR, H.

1985 "The Nāgārjunakoṇua Phase of the Lower Krṣnā Valley Art: A Study based on epigraphical Data », dans Indian Epigraphy. Its Bearing on the History of Art, édité par Frederick M. Assm: \& \& G. S. Ga, New Delhi, Bombay, Calcutta, Oxford \& IBH Publishing Co. / American Institute of Indian Studies. p. 29-34. 
SCHMID, Charlotte

2005a « Mahābalipuram : la Prospérité au double visage », Journal asiatique 293, p. 459-527 [paru en 2006].

2005b «Au seuil du monde divin : reflets et passage du dieu d'Ālanturai à Pullamańkai », BEFEO 92, p. 39-157 [paru en 2007].

À par. Le don de voir. Premières représentations krishnaïtes de la région de Mathurā, Paris, EFEO (Monographies 193).

SIRCAR, Dinesh Chandra

1963 «More Inscriptions from Nagarjunikonda », Epigraphia Indica XXXV, p. 1-36.

SirCAR, Dinesh Chandra \& K. G. KrishnaN

1960 «Two Inscriptions from Nagarjunikonda », Epigraphia Indica XXXIV, p. 17-22.

SMITH, David

1997 The Dance of Siva. Religion, Art and Poetry in South India, Cambridge, Cambridge University Press (Cambridge Studies in Religious Traditions 7) [éd. indienne : New Delhi, Foundation Books, 1998].

Shulman, David Dean (trad.)

1990 Songs of the harsh Devotee: the Têvāram of Cuntaramūrti Nāyanār. Translated and annotated, Philadelphia, University of Pennsylvania.

Sivaramamurti, Calambur

1952 Mahābalipuram, New Delhi, Archaeological Survey of India [5 édition, 1992].

1955 Royal Conquests and cultural Migrations in South India and the Deccan, Calcutta, Indian Museum.

2006 Mahāhalipuram, revised by B. Narasimhaiah, New Delhi, Archaeological Survey of India (World Heritage Series).

SRINIVASAN, C. R.

1979 Kāñchipuram through the Ages, Delhi, Agam Kala Prakashan.

SRINIVASAN, K. R.

1960 Some Aspects of Religion as revealed by early Monuments and Literature of the South (Sankara Parvati Endowments Lectures 1959-60), Madras, University of Madras.

1964 Cave-Temples of the Pallavas, Delhi, Archaeological Survey of India (Architectural Survey of Temples 1 ).

Srinivasan, Doris Meth

1984 "Significance and Scope of Pre-Kuṣanna Śaivite Iconography ", dans Discourses on Siva, édité par M. W. Miister, Bombay, Vakils, Feffer \& Simons, p. 32-46.

STIETENCRON, Heinrich von

1969 "Bhairava ", Zeitschrifi der Deutschen Morgenländischen Gesellschaft, Supplementa I, p. 863-871.

Subramaniam, T. N.

1967 The Pallavas of Kanchi in South-East Asia, Madras, Swadesamitran Press.

TöRšöK, Judith

2004 «Śiva le fou et ses dévots tamouls dans le Têvāram», South Indian Horizons. 
Felicitation Volume for François Gros on the occasion of his 70th Birthdan, édité par Jean-Luc (IHIIIIIARI) \& Fva WII.DH: avec la collaboration de A. MLrtginsai, Pondichéry, IFP \& EFEO (Publications du Département d'indologie 94), p. 3-28.

Yokocil, Yuko

2005 The Rise of the Warrior Goddess in Ancient India. A Study of the Myth Cycle of Kaussikī-Vindhyavassini in the Skandapurāna, $\mathrm{PhD}$ Dissertation, Groningen. January 2005.

VI:NKATLSAN, P.

1984 «Two Jaina Inscriptions from Siyamangalam ». Journal of the Epigraphical Society of India 11, p. 21-24.

WISSILLS-MI:VISSI:N, Corinna

2001 The Gods of the Directions in ancient India: Origin and ear/1. Development in Art and Literature (until c. 1000 AD), Berlin, Dietrich Reimer Verlag (Monographien zur Indischen Archäologie, Kunst und Philologie 14).

\section{Liste des illustrations}

Fig. 1 Dakṣināmūrti, face sud du Kailāsanātha de Kāñcipuram, début du vıÍ siècle (cliché : Emmanuel Francis).

Figg. 2 Jalandharasamhāramūrti, face nord du Kailāsanātha de Kāñcipuram, début du vill siècle (cliché : Charlotte Schmid).

Fig. 3a et 3b Le combat d'Indra contre Skanda, chapelle n 11 du grand prākāra du Kailāsanātha de Kāñcipuram, début du vill siècle (clichés : Emmanuel Francis).

Fịg. 4 l.e Séducteur en marche, face sud du Kailāsanātha de Kāñcipuram. début du vill" siècle (cliché : Charlotte Schmid).

Fig. 5 Le Séducteur en marche, chapelle de l'angle sud-ouest du Kailāsanātha de Kāñcipuram. début du viII" siècle (cliché : Emmanuel Francis).

Fig. 6 Le Séducteur en marche, face ouest de l'I lnavāttāneśvara de Kāñcipuram, vIII'-IX" siècle (cliché : Emmanuel Francis).

Fig. 7 Le « Marcheur », chapelle $\mathrm{n}^{\circ} 52$ du grand prākāra du Kailāsanātha de Kāñcipuram. début du vill siècle (cliché : Valérie Gillet).

Fig. 8 Śiva dans la forêt de pins, époque cōla, temple de Kovintaputtūr, face nord, $x^{e}$ siècle (cliché : (harlotte Schmid).

Fig. 9 La décapitation de Brahmā, mur sud (face au nord) du prākāra du Kailāsanātha de Kãñcipuram, début du viII" siècle (cliché : Emmanuel Francis).

Fig. 10a Dvārapāla, Kailāsanātha de Kãñcipuram, début du vıII siècle (cliché : Emmanuel Francis).

Fig. 10b Le Séducteur en marche. Kailāsanātha de Kāñcipuram, début du vil' siècle (cliché : Charlotte Schmid).

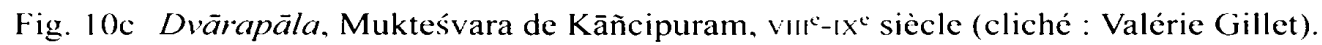

Fig. 11 a et $11 \mathrm{lb}$ Gardiens de porte, petit prākāara du Kailāsanātha de Kāñcipuram, début du vill siècle (clichés : Emmanuel Francis).

Fig. 12 Inscription de Vāyalūr, début du vill siècle, détail (cliché : Emmanuel Francis).

Fig. 13 Murs d'échiffre de Tirunāvalūr, $x^{\mathbb{E}}$ siècle (cliché : Emmanuel Francis).

Fig. 14 Monolithe de Tirunāvalūr, IXe siècle (cliché : Emmanuel Francis).

Fig. 15 Brahmā de Tirunāvalūr. $1 x^{*}$ siècle (cliché : Emmanuel Francis). 